University of Louisville

ThinkIR: The University of Louisville's Institutional Repository

Electronic Theses and Dissertations

$12-2005$

\title{
Human performance in agile production systems : a longitudinal study in system outcomes, human cognition, and quality of work life.
}

John K. Layer 1963-

University of Louisville

Follow this and additional works at: https://ir.library.louisville.edu/etd

\section{Recommended Citation}

Layer, John K. 1963-, "Human performance in agile production systems : a longitudinal study in system outcomes, human cognition, and quality of work life." (2005). Electronic Theses and Dissertations. Paper 798.

https://doi.org/10.18297/etd/798

This Doctoral Dissertation is brought to you for free and open access by ThinkIR: The University of Louisville's Institutional Repository. It has been accepted for inclusion in Electronic Theses and Dissertations by an authorized administrator of ThinkIR: The University of Louisville's Institutional Repository. This title appears here courtesy of the author, who has retained all other copyrights. For more information, please contact thinkir@louisville.edu. 
HUMAN PERFORMANCE IN AGILE PRODUCTION SYSTEMS:

A LONGITUDINAL STUDY IN SYSTEM OUTCOMES, HUMAN COGNITION, AND QUALITY OF WORK LIFE

\author{
By \\ John K. Layer \\ B.S. Mechanical Engineering, University of Evansville, 1987 \\ M.B.A., Arizona State University, 1991
}

\begin{abstract}
A Dissertation
Submitted to the Faculty of the

Graduate School of the University of Louisville

in Partial Fulfillment of the Requirements

for the Degree of
\end{abstract}

Doctor of Philosophy

Department of Industrial Engineering

University of Louisville

Louisville, Kentucky

December 2005 
Copyright 2005 by John K. Layer

All rights reserved 

HUMAN PERFORMANCE IN AGILE PRODUCTION SYSTEMS:

A LONGITUDINAL STUDY IN SYSTEM OUTCOMES, HUMAN COGNITION, AND QUALITY OF WORK LIFE

\author{
By \\ John K. Layer \\ B.S. Mechanical Engineering, University of Evansville, 1987 \\ M.B.A., Arizona State University, 1991 \\ A Dissertation Approved on
}

November 22, 2005

by the following Dissertation Committee:

Dissertation Director 


\section{ACKNOWLEDGMENTS}

I would like to extend my appreciation and gratitude to my dissertation committee chairperson, Dr. Waldemar Karwowski who continually challenges me to strive for higher levels of inquiry and academic synthesis. Similarly, I would like to thank my remaining dissertation committee members, Dr. Gail DePuy, Dr. William Biles, Dr. Gerald Evans, and Dr. Allen Furr, for their continual support and critique during this dissertation process. An "interdisciplinary" appreciation is extended to Dr. Allen Furr and Dr. Wayne Usui of the University of Louisville Sociology Department who introduced and instructed me in research methods associated with the social sciences, as well as granting me access to departmental laboratory facilities.

This dissertation research would not have been possible without the corporate participation of W. M. Kelley Company, Inc. of New Albany, Indiana and Advanced Production Systems, Inc. of Louisville, Kentucky. I wish to thank the management and employees of both companies for their willingness to participate in this research.

A very special word of thanks goes to Dr. Hanne Albrechtsen and the collaborative relationship that she fostered between the Ris $\varnothing$ National Laboratory, Roskilde, Denmark, and myself during this dissertation time frame. The spirit of mutual scientific interest and collaborative research that Dr. Albrechtsen exemplifies shall remain a fundamental academic characteristic that I will always aspire to. 
No deeper appreciation could be stated than that for my wife, Katrina. My pursuits would feel rather mediocre if it was not for her patience, encouragement, and support that provide me the determination to persevere. 


\title{
ABSTRACT \\ HUMAN PERFORMANCE IN AGILE PRODUCTION SYSTEMS: A LONGITUDINAL STUDY IN SYSTEM OUTCOMES, HUMAN COGNITION, AND QUALITY OF WORK LIFE
}

\author{
John K. Layer
}

December 2005

This dissertation examines a research objective associated with human performance in agile production systems, with specific attention towards the hypothesis that system outcomes are the causal result of worker human cognition and quality of work life attributes experienced in an agile production system. The development and adoption of world class agile production systems has been an immediate economic answer to the world-wide competitive call for more efficient, more cost-effective, and more quality laden production processes, but has the human element of these processes been fully understood and optimized?

Outstanding current literature suggests that the recent movements toward higher standards in systems outcomes (i.e. increased quality, decreased costs, improved delivery schedules, etc) has not been truly evaluated. The human-machine interaction has not been fully comprehended, not to mention quantified; the role of human cognition is still under evaluation; and the coupling of the entire production system with respect to the human quality of life has yielded conflicting messages. 
The dissertation research conducted a longitudinal study to evaluate the interrelationships occurring between system outcomes, applicable elements of human cognition, and the quality of work life issues associated with the human performance in agile production systems. A structural equation modeling analysis aided the evaluation of the hypotheses of the dissertation by synthesizing the three specific instruments measuring the appropriate latent variables: 1 system outcomes - empirical data, 2 . human cognition - cognitive task analysis, and 3. quality of work life - questionnaires into a single hypothesized model. These instruments were administered in four (4) waves during the eight month longitudinal study.

The study latent variables of system outcomes, human cognition, and quality of work life were shown to be quantifiable and causal in nature. System outcomes were indicated to be a causal result of the combined, yet uncorrelated, effect of human cognition and quality of work life attributes experienced by workers in agile production systems. In addition, this latent variable relationship is situational, varying in regards to the context of, but not necessarily the time exposed to, the particular task the worker is involved with. An implication of this study is that the quality of work life attributes are long-term determinants of human performance, whereas human cognition attributes are immediate, activity based determinants of human performance in agile production systems. 


\section{TABLE OF CONTENTS}

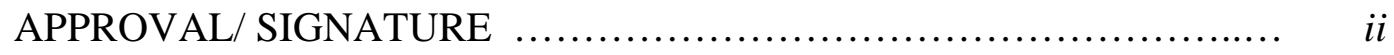

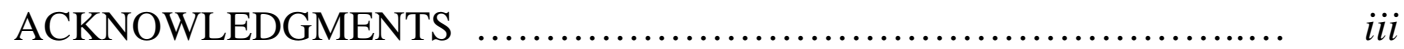

ABSTRACT ........................................................... $v$

LIST OF TABLES .................................................. $i x$

LIST OF FIGURES ................................................ $x i$

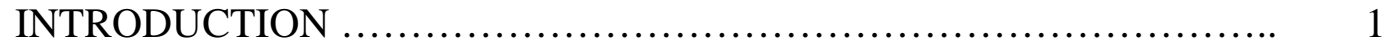

LITERATURE REVIEW ............................................. 5

Current Socio-technological Problem Space.......................... 5

Current Definition of a Socio-technical System 5

Scope of the Socio-technological Problem Space 7

The Problem Space and Human cognition $\quad 8$

Environmental Pressure, Affordance, and Change 15

Embodied and Distributed Cognition in Relation to the Environment 17

Human-Work Domain $\quad$........................................... 20

Adaptability and Flexibility 20

Complexity and Congruence $\quad 22$

Decision Making and Human Error 23

Learning and Training $\quad 26$

Empowerment and Satisfaction $\quad 27$

Cognition in Relation to the Work Domain 28

The Need For a More "Mid-Range" Model $\quad$........................... $\quad 35$

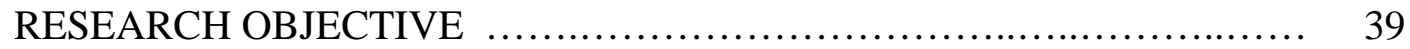

Synthesis of an Ecological Cognitive Model .......................... 39

An Expanded Ecological Approach in Defining the Problem Space 39

An Expanded Skill, Rule, Knowledge, \& Wisdom Taxonomy 41

The Human-Work Domain Sub-model 42

Research Hypotheses ........................................... 44

Hypothesis 1

Hypothesis $2 \quad 44$ 


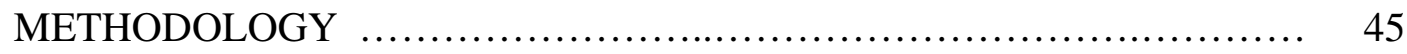

Causal model .......................................................... 45

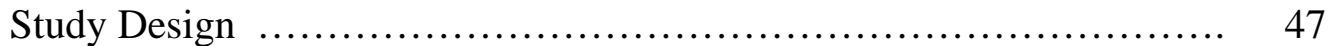

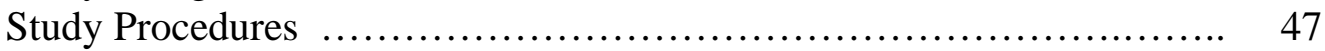

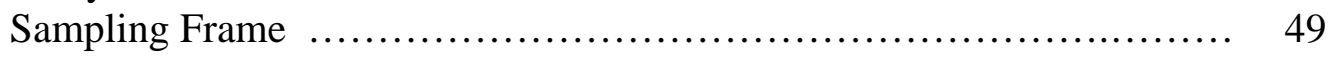

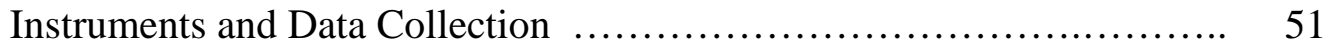

System Outcomes: Empirical Data 52

Human Cognition: Cognitive Task Analysis 53

Quality of Work Life: Questionnaire 57

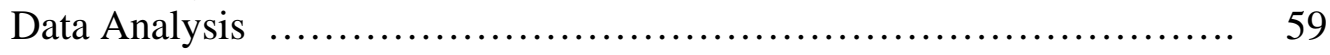

Statistical Descriptive Statistics $\quad 59$

Structural Equation Modeling of the Causal Model 60

RESULTS AND DISCUSSION........................................ 68

Causal Model Structural Validity Analysis............................. 68

Model Specification $\quad 68$

Model Identification $\quad 73$

Data Abnormality Evaluation $\quad 74$

Parameter Estimation $\quad 77$

Goodness of Fit Evaluation $\quad 79$

Model Respecification $\quad 82$

Interpretation of Modeling Results $\quad 88$

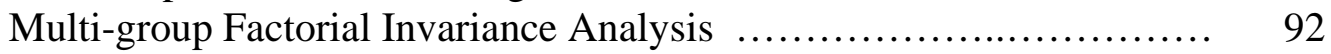

Testing for Invariance Across Companies 94

Testing for Invariance Across Task Activities 96

Testing for Invariance Across Data Collection Waves 100

Testing for Invariance Across Data Collection Periods 102

Testing for Invariance Across Workers 105

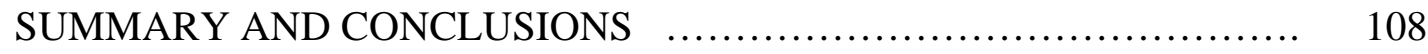

REFERENCES (....................................................... 115

APPENDICES F................................................. 125

Appendix A. Quality of Work Life Questionnaire Items ............... 125

Appendix B. Quality of Work Life Questionnaire QWL-1 ............. 129

Appendix C. Quality of Work Life Questionnaire QWL-2 ............... 132

Appendix D. Cognitive Task Analysis Data Collection Form .............. 135

Appendix E. Structural Equation Model Evaluation Form ............... 137

Appendix F. SPSS Descriptive Statistics Output........................ 140

Appendix G. AMOS Structural Equation Modeling Output............... 144

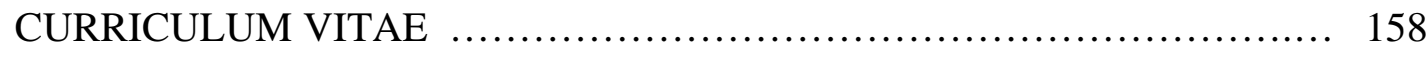




\section{LIST OF TABLES}

Table 1. Study Population Descriptives per Data Collection Wave ...... 51

Table 2. System Outcomes Latent Dependent Variables ............... 53

Table 3. Example of the Activity Attribute Coding Taxonomy ......... 55

Table 4. Dependent Human Cognition Indexed Variable Definitions .... 56

Table 5. Human Cognition Latent Independent Variables .............. 56

Table 6. Quality of Work Life Latent Independent Variables ........... 58

Table 7. Common Structural Equation Modeling .................... 64 Goodness of Fit Indices

Table 8. Cronbach's Alpha $(\alpha)$ Progression During Wave ............. 75 Data Collection

Table 9. Goodness of Fit Summary: Model A ..................... 80

Table 10. Goodness of Fit Summary: Model C ..................... 87

Table 11. Model Respecification Summary Information ............... 89

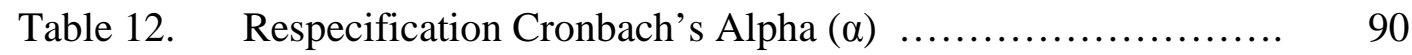
Summary Information 
Table 13. Testing for Invariance Across Companies

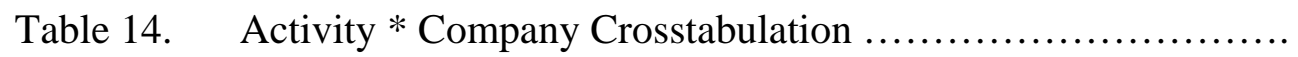
97

Table 15. Testing for Invariance Across Task Activities 98

Table 16. Testing for Invariance Across Waves 101

Table 17. Testing for Invariance Across Periods 104

Table 18. Testing for Invariance Across Workers 106 


\section{LIST OF FIGURES}

Figure 1. Vertically-oriented Socio-technical System $\ldots \ldots \ldots \ldots \ldots \ldots \ldots . . . \ldots$ (Rasmussen 2000)

Figure 2. Level of Automation Evaluation Flow Chart .................. 14

(Parasuraman, Sheridan, \& Wickens 2000)

Figure 3. Balance between Uncertainty and Flexibility f................. 21

(De Toni \& Tonchia 1998)

Figure 4. Structure of Human Error Analysis in terms of System ......... 24

Disturbances (Luczak, Reuth, \& Schmidt 2003)

Figure 5. Ris $\varnothing$ Work Analysis Perspectives ......................... 29

(Pejtersen, Albrechtsen, Cleal, Hansen, \& Hertzum 2003)

Figure 6. An Ecological Cognitive Framework ........................ 40

Figure 7. An Expanded Skill, Rule, Knowledge, \& Wisdom Taxonomy ... 42 (derived from Neerincx, VanDoorne, \& Ruijsendall 1999)

Figure 8. The Human-Work Domain Sub-Model ....................... 43

Figure 9. Proposed Human-Work Domain Causal Model …............. 45

Figure 10. Example of a Hierarchical Task Analysis ...................... 54

Figure 11. Proposed Human-Work Domain ................................. 69 Structural Equation Model

Figure 12. Model A: Proposed (AMOS Standardized) …................. 78 Human-Work Domain Causal Model $(\mathrm{n}=205)$ 
Figure 13. Model B: Respecified (AMOS Standardized)

Human-Work Domain Causal Model $(n=205)$

Figure 14. Model C: Respecified (AMOS Standardized)

Human-Work Domain Causal Model $(\mathrm{n}=205)$ 


\section{INTRODUCTION}

Agile production systems are associated with numerous configurations: just-in-time, advanced manufacturing, lean production, etc. While each system has particular individual characteristics, they all share one common theme: "to do more with less". The world competitive atmosphere has created a situation where production must become more flexible, more adaptable, more productive, more cost efficient, more schedule efficient, and more quality driven (Lewis \& Boyer 2002, and Maturana, Shen, \& Norrie 1999). Kidd (1994) has described agile production not just a production or manuafacturing process, but a methodology for integrating the entire organization, people, and technology in response to the ever-changing, ever-increasing competitive atmosphere. Therefore, an agile production system shall be defined for the purpose of this research as a production system that integrates technology, humans, and infrastructure intentionally designed to embrace rapid customer change.

It is worthy to note that the advent of agile production systems have produced positive economic benefits over the last twenty years at a corporate level, yet the sustainable affects of this movement of process change as it equates to the individual has not been adequately quantified. Haynes (1999) has stated that the proponents for flexible and adaptable manufacturing with the vast majority of literature emanate from a business, rather than a scientific background. Therefore, the vast majority of the current literature 
has been presented to and accepted by the wide general public, but has been found lacking in validity by the more academic community. This lack of validity has facilitated the development of a substantial body of literature that speaks of the overarching concern for worker health or the quality of life in agile production system environments.

Numerous authors (Genaidy \& Karwowski, in press, Schultz, McClain, \& Thomas 2003, Carayon \& Smith 2000, Eklund 2000, and Lee \& Lee 2001) have documented the fact that little research has been conducted to evaluate the "individual's" situation.

The agile production system has more explicit human cognitive requirements than production systems based on the Fordist mass production model, and as such places more pronounced mental demands on the individual. Rasmussen (2000) has stated that the individual's work routines have been enlarged by the use of automation and the widening of the individual's work domain, moving the task to a higher cognitive level where flexibility and adaptation to task demands are essential. This higher cognitive level of involvement has been described by Mikkelse, Øgaard, Lindoe, \& Olsen (2002) within the contexts of the job strain model and the corresponding psychological effects associated with high work load, increased work pressure, diminished job control, training, and use of new technologies. Bedny, Karwowski, \& Bedny (2001) have described the unity of cognition and behavior within the activity theory; stating "activity is a complex system of intimately related cognitive and motor components (actions) specific to humans and is contained in a coherent system of internal mental and motivational processes and external behavior that are systemically combined and directed to achieve the current conscious goal". 
It is reasonable to believe in today's competitive world market that the corporation should remain competitive and profitable, therefore it is acknowledged that the system outcomes (i.e. increased quality, decreased costs, improved delivery schedules, etc) be maximized. It is further recognized that the human individual is at the center of this production process and that the human cognitive considerations, as well as the human quality of life inter-relation with the system outcome parameters be evaluated and optimized concurrently.

The composition of this thesis is intended to take the reader from a broad perspective to a more narrow viewpoint. The literature review section describes the broad sociotechnological problem space that places the human worker in a vast environment of continual change, then proceeds to discuss the more specific or narrow aspects of what human attributes are contained in the human-work domain. This broad to narrow convergence of the literature review section ends with a call for a more "mid-range" model of the socio-technical system where human performance is quantifiable and testable. In a similar fashion, the research objective section first develops a broad ecological cognitive model synthesized from the cited literature review references, and then proposes a more narrow human-work domain submodel. It is only after this definition of the human-work domain submodel that specific study hypotheses are developed and evaluated.

The methodology and results sections of this thesis describe the development and evaluation of proposed causal models used to evaluate the research hypotheses. The development a data collection instruments, study procedures, and structural equation modeling processes are defined and evaluated. The summary and conclusion section 
discusses the causal model validity surrounding the specific latent variables, as well as temporal and contextual considerations pertaining to the research hypotheses. 


\section{LITERATURE REVIEW}

\section{CURRENT SOCIO-TECHNOLOGICAL PROBLEM SPACE}

\section{Current Definition of a Socio-technical System:}

The socio-technical system has been referred by Griffith \& Dougherty (2002) as a combination of social, psychological, environmental, and technological sub-systems that are assessed as a whole; an integrated system where organizations made up of people (the social and psychological systems) using tools, techniques, and knowledge (the technical system) to produce goods and services valued by customers (the organization's external environment). Therefore, the general socio-technical system encapsulates the problem space of this research ... many organizations working with a multitude of varying tools and knowledge bases which produce goods and services for the global market ... needing to understand the relationships between people, technology, and organizational outcomes (Griffith \& Dougherty 2002). The socio-technical system is a broad problem space that has a direct bearing on the relationships on the individual worker and the associated work environment.

Lewis \& Boyer (2002) state "study results indicate that high-performing plants employ: a strategy that emphasizes quality, delivery, and flexibility over costs; a balanced culture that stresses flexibility and control; and systematic practices that facilitate change (training, pilot projects, long-term objectives).” Unfortunately, Lewis \& Boyer present that advanced manufacturing technology, however, has proven a 
considerable challenge with results typically falling below expectations. "Reports suggest that $50-75 \%$ of implementations are dubbed failures in terms of quality, flexibility, and reliability ... although the researchers claim that the technological equipment is not the problem, rather the inadequate attention to strategic priorities, culture, and employee training support." Azani (1999) confirms that many failures of advanced manufacturing implementations revolve around issues other than the technology, issues such as: lack of management support, political self-interest, lack of training, insufficient preparation, employee's resistance to change, and the existing organizational culture.

In order to combat the non-technical issues relating to the socio-technical system implementation and performance it is critical to keep the human cognitive attributes at the center of the consideration. Lewis \& Boyer (2002) describe a "human-centered culture as emphasizing flexibility and empowerment. Organizations that espouse these values seek to continuously expand employee's expertise and discretion."

Some researchers have labeled the socio-technical system as a paradigm. Majchrzak \& Borys (2001) include a reference that the system is a paradigm "consisting of a conceptual scheme, a methodology, a design process, a set of values about work, contextual conditions such as interdependence with the environment, and an historical tradition built on psychology, sociology, and workplace research.” Majchrzak \& Borys argue that the vastness of socio-technical system theory allows an "abstractness" that suggests the principles are not applicable to empirical testing, or to practice in general. The object of this research is to reduce this "abstractness" to a more practical and quantifiable application. 
$\underline{\text { Scope of the Socio-technological Problem Space: }}$

In the spirit of the previous discussion concerning the abstractness concerns of Majchrzak \& Borys (2001), Griffith \& Dougherty (2002) have referenced literature that stated that the current socio-technical framework is unusable as a basis of theory since key sub-systems (i.e. economics) are not sufficiently included and the framework adopts too naïve a view of social systems. Griffith \& Dougherty describe that there exist two basic concepts of socio-technical system theory: 1. human quality of work life is a key consideration, and/or 2. interdependencies or relationships between people, technology, and the organization.

Kaghan \& Bowker (2001) have stated that while there exists a definite "interdependence" of the social and technical systems of an organization, the current socio-technical system models do not address the critical issues of stability and change in complex systems. Kaghan \& Bowker have suggested a "neo-rational choice" approach concerning a more complex adaptive system, where the premise is a grouping of agents with differing cognitive abilities making rational choices while operating in, and adapting to, the local environments and constraints provided therein.

Rasmussen (2000) has described our society as becoming increasing dynamic where "changes and disturbances propagate rapidly and widely and the increasing scale of operations require also that rare events and circumstances are considered during systems designs ... that contributions should be based on models of adaptive human behavior in complex, dynamic systems." Rasmussen (2000) continues to define the human condition in a socio-technical system as a situation where work routines are enlarged by 
the use of automation and the widening of the individual work domain, moving the task to a higher cognitive level, where flexibility and adaptation to task demands are essential.

\section{The Problem Space and Human Cognition:}

The complex socio-technical system has been discussed in the context of a vertically-oriented system (Rasmussen 2000) comprised of a series of hierarchical levels beginning with the government situated at the top, followed by regulators, the company, management, staff, and finally the productive work of the individual. This complex system (Figure 1) is influenced by numerous environmental stressors such as changing political and public climate, changing market conditions, changing competency and education, as well as the pace of technological change itself.

Kaghan \& Bowker (2001) while discussing the need for more of an adaptive model of a socio-technical system, recognizes the cultural specificity of human intelligence and discretion where individuals act pragmatically rather than rationally ... an individual's behavior may be mediated by the culture in which they live or work. Kaghan \& Bowker go on to discuss the "architecture of complexity" which applies complexity theory to turbulent environments where self-organizing networks of agents "co-evolve" to the "edge of chaos."

Bedny, Karwowski, \& Kwon (2001) describe the analysis and design of manufacturing assembly operations utilizing the activity theory. "Activity is considered as an organized system with its own structure comprised of interconnected units and the specific relationships among them." This study defined the activity as having both motor actions and cognitive actions, where the operator's behavior is composed of various 


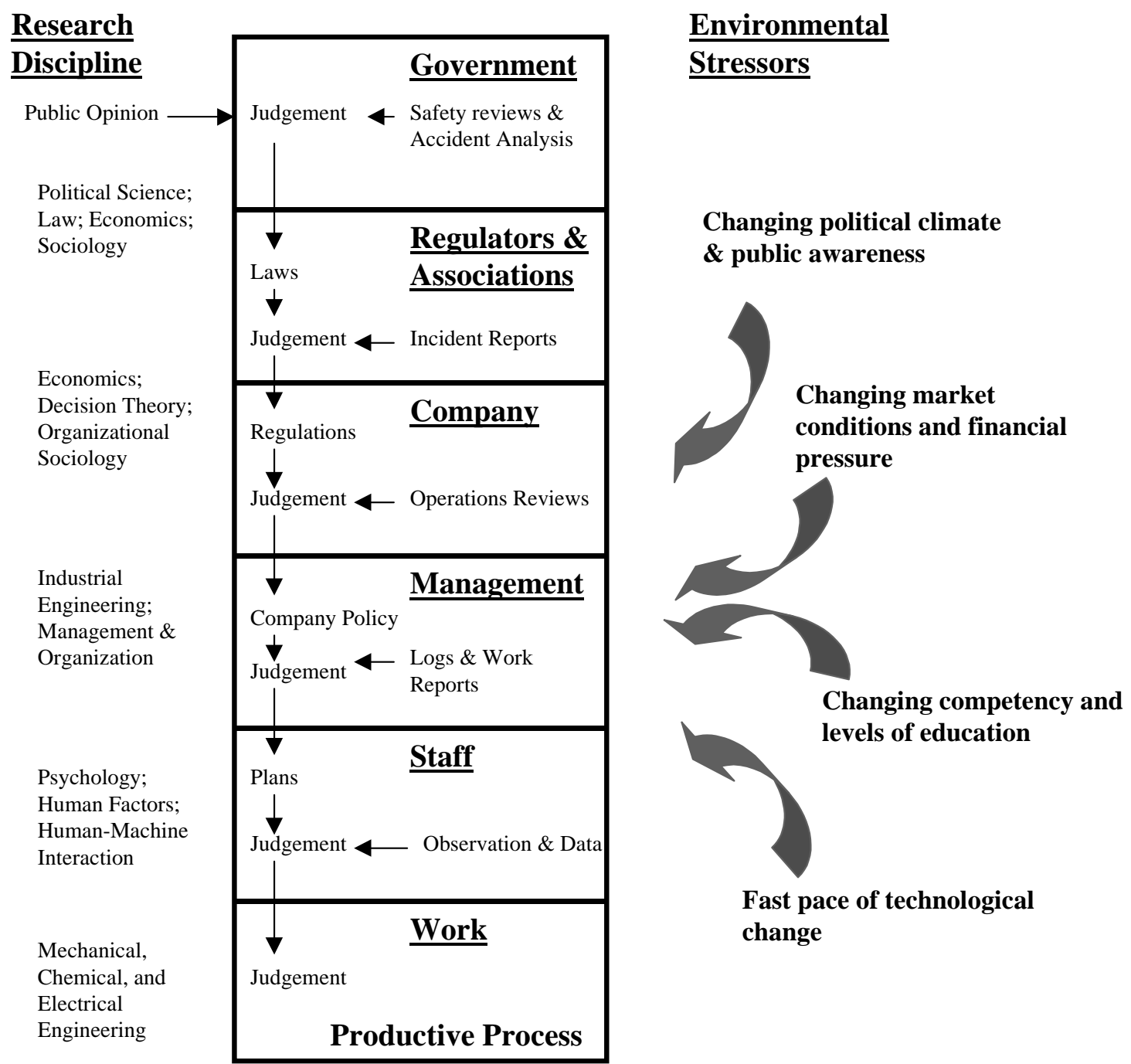

Figure 1. Vertically-oriented Socio-technical System (Rasmussen 2000)

actions and interconnections. Bedny, Karwowski, \& Kwon (2001) state that complexity of a task is the major cause of mental workload. These authors state that the evaluation of task complexity includes: 1 . workers' concentration and attention on the different elements of the task, 2. emotional stress, 3. compatibility of simultaneously executing 
different elements of an activity, 4. establishing a commensurable unit for the comparison of tangible and intangible elements, or 5. the duration over which different information must be maintained in working memory.

Bedny, Karwowski, \& Bedny (2001) define the principle of unity of cognition and behavior as it applies to activity theory. "Activity is a complex system of intimately related cognitive and motor components (actions) specific to humans and is contained in a coherent system of internal mental and motivational processes and external behavior that are systemically combined and directed to achieve the current conscious goal." The authors state that methods of performance and the accompanying motivational states may be conscious or unconscious, although the goal of activity is always conscious. Therefore, people do not merely react to stimulus, they update input information, form different goals according to personal motives, and organize their behavior to achieve conscious goals.

Bedny, Karwowski, \& Bedny (2001) state that the study of human-system interaction should not view human behavior "only from the point of view of stimulus-response (S-R) relationships, but also from that of cognitive regulation of external behavior. Furthermore, many internal mental operations have their origins in external mental operations. Without understanding their origins and the interdependence of the internal and external components of activity, the cognitive task analysis will be incomplete." Bedny, Karwowski, \& Bedny further define the goal in activity theory is a "cognitive component connected with a motive. The motive-goal pair creates a vector that lends activity a goal-directed character. Motives push people to reach goals; goals are 
cognitive representations of imagined future results of an action. Goals do not exist without a motive."

Mikkelse, Øgaard, \& Lindoe (2002) suggest that the "job strain model is particularly attractive for studying the psychological effects of jobs involving modern computerbased technology. This is largely because such jobs frequently vary considerably in cognitive demands such as high work load, work pressure, diminished job control, inadequate employee training, and use of new technology. Both the distribution of workload and the nature of the work itself are changing significantly as a consequence of new technologies." This study confirmed results from earlier studies and suggested that interventions such as giving employees appropriate training with computers under nonthreatening conditions, will reduce their overall computer anxiety. Mikkelse, Øgaard, \& Lindoe (2002) state "the search for flexibility in knowledge and skills in working life puts new demands on the workforce. Computerized systems have become an integral part of modern business. This means that an employee is required to consider learning as a lifelong process of constructing and applying knowledge in specialized problem area. The authors" state "a review of literature suggests that around one third of employees within most work environments experience computer anxiety to some degree ... and computer anxiety is not well understood."

A more technical aspect of the socio-technical system has been defined by Kaber, Onal, \& Endsley (2000), where the historical context of "traditional automation" is "the implementation of technology based on its capabilities, but lacking in consideration of the effects of application on a human operator." This process was based on what Griffith \& Dougherty (2002) have defined "technological determinism", where it was believed 
that technology resulted in a causal affect on the organization's behavior. Researchers have realized over the last three decades that traditional automation (technological determinism) has many negative performance and safety consequences associated with the human out-of-the-loop performance problem (i.e. increase in complacency, decrease in situational awareness and vigilance for example). The researchers have recognized that a human-centered level of automation is one approach to minimize this problem.

Endsley \& Kaber (1999) have provided an automation taxonomy that defines ten specific levels of automation within the human-system relationship. This automation taxonomy alludes to a linear progression from manual control (which includes no automation and the worker completes all tasks, monitoring, and decision making) to full automation (the system completes all tasks, monitoring, and decision making with no human intervention); the mid-range of the taxonomy affords a shared role between the human and the system. The automation taxonomy of Endsley \& Kaber (1999) is summarized as follows:
a. Manual Control
b. Action Support
c. Batch Processing
d. Shared Control
e. Decision Support
f. Blended Decision Support
g. Rigid System
h. Automated Decision Making
i. Supervisory Control
j. Full Automation

The use of such an automation taxonomy aids the design of human-centered systems, where human cognitive processing and system performance can be optimized. Endsley \& Kaber (1999) evaluated the automation taxonomy in regards to the ten previously 
described levels of automation in regards to the functions of 1. monitoring displays, 2. generating processing options, 3. selecting the optimal option, and 4. implementing the optimal option. The results of their study support a current discussion that worker involvement under normal operation is maintained when the system consists of an intermediate level of automation which enhances the worker's situational awareness while minimizing vigilance and complacency problems. System performance is maximized specifically when the automated system assumes the task implementation and when the human maintains the more cognitive function of option generation. Unlike the previous example of task implementation, Endsley \& Kaber (1999) state, "The fact that the joint human-machine generation of options produced worse performance than generation by either the human or machine component alone is sufficient. Most expert system and decision support systems being currently developed are directed at this type of interaction." Endsley \& Kaber successfully indicate that the level of automation (shared roles in the human-system design) drastically affects the overall system performance. A practical guide in deciding the appropriate level of automation in a particular advanced manufacturing application is proposed by Parasuraman, Sheridan, \& Wickens (2000). A structured approach (Figure 2) is taken in order to properly to evaluate the human performance consequences in conjunction with the secondary considerations of automation reliability and decision cost for any given automation decision. 


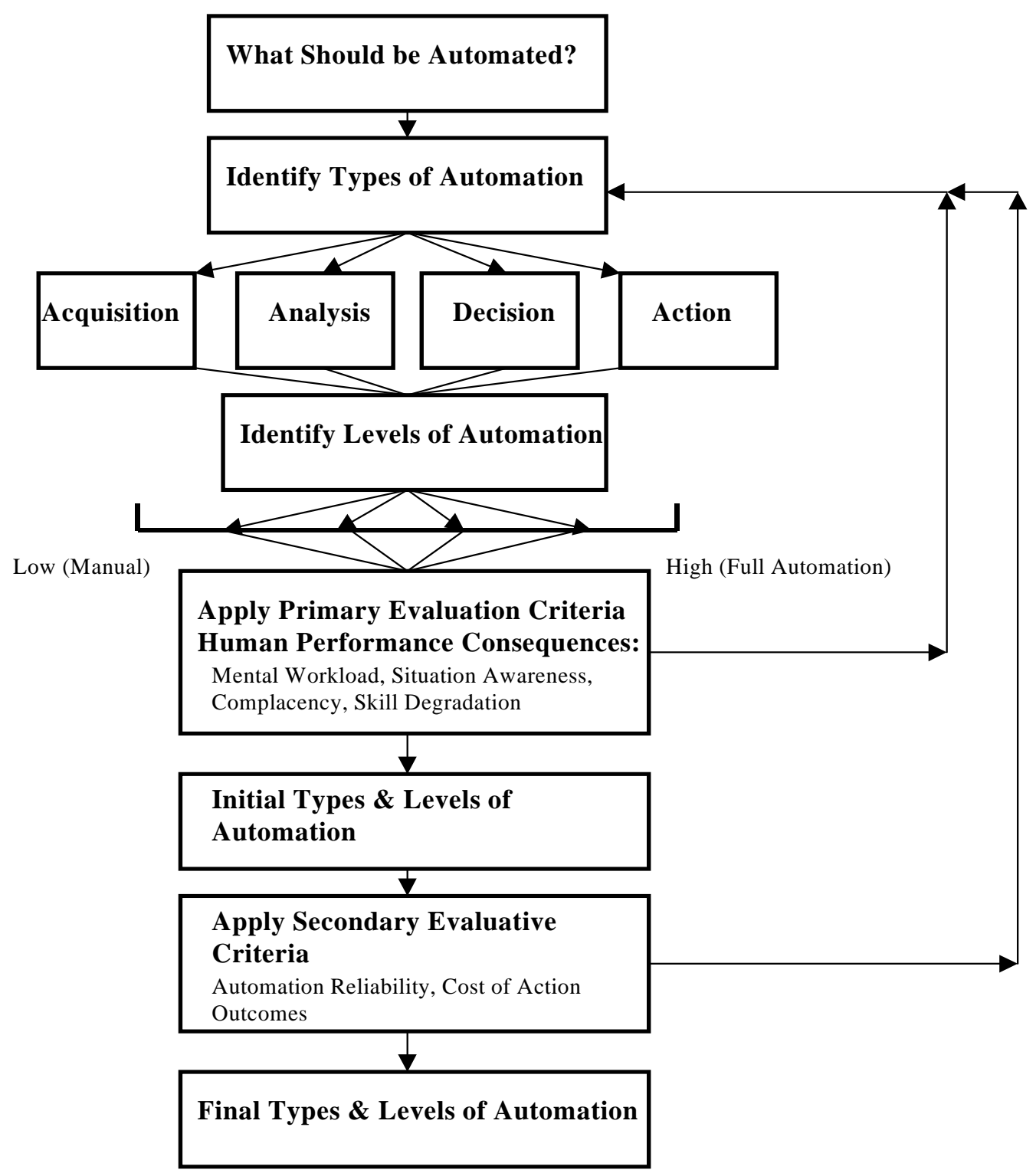

Figure 2. Level of Automation Evaluation Flow Chart

(Parasuraman, Sheridan, \& Wickens 2000) 


\section{Environmental Pressure, Affordance, and Change:}

The cross-disciplinary dynamic society has created several changes to sociotechnical work conditions. Rasmussen (2000) has described five work conditions that have facilitated substantial change in our environment: 1. pace of change, 2. scale of operations, 3. integration of operations, 4. aggressive competition, and 5. de-regulation. The pace of technological change is much faster than our managerial ability to cope with the change. This condition of change is compounded when considered in respect to the scale and integration of operations which are increasing to a point where the potential for a large disturbance may be small, but the implications of such a disturbance could be quite large.

Cañas, Quesada, Antoli, \& Fajardo (2003) in their study of cognitive flexibility and adaptability state that "most researchers seem to believe that an unexpected change in the environment is the crucial factor when observing a drop in performance after extensive practice at a task." The study results support this belief however, the full effect of the change on the individual depended on the problem-solving strategy used. As an example, Fang \& Salvendy (2001) state that "the changes in information technology have fundamentally changed human behaviors in daily life." The authors summarize the progression of study of various integrative works that evaluated people, technology, and organizations in conjunction with mental workload models and predictive implementation models.

Gielo-Perczak \& Karwowski (2003) elaborate on the earlier works of Rasmussen and describe the "need for a conceptual framework of a human system with perceptive insight into the complexity of the mutual relationships between human performance and the 
environment." Gielo-Perczak \& Karwowski go on to state that "the description of human operators who actively participate in purposeful work tasks in a given environment, and their performance on such tasks should reflect the complexity of brain activity, which includes cognition and the dynamic process of knowing."

Gielo-Perczak \& Karwowski (2003) state "the affordances of the environment are what it offers or provides the human (and other organisms) for human benefit or human ill. Humans aim to change and do change the environment in order to change what the environment affords them ... affordances are opportunities for action." The authors summarize that "an animal's ecological niche is defined by what its habitat affords. When an animal's physiological state no longer meets its internal demands, action is generated to bring it to a more satisfying state ... the brain is continually exerting control over its environment by constructing behavioral control networks."

O’Hare, Wiggins, Williams, \& Wong (1998) describe cognitive task analysis techniques, with specific attention to the critical decision method that focuses on naturalistic environments. The author's particular study centered on extreme time pressure during the decision-making situational assessment process, as presented in the recognition-primed decision model. "This time pressure combined with the decision strategy of generating and evaluating action options in this more analytical manner may also explain why the estimated mental workload associated with the decisions was rated high." The critical decision-making attributes consist of goal specification, cue identification, expectancy, conceptual model, influence of uncertainty, information integration, situation awareness, situation assessment, options, stress, basis of choice, and analogy. O'Hare, Wiggins, Williams, \& Wong found that “expert decision-makers were 
behaving in ways described by the recognition-primed decision-making model, especially with regard to serial rather than concurrent evaluation of options." Pliske, McCloskey, \& Klein (2001) summarize the recognition-primed model as "how people can use experience to make rapid decisions under conditions of time pressure and uncertainty that preclude the use of analytical strategies." Wilson (2002) also describes the timepressured aspect of embodied cognition, in that task related activities "require real-time responsiveness to feedback from the environment. These activities are not especially intelligent in and of themselves, it is claimed that greater cognitive complexity can be built up from successive layers of procedures for real-time interaction with the environment. Humans predictably fall apart under time pressure. That is, we very often do not successfully cope with representational bottlenecks."

\section{Embodied and Distributed Cognition in Relation to the Environment:}

Gielo-Perczak \& Karwowski (2003) propose that previous cognitive science has been somewhat "Cartesian" in its development of the distinction between the mental and physical. Gielo-Perczak \& Karwowski go on to state "that minds are not architectural modular structures that deal in information, but are constituted by the dynamic interactions of perceiver and percept, knower, and that which is to be known."

Wilson (2002) states "the emerging viewpoint of embodied cognition holds that cognitive processes are deeply rooted in the body's interactions with the world. There is a growing commitment to the idea that the mind must be understood in the context of its relationship to a physical body that interacts with the world ... affordances or the potential interactions with the environment." Wilson describes situated (or embodied) 
cognition as "cognition that takes place in the context of task-relevant inputs and outputs. That is, while a cognitive process is being carried out, perceptual information continues to come in that affects processing and motor activity is executed which effects the environment in task-relevant ways. Parasuraman (2003) supports the view of Wilson by referring to cited works that propose the "embodied mind is shaped by, and helps shape action in, a physical world".

Bedny, Karwowski, \& Bedny (2001) describe a form of embodied cognition when they describe one of the basic principles of activity theory: one's personality develops through activity and social interaction. Bedny, Karwowski, \& Bedny cite prior literature from as early as 1965 that describes an attribute of embodied cognition by stating "people change the world and thereby change themselves." The authors describe the idea of the interaction of cognitive and motor components of activity can be very useful, but so far it has not received enough attention in cognitive psychology and ergonomics. Referenced cited literature explains "the external practical activity is internalized and becomes internal cognitive activity through human work and social interaction. As a consequence, the internal mental activity is similar to external behavior in that it is composed of actions and operations. Not only does external, practical activity depend on cognition, but also cognition depends on behavior." The authors state that "cognition is the regulator of external behavior, and at the same time cognition in internal mental activity has a great deal in common with external behavior. In the theory of activity, cognition is a system of perceptual, imaginative, mnemonic, decision-making, and other mental actions. These mental actions are developed through practice (work) and social interaction." 
Wilson (2002) describes the debate of whether or not the environment is part of the cognitive system ... "that cognition is not an activity of the mind alone, but is instead distributed across the entire interacting situation including mind, body, and environment. The forces that drive cognitive activity do not reside solely inside the head of the individual, but instead are distributed across the individual and the situation as they interact $\ldots$ therefore to understand cognition we must study the situation and the person together as a single unified system." This view of a "distributed cognition" is shared by Parasuraman (2003) who describes a "joint cognitive system" where human behavior is situated and context-dependent. Parasuraman goes on to state that this contextdependency is often determined by the technological changes present in the environment.

Gielo-Perczak \& Karwowski (2003) cite referenced literature by describing "the inter-dependencies of operators and resources of work systems which contribute to performing the control activity as developed in the theory of distributed cognition". The authors' reference cited literature that states "mental elements represent the ecology of human-machine systems in which the work tasks are performed." 


\section{HUMAN-WORK DOMAIN}

The specific human-work domain of the socio-technical system presents several special considerations or attributes in regards to human performance in agile production systems.

\section{Adaptability and Flexibility:}

Vicente (1999) has concluded quite convincingly that, "As socio-technical systems become more and more complex, change will become the norm, not the exception. Therefore, to be competitive in this knowledge-based global economy, there will be an increased demand for workers, managers, organizations, and technology to be flexible and adaptive. At the same time, there will be an accompanying need for learning to learn."

De Toni \& Tonchia (1998) describe the requirement for, and the condition of flexibility within a manufacturing environment. The authors note the "consideration of flexibility as internal (to the manufacturing system) or otherwise external (namely, how it is perceived by the customer); the difficulty of limiting the flexibility of the manufacturing system (how must the suppliers' flexibility be directed?); the evaluation of flexibility in potential or effective terms; the emphasis on the ability to adapt (reactive) or change (proactive)." The authors state "as regards flexibility determinants, these are 
relative to variables such as the growing uncertainty of the demand, the increasingly shorter life-cycles of products and technologies, the increasingly wider range of products, increasingly marked product customization, increasingly shorter delivery times.

Therefore flexibility, seen as performance, may be required in relation to variables such as production volumes, mix, introduction of new products, etc., as seen when analyzing the classification of flexibility per object of the variation; this requires an analysis of the tradeoffs between performances when choosing configuration and functioning of the manufacturing system" (Figure 3).

\section{$\underline{\text { Uncertainty }} \quad \underline{\text { Flexibility }}$}

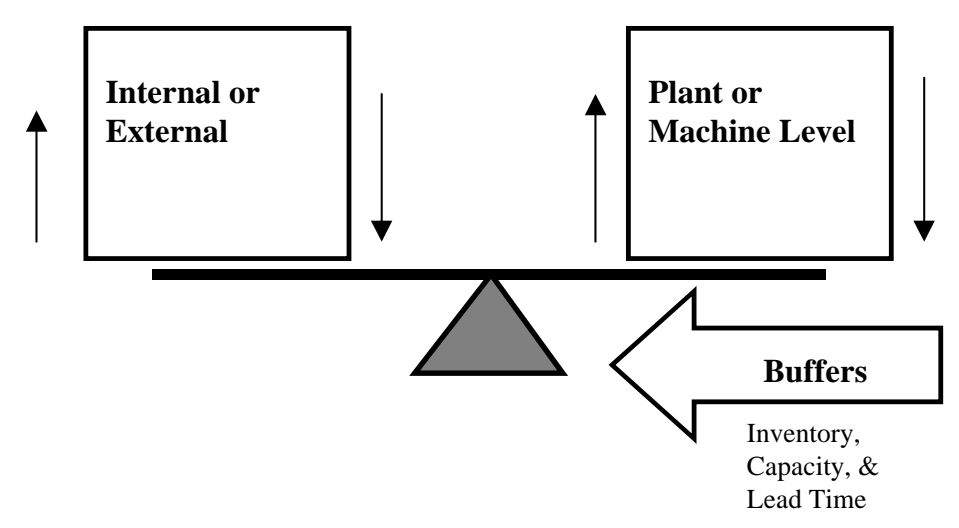

Figure 3. Balance between Uncertainty and Flexibility (De Toni \& Tonchia 1998)

De Toni \& Tonchia (1998) state "the concept of complexity is relative to two dimensions: uncertainty and time. Uncertainty may be informative (lack of information) and cognitive (subjective limits of the agents making the decisions). Time intervenes in 
terms of sequentially (for the irreversible nature of the decisions) and cumulativeness (for the increasing wealth of knowledge which can improve decision-making performances)."

\section{Complexity and Congruence:}

Prastacos, Soderquist, Spanos, and Van Wassenhove (2002) state that "a new type of leadership has always been required to solve new problems and take advantage of new opportunities ... what has not always been around however, is the phenomenal pace of change." Organizational flexibility and innovation is stated as the primary imperatives for managing change.

Koberg, Detienne, and Heppard (2003) in their study of the influence of environmental, organizational, process, and managerial characteristics affecting innovation cites that "complexity theory combines open with rational assumptions, to combine elements of stability, instability, and bounded instability into behaviors that apply in all human organizations, at the same time, under all conditions. At the same time instability underlines all human organizations; more complicated than stability, it produces patterns of behavior that are unpredictable.” Koberg, Detienne, and Heppard (2003) state "complexity theory argues that human organizations are complex adaptive systems characterized by cognitive structures influencing an agent's behavior."

"Organizational behavior may not be possible to predict in advance, over the long term it develops uniformity or structure - known as bounded instability. Instability and bounded instability are, according to complexity theory, the fundamental properties of innovative and creative systems. In order to produce creative, innovative, continually changeable behavior, systems must operate far from equilibrium where they are driven by negative 
and positive feedback to paradoxical states of stability and instability, predictability, and unpredictability."

In the complex organization comprising of many integrated components which is in a perceptual state of change and unpredictability it becomes essential that a congruent view of integration is institutionalized. Karwowski et al. (1994) discusses the requirement for congruence when optimizing the organization. "No single factor or component should out weigh the manner in which the factors or components match one another."

\section{Decision Making and Human Error:}

Leach, Jackson, \& Wall (2001) discusses that as workers roles are enhanced in the socio-technical system such that they leverage their existing knowledge of the machine operation and then goes on to assume a supervisory or fault management role in the operation of the process. This allows the worker to gain new training and skills while preventing as well as correcting operational faults.

Luczak, Reuth, \& Schmidt (2003) describe the ramifications of human error in advanced manufacturing environments. "System reliability is not only affected by technical aspects, but also influenced even more through undesired human errors." The authors conclude by summarizing cited flexible manufacturing literature, that "disturbances can be traced back to the following causes: 1. design errors, 2. component errors, 3. human errors, and 4. external errors. Human error and design error comprise approximately $20 \%$ and $30 \%$ of all quantified errors, respectively." The disturbances result in errors that manifest themselves in a manufacturing environment as the form loss 
of time, reduction in quality, production disruption, and accidents. Luczak, Reuth, \& Schmidt define human error as an "execution, respectively non-execution of a planned sequence of mental or physical activities, which can run the system by crossing determined accuracy limits to an undesirable system state." The authors cite specific literature as presenting three reasons why people make errors: 1. task complexity, 2 . poorly designed work situations, and 3. human behavioral characteristics.

Luczak, Reuth, \& Schmidt (2003) describe their process for developing the context of human error analysis with specifying a detailed analysis of potential disturbances associated with a task (Figure 4).

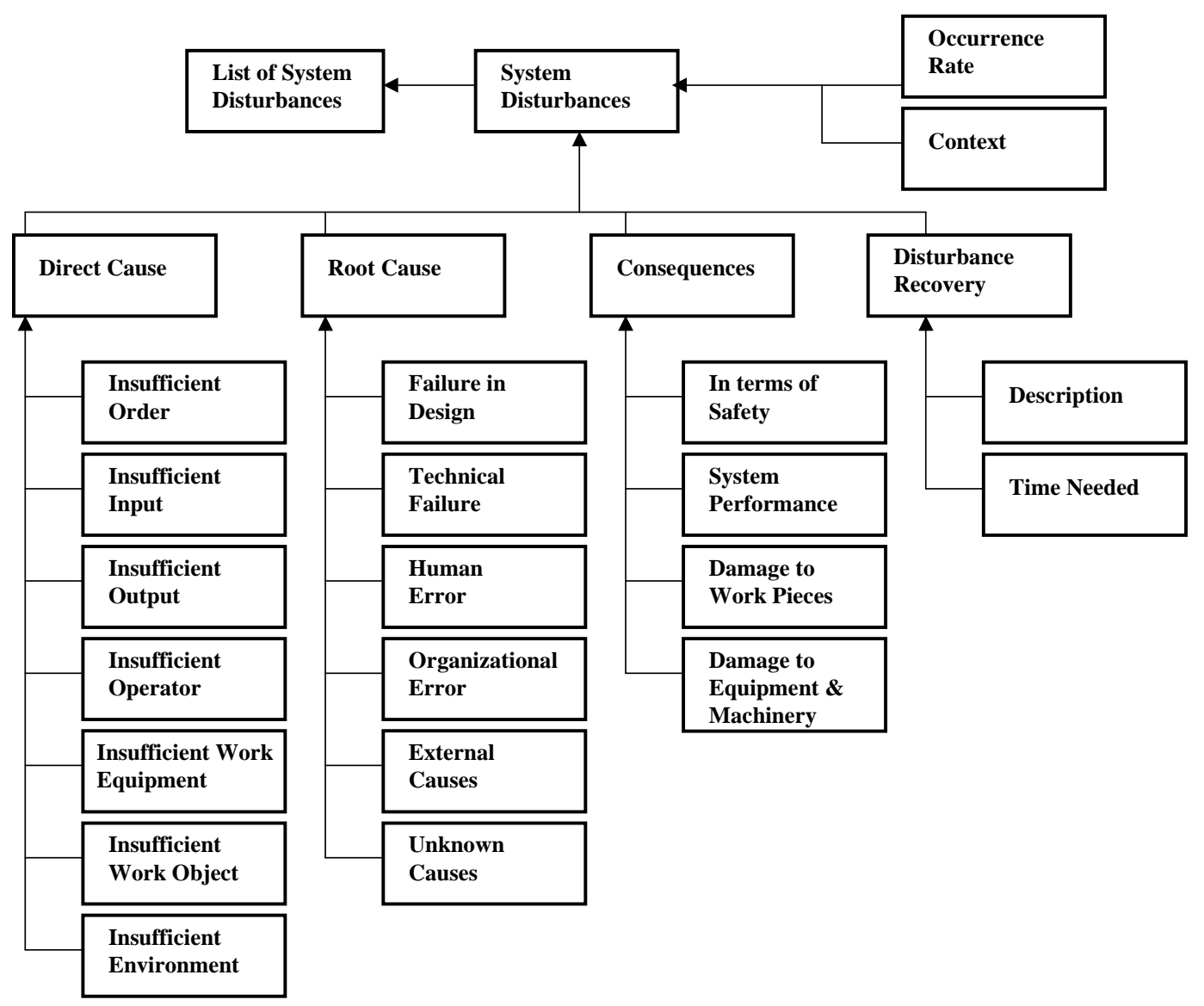

Figure 4. Structure of Human Error Analysis in terms of System Disturbances (Luczak, Reuth, \& Schmidt 2003) 
Stanton \& Stevenage (1998) identify that human error identification techniques may be acquired with relative ease and can provide reasonable error predictions. The authors cite references as stating "one needs to consider the activities of the individual if one is to be able to identify what went wrong. Rather than viewing errors as unpredictable events, this approach regards them to be wholly predictable occurrences based upon an analysis of an individual's activities." The authors describe the process of decomposing the error evaluation process. First, by performing a hierarchical task analysis identifying the action stages of a complex task. Second, developing an error classification taxonomy that can be applied to the hierarchical task analysis. Finally, conduct a consequence and recovery analysis of the coded error associated with each step of the hierarchical task analysis.

Klein, Kaempf, Wolf, Thorsden, \& Miller (1997) state "the decision requirements of a task are the key decisions and how they are made ... operators must make critical decisions under time pressure, ambiguity, shifting situation dynamics, ill-defined goals, and other features of naturalistic environments." The authors describe the importance in analyzing decisions as the getting inside the heads of people, to understand the cues and patterns and relationships they perceive, the knowledge they are using, and the strategies they are applying.

Militello \& Hutton (1998) propose a practical cognitive task analysis framework to aid the identification of cognitive skills or mental demands needed to perform a task proficiently. The cognitive demands table is presented as a means to organize and synthesize cognitive data witnessed by observation or through interviews. The cognitive demands table can be utilized in conjunction with the hierarchical task analysis and error 
classification taxonomy described by Stanton \& Stevenage (1998) as a finer resolution of the action stages of a particular tasks in evaluating the cognitive aspects such as:

1. identifying the difficult cognitive element, 2. why was it difficult, 3. common errors, and 4. cues and strategies used.

\section{Learning and Training:}

Bedny, Karwowski, \& Bedny (2001) have described the activity theory as it pertains to the learning process. They state, "the first stage of learning, mastering of mental skills and knowledge involves use of different objects, schemes, and external signs. The learner's cognitive activity is to a large degree externalized. Only in subsequent stages of learning will student's actions transform into the mental internal plane. This is why motor and verbal actions are important in the training process. Mental activity is formed with the support of external activity."

Brezocnik, Balic, \& Brezpcnik (2003) utilize a cognitive psychology model to define the types of problems likely to occur in a manufacturing environment. Their four types of problems are derived from a matrix describing problems with respect to the clarity of purpose and the certainty of the environment. The authors go on to state in "many areas of science and technology it has been possible recently to notice the shift towards the conceiving of intelligent systems capable of learning and efficiently responding to increasing complexity, unpredictability, and changeability of the environment. During the learning process, the system behavior gradually improves. Machine learning as the area of artificial intelligence is increasingly gaining importance." Generally, according to the learning capability, the intelligent systems can be divided into three groups: 
a. based on conventional knowledge bases

b. based on learning during interactions with the environment

c. based on learning during interactions with the environment, as well as other environments.

\section{Empowerment and Satisfaction:}

Leach, Jackson, \& Wall (2001) state that empowerment alone in not sufficient to guarantee organizational performance benefits, although in the socio-technical system workers are required to be willing and able to exhibit initiative and adopt a proactive to their work due to the greater variability, complexity, and rate of change of today's manufacturing environment. The key as Leach, Jackson, \& Wall (2001) attest is to couple immediate, specific, and non-threatening performance feedback with the empowered workers as an opportunity to learn. This coupling will allow the workers the opportunity to evaluate their own performance, make corrections, enhance their learning potential, and take ownership of the process becoming more self-reliant and productive.

Wagner, Leana, Locke, \& Schweiger (1997) attempted to evaluate the cognitive versus motivational frameworks in regards to participation-performance of 124 previously conducted studies. The premise of their study was to suggest that the "potential of participation might lie not in its power to motivate employees but rather in its ability to facilitate cognitive growth and awareness through the transfer of knowledge among individuals who might not otherwise share information." While their evaluation was not conclusive concerning the participation-performance relationship, it did provide 
support for the differential cognitive and motivational frameworks in regards to the participation-satisfaction relationship.

\section{Cognition in Relation to the Work Domain:}

Rasmussen (1990) has explained that "many modern flexible systems, such as manufacturing systems in highly turbulent and competitive environments, (have) less stable work procedures... tasks are discretionary, require consideration of goals and constraints, and exploration of the boundaries of acceptable performance." Rasmussen explains that the objects of classification are no longer bound to the "task", but relate to the work environment, interpretations by the individual actors, and to the abilities, cognitive processes, preferences, and social factors associated with the actors.

The process of "cognitive work analysis" provides a broad integrated evaluative framework of the behavior shaping constraints afforded by the work environment and perceived by the worker. This framework facilitates complex socio-technical systems by qualitatively describing worker behavior within a contextual manner that is susceptible to discretionary worker goals and decision-making. Cognitive work analysis has been defined by the research of the Ris $\varnothing$ National Laboratory (Rasmussen, Pejtersen, \& Schmidt 1990) as a multi-facet taxonomy "along the dimensions of: 1. the work domain representation; 2. activity analysis in domain terms; 3 . activity analysis in decisionmaking terms; 4. information processing strategies; 5. actual work organization; 6. social organization, and finally 7. cognitive control of activities." This research revolves around not just the task, but the entire socio-technical work environment (including the worker's perception of the work environment and the corresponding action alternatives). 
A representation of the Ris $\varnothing$ Work Analysis Perspectives (Pejtersen, Albrechtsen, Cleal, Hansen, \& Hertzum 2003) is shown in Figure 5. The figure illustrates the evaluation of the human-work domain as the successive inward movement from the actual work environment, through the progressively smaller, less encompassing work perspectives (less degrees of freedom in making choices) of organizational (including social), domain, activity, and finally the individual agent's characteristics. Rasmussen (1994) stated that these perspective changes were the result of the multiple disciplinary concepts required to evaluate the behavior shaping constraints present in the human-work domain.

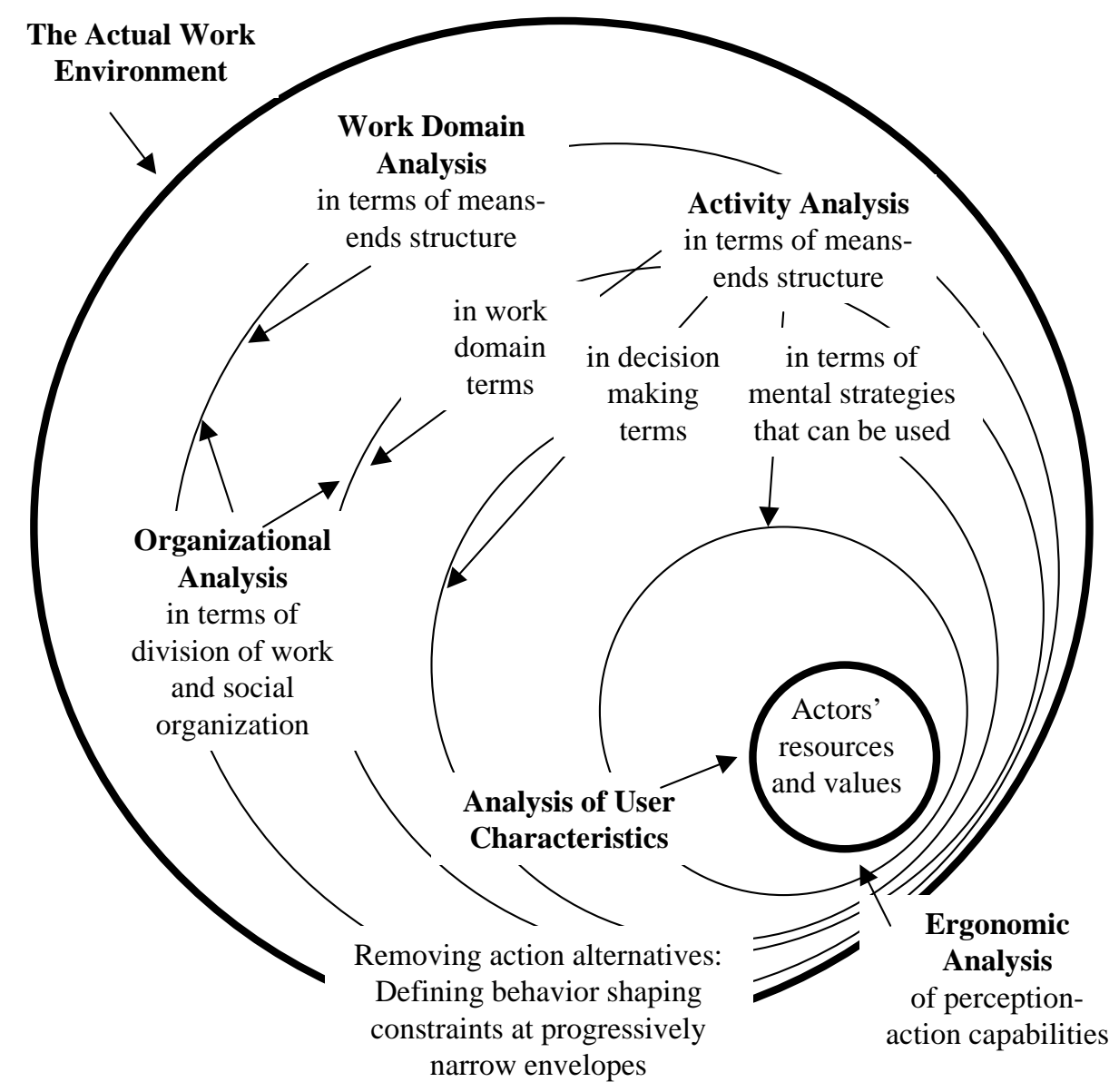

Figure 5. Ris $\varnothing$ Work Analysis Perspectives

(Pejtersen, Albrechtsen, Cleal, Hansen, \& Hertzum 2003) 
Vicente (1999) has taken a formative approach to cognitive work analysis by discussing the process of identifying the technical and organization requirements in regards to supporting work. Vicente references Rasmussen (1986) by summarizing the five different aspects of work requiring consideration in complex socio-technical systems: 1. work domain, 2. control tasks, 3. strategies, 4. social organization, and 5. worker competencies.

A complex system that contains this discretionary component of worker behavior is defined as an intentional system, which is differentiated from a purely causal system that is exclusively defined by physical systems and laws. Intentional systems therefore yield a great diversity in behavioral patterns (Pejtersen, Albrechtsen, Cleal, Hansen, \& Hertzum 2003). Some researchers have stated that it is difficult to fully evaluate in an ecological framework with the resultant variants (Wong, Sallus, \& O'Hare 1998), to the point that the validity and reliability of an individual agent's discretionary decisionmaking is "fragile and contestable" (Schmidt 1990). Schmidt (2000) has stated, "The challenge is to develop the conceptual implications of this insight and understand the intricate interplay of the causal and the intentional ..."

Genaidy, Karwowski, \& Shoaf (2002) have presented the work system compatibility theory that is defined as the degree of equilibrium between the energy expenditure and energy replenishment forces. Energy expenditure forces include physical task demands, cognitive-based tasks, physical environment conditions, and non-physical environment conditions. Energy replenishment forces include such attributes as autonomy, task organization, decision making, individual growth in skills and knowledge, personal development, rewards, and knowledge of results. The work system compatibility theory 
strives to bring balance among different elements in the work system by following two basic premises: " 1 . the synergistic effects of the entire domain of work factors upon the performance of individuals in the workplace must be considered, and 2. the work system elements must be balanced to achieve simultaneous optimization of all facets of workplace human performance measures." Genaidy, Karwowski, \& Shoaf describe the approach as having two integrative aspects: 1 . all work domain factors present at the organizational, process, and job levels are to be included, and 2. the strategy is integrated to form a multi-disciplinary approach. "Elements of quality of work life include: safe/healthy/comfortable workplace, social integration in work organization, supportive organizational and technical environment, and rewarding workplace."

Havn (1994) describes that "in the design of an artifact to be operated by people the constructor is bound to consider the user's mental and physical capacity in work settings - effects of stresses, psychomotor ability, perceptual activity, mental processing workloads, and so forth. In manufacturing systems, however people are not simply affected by the technology ... we cannot describe people as merely "factors," we have to take as a starting point that people are "actors" ... who are using the application in work processes. It has been gradually realized that controls and tasks designed to reduce both mental and physical strain of the operator allowed for improved performance of the human-machine system."

Karwowski, Siemionow, \& Gielo-Perczak (2003) describe an "emerging field of study, named hereby as physical neuroergonomics, that focuses on the knowledge of human brain activities in relation to the control and design of physical tasks. Motor, cognitive and emotional aspects and their inter-relationships in connection to physical 
ergonomics are considered." Neuroergonomics as defined by Parasuraman (2003), maintains that the "human brain implements cognition and is itself shaped by the physical environment." This movement in the ergonomic discipline has been facilitated by as Karwowski, Siemionow, \& Gielo-Perczak describe, an "increasing sophistication of the ergonomics inquiry into the human characteristics and human functioning that are relevant to the design process. The expansion from the physical (motor), to cognitive, to esthetical and, recently, to affective (emotional) factors introduced the necessity to consider more and more the human brain functioning, and the ultimate supreme role of the brain in exercising control over human behavior in relation to the affordances of the environment."

Karwowski, Siemionow, \& Gielo-Perczak (2003) identify the "need for tools for prediction of human performance, with defined error modes taking into account human emotions, imagination and intuition with reference to affordances of the environment (Gielo-Perczak \& Karwowski 2003)." “Although our rationality has made us much more aware of our natural human limitation, there is an emerging need for the concept of a human system with perceptive insight into the complexity of the mutual relationships of human performance and the environment. The majority of contemporary ergonomics literature refers to three modes of human performance based on Rasmussen's framework that includes the skill-, rule-, and knowledge-based forms. However, as the human brain is a dynamical system that aims to exercise control over the environment, human performance can be modeled as a dynamic, non-linear process taking place over the interactions between the human brain and the environment, based on the concepts of affordances, emotion, and intuition." This state described by Karwowski, Siemionow, \& 
Gielo-Perczak can be summarized according to the expanded skill, rule, knowledge, and wisdom taxonomy defined in the research objective of this study, which was based specifically on the interaction with the external environment and the enabling attributes associated with the external environment.

Xie \& Salvendy (2000) state "that mental workload could be described more precisely using a group of variables such as instantaneous workload, peak workload, average workload, accumulated workload, and overall workload rather than using a single variable only. A mental workload model, which considered both individual differences and task characteristics, was used to model and predict. By knowing the task demands and the population that the task will be assigned to, the mental workload of the population can be predicted before tasks are actually assigned to the participants. Mental workload is the consequence of or is synonymous with human mental effort. Both taskrelated factors, such as task complexity and task type, and individual-related factors, such as domain knowledge, have significant effects on overall mental workload."

Wei \& Salvendy (2000) state "the development of advanced technologies increases the amount and complexity of the information the human has to process on a job. These changes lead to jobs involving more and more cognitive task elements. Jobs requiring high cognitive capabilities may produce high human mental workloads." However, the authors state human cognitive capabilities or mental abilities are limited. It is worthy to note that this position is different than the ecological cognitive framework proposed in the research objective of this study, where human cognition is proposed as being enhanced by the external environment afforded attributes of embodied and distributed cognition. Wei \& Salvendy construct a human-centered cognitive performance model 
based on human information processing theory. Eleven broad cognitive modules were developed and decomposed into specific cognitive attributes that could be represented and evaluated via the Purdue Cognitive Task Analysis Questionnaire. The broad cognitive evaluation modules included information interface, information handling, mental plan \& schedule, mental execution, monitor, communication, learning, attention, memory, motivation, and environment. The results of this method are not as accurate as some forms of cognitive task analysis, but the questionnaire format makes its much more economical. "The results support that it is possible to analyze human cognitively oriented work in terms of meaningful job elements of a worker-oriented nature and that this analysis can be carried out with acceptable construct validity and reliability. There is evidence that such job elements tend to form reasonable stable job dimensions that characterize the potential structure of cognitive capability requirements of human work." 


\section{THE NEED FOR A MORE “MID-RANGE” MODEL}

The process of creating technology transforms the human condition with respect to its environment. Grammig (2003) describes the socio-technical relations between the various levels of human-nonhuman transformations and elaborates on the work of Latour who defined eleven distinct relational levels associated with a complex socio-technical system. Grammig presents arguments based on anthropology, cultural, and societal implications of technology, while being derived from a different discipline as the cited works of Rasmussen. Grammig's work parallels the derived understanding of the sociotechnical system.

The recent works that define the various levels of human-nonhuman interaction at the various levels of the socio-technical system allude to the human situation complexity but fail to identify the causal nature of the human-environment relationship. Grammig (2003) summarizes that the value of the current hierarchical socio-technical relations thus far has been the avoidance of separating the human and nonhuman relations to explain failure of application or understanding of the various relational levels.

Badham \& Ehn (2000) describe a large rift between the models, methods, relations, and evaluation of the engineering and social sciences disciplines in regards to the sociotechnical system. The "institutionalized splitting" to the point of mutual criticism and 
fear to explore in the other area has detracted from reaching a multi-disciplinary interpretation of the socio-technical system.

Majchrzak \& Borys (2001) have described the need for a more user-centered model of a socio-technical system, a model that would balance the human quality of work life and the organizational performance needs of a manufacturing environment. Their model as presented differs from classical socio-technical models in that it develops specificity (in lieu of abstractions) and can be tested and includes the following perspectives:

- Addresses all elements in an organization

- Incorporates Chern's classical socio-technical system design principles of: Compatibility Minimal critical specifications Socio-technical variance criterion Multifunctionality principle Boundry location Information flow Support congruence Design and human values Incompletion

- $\quad$ Considers social and technical organizational elements

- $\quad$ Incorporates quality of work life organizational design elements

- $\quad$ Provides process variance control strategies

Griffith \& Dougherty (2002) have defined the need to leap beyond the sociotechnical system paradigm and delve into the dynamics of the connections and relationships concerning technology development and change ... the actual nature of these relationships remain confusing, under-explored, and unarticulated across multidisciplinary literature. Issues such as technological determinism where it is believed that technology is the critical factor affecting the organizational attributes needs to be evaluated in regards to adaptation and social integration criteria. 
Duffy \& Salvendy (1999) describe "the emergence of skills, task, and behaviors as indicators of success and competitive advantage in an advanced manufacturing environment give rise to the need for a shift of focus from technology as a competitive advantage to the effect of technology on the organization's competitive advantage. Previous models that focus solely on technology's effect on organizational structure, job satisfaction, or quality of work life alone are insufficient." The authors discuss that the effect of technology on system task characteristics is not well understood and researchers have failed to agree on the relevant dimensions of technology that capture both organizational and human issues. Duffy \& Salvendy state that "the significance of the interaction of these human (cognitive skills such as learning and problem solving) and organizational issues is now recognized as a determinant of success of organizations navigating through technological change."

The previous argument of Majchrzak \& Borys (2001) that the vastness of sociotechnical system theory facilitates an "abstractness" that suggests the principles are not applicable to empirical testing, or to practice in general, is reiterated here. There is a need for a "mid-range" socio-technical system theory that simplifies the current abstractions and focuses on specific testable and measurable perspectives. This "midrange" socio-technical system theory would involve all elements of an organization, including both social and technical elements, incorporate the human quality of work life, and have the capability of ensuring variance control strategies. Therefore, the need for a “mid-range” socio-technical system theory called upon by Majchrzak \& Borys (2001) that encompasses the interdependence of the work environment and the worker, while 
providing a manageable and quantifiable model that affords the ability to provide testable and measurable relational perspectives is anxiously awaited. 


\section{RESEARCH OBJECTIVES SYNTHESIS OF AN ECOLOGICAL COGNITIVE MODEL}

\section{An Expanded Ecological Approach in Defining the Problem Space:}

In order to fully evaluate the human cognitive state with respect to agile production systems, a broad framework that attempts to synthesize the "abstractness" of the previously referenced socio-technical system literature is proposed. This framework is intended to summarize the preceding discussions, while proposing a human cognitive and ecological framework for further evaluation. Rasmussen (2000) has defined the ecological approach as aiming to control human behavior by shaping the conditions of adaptation to the work environment. The proposed ecological cognitive framework (Figure 6) attempts to indicate those conditions that create or more aptly, enable, a situation of adaptation while maintaining human cognition as the center attribute or consideration.

The ecological cognitive framework presents a situation where the external environment interacts with a human-work domain sub-model in specific ways. In a timedependent fashion the external environment influences technologies, artifacts, cultures, and system outcomes by providing an external pressure (i.e. competitive cost requirements, customer quality expectations, or government regulations) by virtue of 


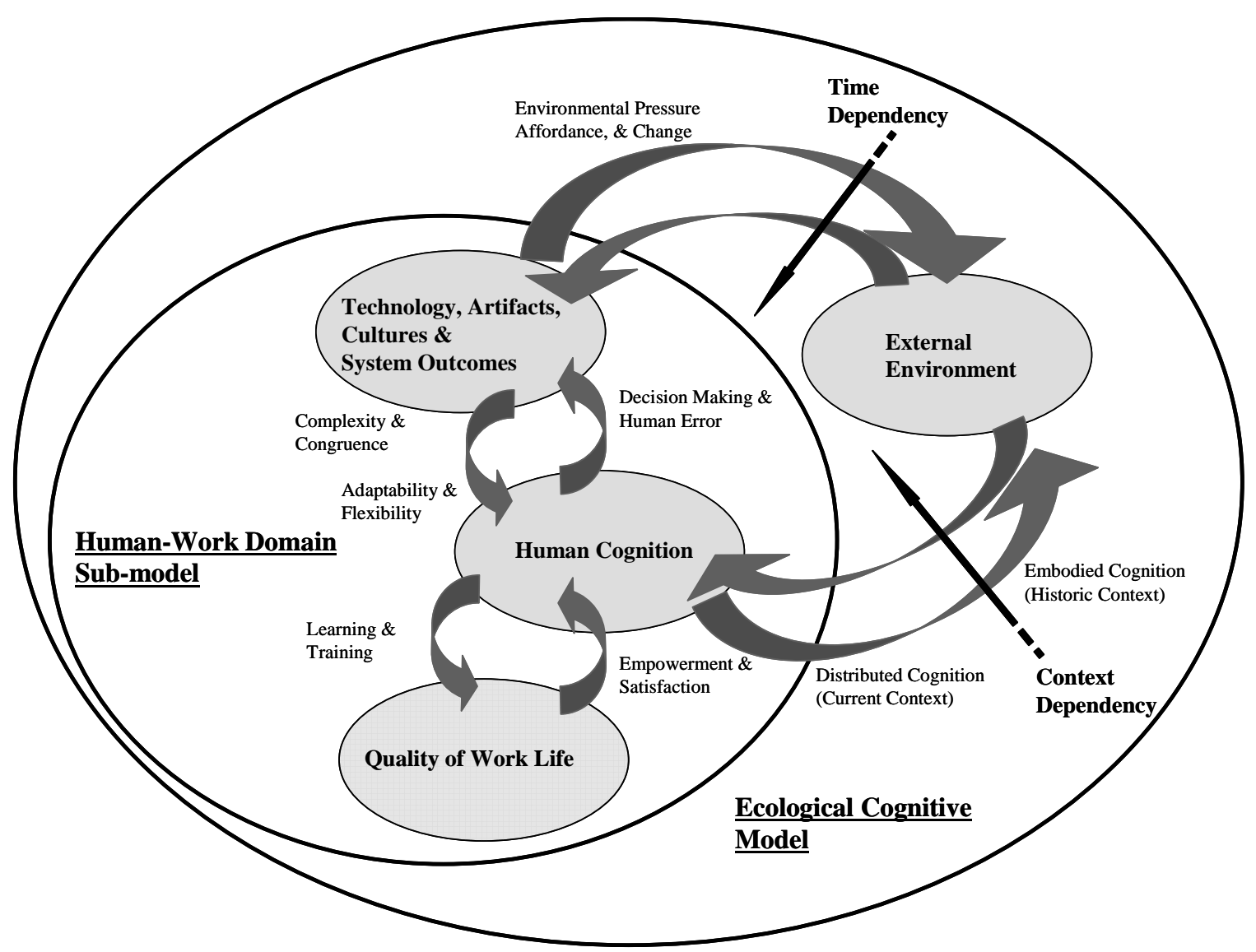

Figure 6. An Ecological Cognitive Framework

affordances or opportunities. This process of change is very visual, and can be witnessed virtually in every aspect of daily technological life. In a more subtle fashion, the presence of advanced technologies and artifacts in turn affect the external environment by providing satisfaction and enabling higher levels of expectation, thus providing a form of creative or enabling feedback.

The external environment also interacts with the human cognitive capabilities. In a historic context-dependent manner the environment provides a form of embodied cognition as an attribute to the human cognitive process, thereby enabling the cognitive 
capabilities of an individual by merit of previous location, domain, or context. In a current context-dependent manner the external environment enables human cognition by the process of distributed cognition. This state of being suggests that by one's current location, domain, or context a person can be in the proximity of elements of distributed cognition that may be exercised. Therefore, an individual's total cognitive capability may not be limited to one's own mental fortitude, but be leveraged by distributed and available "bits" of cognition.

\section{An Expanded Skill, Rule, Knowledge, and Wisdom Taxonomy:}

An exploration that suggests the expansion of Rasmussen's SRK taxonomy (Rasmussen 1986) to include consideration of the external environment's temporal and contextual contribution to one's cognitive capability is presented in Figure 7, which has been derived from the Neerincx, Van Doorne, \& Ruijsendall (1999) simplified representation of the Rasmussen SRK taxonomy.

The presence of external environment's cognitive enabling allows the classical taxonomy of information processing to be expanded to encompass a level of "WisdomBased" human performance that surpasses the levels of "Knowledge-", "Rule-", and "Skill-Based" levels of consideration, which is characterized by analytical reasoning, stored rules, and perception-action respectively. The suggested level of "Wisdom-Based" human performance is characterized by an adaptive sense of "anticipation" (akin to the Gielo-Perczak \& Karwowski 2003 term “intuition”) that allows an individual the ability of "assimilation" concerning multiple scenarios from signals presented by the 


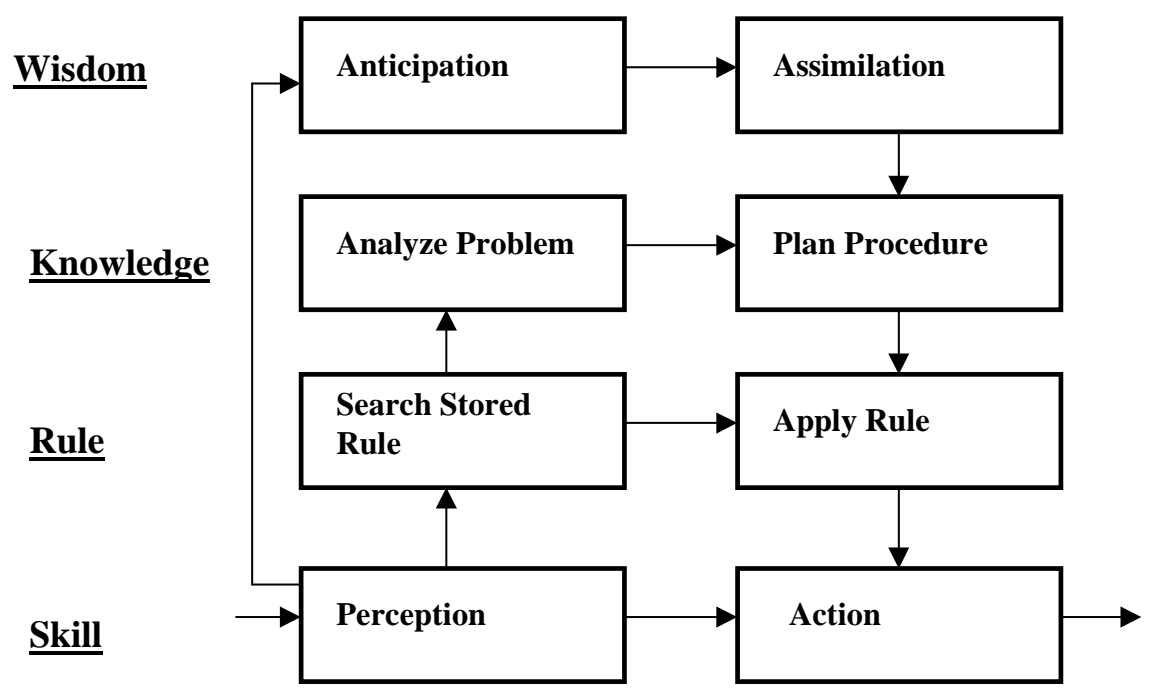

Figure 7. An Expanded Skill, Rule, Knowledge, \& Wisdom Taxonomy (derived from Neerincx, VanDoorne, \& Ruijsendall 1999)

environment. The attributes of "anticipation" and "assimilation" are products of the external environmental enabled context-dependent distributed and embodied cognition and the time-dependent affordance that is enacted by an individual.

\section{The Human-Work Domain Sub-Model:}

It shall be the intent and objective of this research to delve specifically into the Human-Work Domain Sub-model (Figure 8) and ascertain the relationship between specific sub-model variables. The Human-Work Domain Sub-model was derived from the Ecological Cognitive Framework (Figure 6) and shall be depicted as having three interactive latent variables: 1 . system outcomes, 2. human cognition, and 3. quality of work life. 


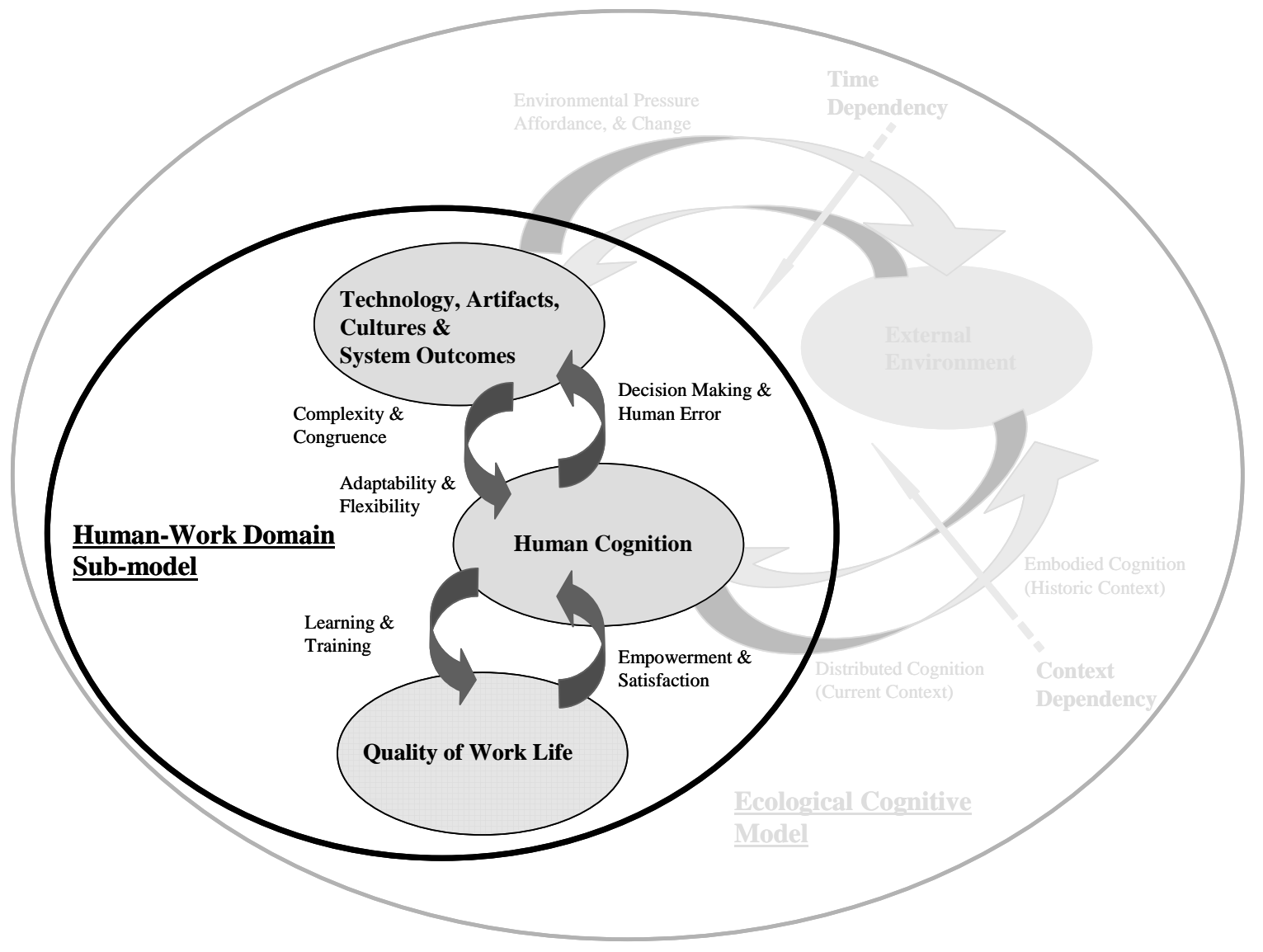

Figure 8. The Human-Work Domain Sub-model

The following variable descriptive definitions shall be utilized throughout this study thesis:

System Outcomes - The empirical, measurable variables of a prescribed production process that is used to measure quality compliance, schedule performance, and cost performance.

Human Cognition - The situational mental processes of perceiving, processing, decision-making, and execution associated with a task in an agile production environment.

Quality of Work Life - The psychosocial satisfaction one maintains towards their work tasks, work environment, coworkers, supervision, organization, etc. 


\section{RESEARCH HYPOTHESIS}

The following agile production system human-work domain hypotheses have been evaluated during this research:

Hypothesis 1: The system outcomes associated with an agile production process are the causal result of a worker's level of cognitive activity, as well as the worker's maintained perception of his/her quality of work life according to the proposed causal model (Figure 9).

Hypothesis 2: The human-work domain sub-model relationship (Figure 8) present in an agile production system is temporally and contextually situational (including intentional and causal components). Therefore, the relationships between system outcomes, human cognition, and the quality of work life vary in regards to both the time expose to, and context of, the task as the worker anticipates and adapts to an ever-changing environment. 


\section{METHODOLOGY}

\section{Causal Model:}

The proposed structural causal model (Figure 9) hypothesizes the relationship between the task specific system outcomes (latent dependent variable) enabled by human cognition utilized during the task and the quality of work life experienced prior to and during the task.

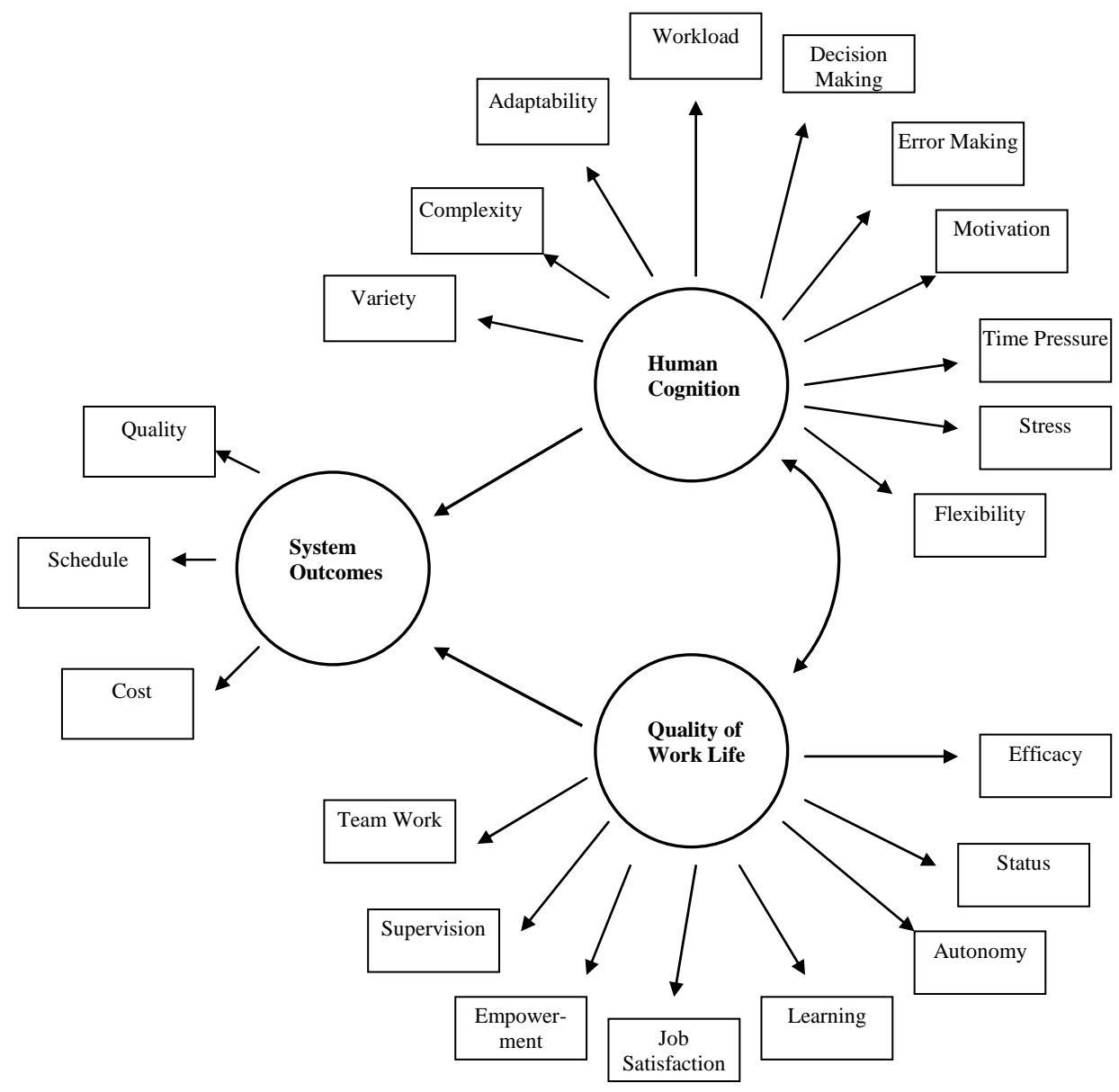

Figure 9. Proposed Human-Work Domain

Causal Model 
The causal model is summarily described by system outcomes as the latent dependent variable which is affected by the two (2) latent independent variables of human cognition and quality of work life. The dependent variable, system outcomes yields three (3) manifest endogenous variables that are the readily measured in today's industrial world with respect to any defined work task: cost, schedule, and quality.

The latent independent variables of human cognition and quality of work life are more difficult to evaluate. Each of these latent variables has several endogenous indexes variables (note that any variable error notation has been excluded for clarity). These independent endogenous variables have been selected in consideration of the hypothesized correlation to the respective latent variables as well as the overarching concern for their representation of the worker's psychological health as described in the Karasek \& Theorell (1990) demand-control model. Karasek \& Theorell present that the worker's psychological strain increases as the psychological demands of the task is increased and the worker's ability to control his or her own skill usage is decreased. This worker's psychosocial condition is further evaluated in the works of the stress-straincoping mechanisms described by Decker \& Borgen (1993), the workload-social interaction-psychological well being of Repetti (1987), and the stress-support-control attributes of Daniels \& Guppy (1994). The comparable relationship of these psychosocial effects on workers, summarily included in this study's definition of human cognition and quality of work life, and the resultant effect on the dependent variable (system outcomes) is the central theme of this research. 


\section{Study Design:}

The research design consisted of an eight (8) month, four-wave longitudinal study of human performance in an actual agile production system, evaluating system outcomes with worker cognitive attributes and quality of work life issues. Each wave of the study was conducted at an approximate two (2) month interval.

The study was conducted as a correlational analysis evaluating and validating the causal model depicted in Figure 9. Three specific instruments: empirical data, cognitive task analysis, and questionnaires (each corresponding to a specific latent variable represented in the casual model) were utilized and will be further defined in later sections of this thesis. Evaluative software analysis tools included AMOS (Analysis of MOment Structures) for evaluating the causal model and SPSS (Statistical Package for the Social Sciences) for evaluating the variable descriptive statistics involved with the study instruments.

\section{Study Procedures:}

This study of human performance within the context of the causal model and utilizing the above-mentioned instruments requires human subject research. An Institutional Review Board (IRB) submittal was prepared and approved. The IRB submittal consisted of the following considerations: subject risk assessment, balancing study risk and benefit, ensuring privacy and confidentiality, data collection and storage, informed consent documentation, and vulnerable population considerations.

This study was designed to maximize internal validity by minimizing interference with or bias towards, the actual work as it is being conducted by the worker in the natural 
context, and as such the collection of cognitive task analysis data was observational only. This style various somewhat from traditional qualitative procedures where more direct interaction with the worker is taken by the researcher (Carstensen \& Schmidt 2002; Pejtersen 2003) in the form of qualitative interviews, focus groups, or informal interaction. The collection of the empirical system outcome data was conducted by the immediate supervisor(s) and is considered part of their normal supervisory tasks, and as such was separate from the worker in both time and place. Therefore, the collection of the system outcome data did not interfere with the study. The quality of work life questionnaire was administered prior to the task execution, at the beginning of the scheduled data collection work shift.

A two-phase study test was conducted in order to evaluate the content validity of the causal model, as well as the specific instrument designs. This two-phase study test was conducted prior to, and in conjunction with, the initiation of the first wave of data collection. First, fictitious but reasonable data was constructed and feed through the instruments and structural modeling process. Second, a critical review of the data collection process, instrument designs, and structural equation modeling process was completed after the first wave of data collection was complete. Modifications were made to coding of the human cognition indexed variables in order to improve the covariance magnitudes as a result of this two-phase study test. The design of the procedures were not modified from those originally proposed, nor were the first wave of raw data found to be lacking.

The chronology of activities during each particular wave of the data collection process included: 1 . presentation of the study objectives and informed consent approval 
process (first wave of testing per worker only), 2. administration of the quality of work life questionnaire to the entire subject population, 3. administration of the cognitive task analysis sequentially to each subject individually for a period of $10-15$ minutes, 4. the receipt of the system outcomes (i.e. quality, cost, and schedule) measures from the specific supervisor(s), and 5. the coding and input of the raw data into the study database. The total data collection 5-step process as defined required approximately one hour of researcher time per database line of subject data.

\section{Sampling Frame:}

The study environment consisted of actual agile production processes comprising of seventy-four (74) multi-skilled, cross-trained workers fabricating and assembling mechanical and electrical equipment from two (2) separate companies during the eight (8) month period. The resultant four-wave data collection procedure yielded a total sample size (n) of 205, which must be considered a nonscientific (nonprobability) pseudopanel sample.

Company 1 represents an electrical panel fabrication and assembly operation where eighteen (18) workers took part in the study, yielding a database sample size (n) of 57. Company 2 is a mechanical equipment fabrication and assembly operation consisting of fifty-six (56) workers who participated in the study, providing a database sample size (n) of 148. The production scope of work for both study companies involved the eight month production of equipment at a specific schedule with specific cost reduction expectations, while remaining flexible in an organizational sense in order to absorb additional scopes of work that could be considered developmental or a one-time 
production in nature. The eight month production scope of work involved: high standards of quality which were many times to be self-assured by the worker, small incoming materials and finished goods buffers, schedule constraints, and small work-inprocess lot sizes. Both companies are to be considered "agile" prior to initiating this study, therefore it would not be correct to view the results of this study as the change brought about by an agile environment. Rather, this sample population is worthy of evaluating the continuous ability and requirements revolving around the continually changing agile production system. The study population descriptives (sample size) per data collection wave can be seen in Table 1 .

Age and gender differences of the study population did not have any significant factor in the analysis of this study. These factors were not hypothesized to be pertinent to the causal model, but were part of the data collection procedure. The age and gender factor were evaluated as part of the structural equation modeling process as an initial factorial verification and not included in any evaluation thereafter.

One of the objectives of this longitudinal study was to evaluate workers during the progression of the four-wave study design, but due to worker attrition only thirty-eight (38) workers were present for all four waves of data collection $(\mathrm{n}=152)$ which is further discussed later in this thesis. Since these workers operate in an agile production environment where their detailed actions as well as their summarily activities are varied, the total sample size $(n=205)$ was considered to be sufficiently independent of task differentiation to validate the structural equation modeling sample size requirement. The sample size requirements are discussed more thoroughly later in this thesis in the applicable sections. 
Table 1. Study Population Descriptives per Data Collection Wave

\begin{tabular}{|c|c|c|c|c|c|c|c|c|}
\hline & \multicolumn{2}{|c|}{1.0} & \multicolumn{2}{|c|}{2.0} & \multicolumn{2}{|c|}{3.0} & \multicolumn{2}{|c|}{4.0} \\
\hline & Count & $\%$ & Count & $\%$ & Count & $\%$ & Count & $\%$ \\
\hline Company 1 & 16 & $32.7 \%$ & 14 & $26.9 \%$ & 13 & $25.0 \%$ & 14 & $26.9 \%$ \\
\hline Total & 49 & $100.0 \%$ & 52 & $100.0 \%$ & 52 & $100.0 \%$ & 52 & $100.0 \%$ \\
\hline
\end{tabular}

\begin{tabular}{|c|c|c|c|c|c|c|c|c|}
\hline & \multicolumn{2}{|c|}{1.0} & \multicolumn{2}{|c|}{2.0} & \multicolumn{2}{|c|}{3.0} & \multicolumn{2}{|c|}{4.0} \\
\hline & $\begin{array}{c}\text { Company } \\
1\end{array}$ & $\begin{array}{c}\text { Company } \\
2\end{array}$ & $\begin{array}{c}\text { Company } \\
1\end{array}$ & $\begin{array}{c}\text { Company } \\
2\end{array}$ & $\begin{array}{c}\text { Company } \\
1\end{array}$ & $\begin{array}{c}\text { Company } \\
2\end{array}$ & $\begin{array}{c}\text { Company } \\
1\end{array}$ & $\begin{array}{c}\text { Company } \\
2\end{array}$ \\
\hline Mech. Fabrication & & 13 & & 12 & & 10 & & 6 \\
\hline Elect. Panel Fabrication & 2 & & 1 & & 2 & & 5 & \\
\hline Mech. Assembly & & & & 2 & & 3 & & 3 \\
\hline Elect. Panel Assembly & 5 & & 7 & & 6 & & 4 & \\
\hline Machine Operation & & 7 & & 7 & & 8 & & 11 \\
\hline Material Transport & & & & & & 1 & & \\
\hline Inspection & 1 & 1 & 1 & 1 & & 1 & 1 & 1 \\
\hline Maintenance & & 2 & & 2 & & 2 & & 4 \\
\hline Office Support & 5 & 1 & 5 & 1 & 5 & 2 & 4 & \\
\hline
\end{tabular}

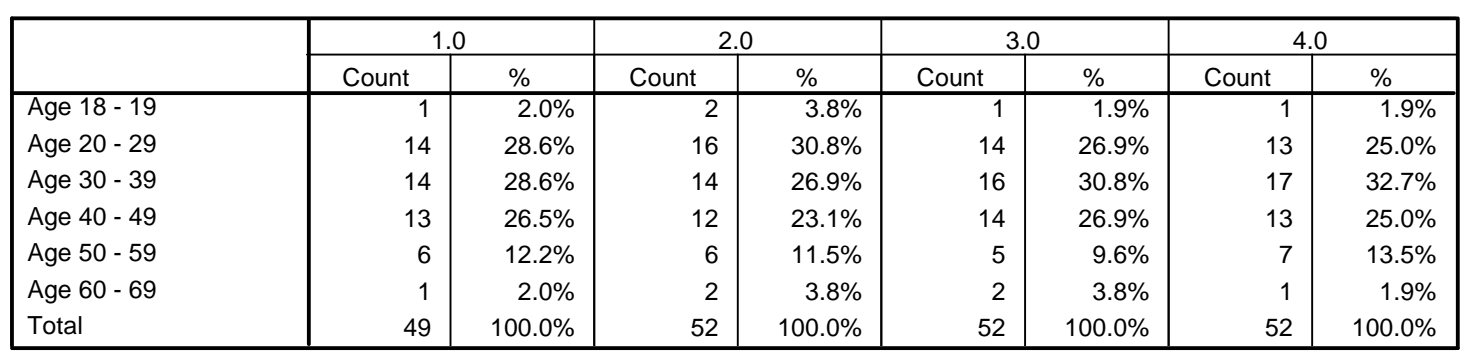

\begin{tabular}{|c|c|c|c|c|c|c|c|c|}
\hline & \multicolumn{2}{|c|}{1.0} & \multicolumn{2}{|c|}{2.0} & \multicolumn{2}{|c|}{3.0} & \multicolumn{2}{|c|}{4.0} \\
\hline & Count & $\%$ & Count & $\%$ & Count & $\%$ & Count & $\%$ \\
\hline Male & 46 & $93.9 \%$ & 50 & $96.2 \%$ & 50 & $96.2 \%$ & 50 & $96.2 \%$ \\
\hline Total & 49 & $100.0 \%$ & 52 & $100.0 \%$ & 52 & $100.0 \%$ & 52 & $100.0 \%$ \\
\hline
\end{tabular}

\section{Instruments and Data Collection:}

The three latent variables involved with the assessment of human performance in an agile production system require three specific instruments measuring the appropriate manifest or indexed variables: 1. system outcomes-empirical data, 2. human cognition- 
cognitive task analysis, and 3. quality of work life-questionnaires. These three instruments were administered in four (4) waves at an interval of approximately two (2) months, for a total of an eight (8) month longitudinal study. Data was collected as to control for the wave number allowing the study to evaluate wave-to-wave changes in the descriptive statistics.

\section{System Outcomes: Empirical Data:}

The latent dependent variable, system outcomes was measured as an index of the three manifest variables of quality, cost, and schedule. Each of these three variables describes a completed attribute of a task and is tracked according to a specific production work order number and worker. The quality of the task was measured using the existing corporate quality system affixing a scale measurement of $0-5($ recoded as $10-15)$ indicating the number of quality problems encountered during the task and attributed to the worker's action or inaction. The cost variable was measured using a percentage of budgeted cost for the actual completed specific task. This measure was a scale measurement of $0-150 \%$ (recoded as $0-15$ ), and proved to be difficult to consistently measure in reference to the directions presented to the responsible supervisors. The schedule variable was measured using the percentage of scheduled duration for the actual completed specific task. This measure was a scale measurement of $0-150 \%$ (recoded as $0-15)$.

To summarize, the empirical data associated with the system outcomes latent dependent variable was collected from the particular company supervisors according to the human subject/wave number and consist of the Table 2 variables: 
Table 2. System Outcomes Latent Dependent Variables

Quality: $\quad$ scale measure: $(10-15)$

Cost: $\quad$ scale measure: $(0-15)$

Schedule: $\quad$ scale measure: $(0-15)$

\section{Human Cognition: Cognitive Task Analysis:}

The latent independent variable, human cognition was measured as an index of the ten (10) indexed variables of task variety, task complexity, worker adaptability, worker flexibility, mental workload, decision-making, error-making, goal motivation, time pressure, and stress considerations. Each of these ten indexed variables describe a cognitive activity attribute of a completed, or failed, task and is tracked according to a specific production work order number and worker.

The process of conducting a cognitive task analysis is discussed by Klein, Kaempf, Wolf, Thorsden, and Miller (1997) as "a method for getting inside the heads of people, to understand the cues and patterns and relationships they perceive, the knowledge they are using, and the strategies they are applying." Cognitive task analysis not only evaluates what the human subject is doing, but also what cognitive processes are involved to determine how and why the test participants make decisions.

The process used in this study revolves around a decision-centered approach, where the human subject's cues, strategies, decisions, actions, recoveries, etc. are analyzed by observation of the actual task execution. A checklist is completed during the task execution while key task element decision-making is taking place. The human subject's 
situation awareness, reactions, judgements, and decision-making processes were evaluated in order to develop consolidated cognitive evaluative approach.

In order to properly consolidate the essential data and present a complete cause and effect diagram it is necessary to correlate the hierarchical task analysis (Figure 10) element dependency, recorded cognitive difficulty and resultant error, and error reduction

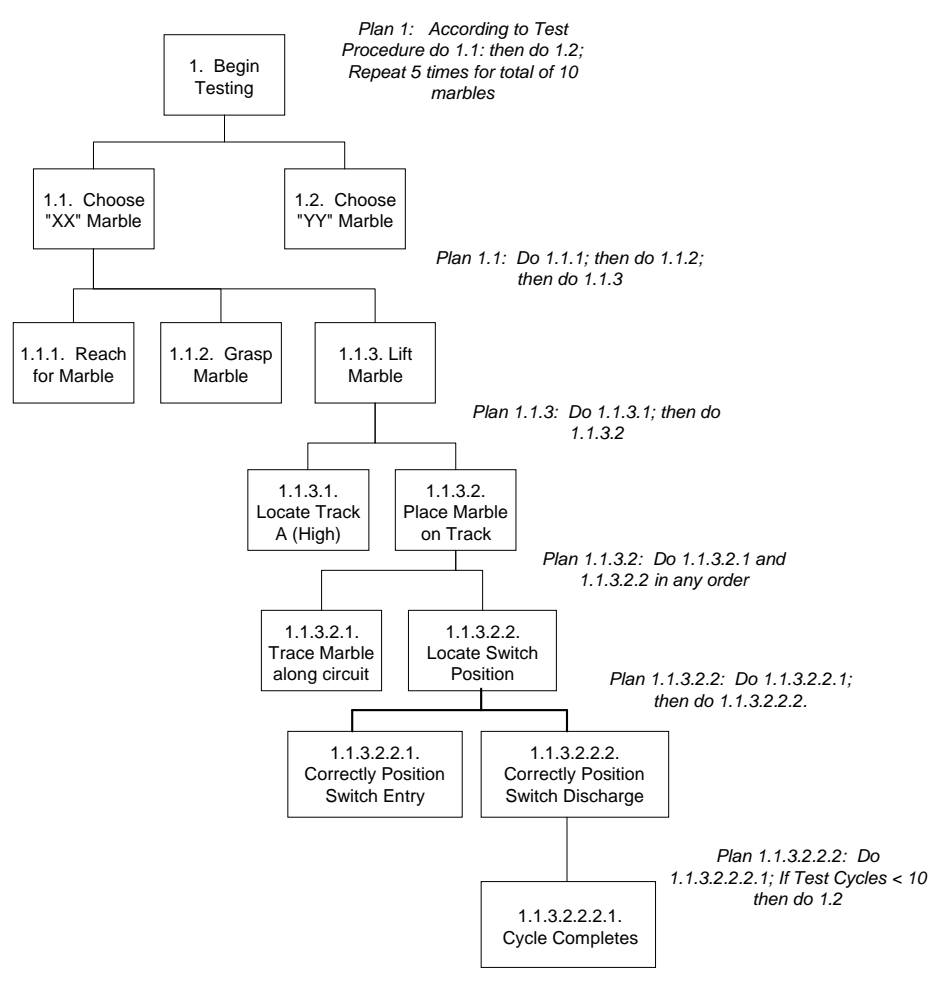

Figure 10. Example of a Hierarchical Task Analysis

recommendation. The first step is to develop a process of activity attribute coding. The combined coding work of Karwowski \& Marras (1999) and Stanton \& Stevenage (1998) was adopted and elaborated to facilitate the study environment. Table 3 presents an example of the activity attribute coding taxonomy used for this study and includes the additional study specific coding for processing and perceptual activity attributes. 
Table 3. Example of the Activity Attribute Coding Taxonomy

\begin{tabular}{|c|c|c|c|c|c|}
\hline \multicolumn{2}{|c|}{ PERCEPTUAL ATTRIBUTES } & \multicolumn{2}{|c|}{ ACTION ATTRIBUTES } & \multicolumn{2}{|c|}{ RETRIEVAL ATTRIBUTES } \\
\hline A & Color & $\mathrm{T}$ & Action too short/ long & l/ & Information not obtained \\
\hline B & Size & $\mathrm{U}$ & Action mistimed & $\mathrm{J} /$ & Wrong information \\
\hline C & Contrast & V & Action in wrong direction & $\mathrm{K} /$ & Information retrieval not complete \\
\hline D & Illumination & w & Action too little/ much & & \\
\hline E & Visual Angle & $\mathrm{x}$ & Misalign & & \\
\hline $\mathrm{F}$ & Vigilance Decrement & $\mathrm{Y}$ & Right action on wrong object & SELECTIC & ATTRIBUTES \\
\hline G & Attention & Z & Wrong action on right object & L/ & Selection omitted \\
\hline $\mathrm{H}$ & Situation Awareness & A/ & Action Omitted & $\mathrm{M} /$ & Wrong selection made \\
\hline \multirow[t]{3}{*}{1} & Spatial Acuity & $\mathrm{B} /$ & Action Incomplete & & \\
\hline & & $\mathrm{C} /$ & Wrong action on wrong object & & \\
\hline & & & & \multicolumn{2}{|c|}{ TRANSMISSION ATTRIBUTES } \\
\hline \multicolumn{4}{|c|}{ PROCESSING ATTRIBUTES } & $\mathrm{N} /$ & Information not transmitted \\
\hline $\mathrm{J}$ & Recall & CHECKIN & TTRIBUTES & $\mathrm{O} /$ & Wrong information transmitted \\
\hline $\mathrm{K}$ & Detection & $\mathrm{D} /$ & Checking Omitted & $\mathrm{P} /$ & Information transfer not complete \\
\hline L & Rate of Movement & E/ & Checking Incomplete & & \\
\hline M & Motor Control & $\mathrm{F} /$ & Right check on wrong object & & \\
\hline $\mathrm{N}$ & Time Pressure & $\mathrm{G} /$ & Wrong check on right object & \multicolumn{2}{|c|}{ PLAN ATTRIBUTES } \\
\hline 0 & Intelligibility & $\mathrm{H} /$ & Wrong check on wrong object & Q/ & Plan preconditions ignored \\
\hline $\mathrm{P}$ & Goal Motivation & & & $\mathrm{R} /$ & Incorrect plan executed \\
\hline Q & Novice or Expert & & & & \\
\hline $\mathrm{R}$ & Age & & & & \\
\hline $\mathrm{s}$ & Time Available for Viewing & & & & \\
\hline
\end{tabular}

The summary diagram of the planned cognitive task analysis takes the resemblance of a cognitive task analysis form (Appendix D). The activity attribute coding taxonomy of Table 3 shall be combined with the cognitive demands table suggested by Militello \& Hutton (1998) to yield the final form of Appendix D, thereby providing a consolidated format incorporating the essential features of several research formats.

The human cognition indexed variables was measured using a percentage of the accumulated indicated activity attributes indicated on the cognitive task analysis form (Appendix D) normalized for the step size of the appropriate hierarchical task analysis (Figure 10). The final accumulated indexing is presented in Table 4. 
Table 4. Dependent Human Cognition Indexed Variable Definitions

\begin{tabular}{ll}
$\begin{array}{ll}\text { Human cognition } \\
\text { Indexed Variable: }\end{array}$ & $\begin{array}{l}\text { Accumulation of } \\
\text { Activity Attribute Types (Table 1): }\end{array}$ \\
\cline { 2 - 2 } $\begin{array}{l}\text { Task Variety } \\
\text { Task Complexity }\end{array}$ & $\mathrm{A}+\mathrm{B}+\mathrm{C}+\mathrm{D}+\mathrm{E}+\mathrm{F}+\mathrm{G}+\mathrm{H}+\mathrm{I} /+\mathrm{N} /+\mathrm{O} /+\mathrm{P} /$ \\
Worker Adaptability & $\mathrm{G}+\mathrm{H}+\mathrm{I}+\mathrm{P}$ \\
Worker Flexibility & $\mathrm{L}+\mathrm{M}+\mathrm{Q}+\mathrm{R}$ \\
Mental Workload & $\mathrm{J}+\mathrm{K}+\mathrm{O}+\mathrm{S}$ \\
Decision-Making & $\mathrm{L} /+\mathrm{M} /+\mathrm{Q} /+\mathrm{R} /$ \\
Error-Making & $\mathrm{T}+\mathrm{U}+\mathrm{V}+\mathrm{W}+\mathrm{X}+\mathrm{Y}+\mathrm{Z}+\mathrm{A} /+\mathrm{B} /+\mathrm{C} /+\mathrm{F} /+\mathrm{G} /+\mathrm{H} /$ \\
Goal Motivation & $\mathrm{P}$ \\
Time Pressure & $\mathrm{N}+\mathrm{S}+\mathrm{D} /+\mathrm{E} /$ \\
Stress Consideration & visible psychological indication assessment
\end{tabular}

To summarize, the cognitive task analysis data associated with the Human cognition latent independent variable was collected according to the human subject/wave number and consist of the Table 5 variables:

Table 5. Human Cognition Latent Independent Variables

$\begin{array}{ll}\text { Task Variety } & \text { scale measure: }(0-100) \\ \text { Task Complexity } & \text { scale measure: }(0-100) \\ \text { Worker Adaptability } & \text { scale measure: }(0-100) \\ \text { Worker Flexibility } & \text { scale measure: }(0-100) \\ \text { Mental Workload } & \text { scale measure: }(0-100) \\ \text { Decision-Making } & \text { scale measure: }(0-100) \\ \text { Error-Making } & \text { scale measure: }(0-100) \\ \text { Goal Motivation } & \text { scale measure: }(0-100) \\ \text { Time Pressure } & \text { scale measure: }(0-100) \\ \text { Stress Consideration } & \text { scale measure: }(0-100)\end{array}$




\section{Quality of work life: Questionnaire:}

The latent independent variable, Quality of work life was measured as an index of the eight (8) indexed variables of teamwork, supervision, empowerment, job satisfaction, learning, autonomy, status, and efficacy. These indexed variables have been chosen due to the apparent significance as indicated in the noted Appendix A referenced literature, as well as numerous research references for a consolidated view of the psychosocial situation present in the workplace. Decker \& Borgen (1993), Daniels \& Guppy (1994), and Furnham, Brewin, \& O'Kelly (1994) combine the cognitive attributes and stress experiences of the worker into a composite consideration ... much like the previous referenced work of Karasek \& Theorell (1990). Each of the above referenced eight indexed variables describes an accumulation of scaled questionnaire items completed by the worker during the time of task execution and is tracked according worker and wave number.

Appendix A presents the inventory of questionnaire items that was used during this study. This listing of items was divided into two questionnaires, QWL-1 and QWL-2 (presented in Appendix B and C, respectively), dividing the items as equitably as possible in regards the indexed variables. The purpose of this action was to administer the questionnaire (QWL-1 or QWL-2) to the human subject every other wave, in lieu of each consecutive wave, measuring the same (or very similar) indexed variables while changing the specific question or wording of the question. The specific items were chosen from the referenced Appendix A literature based on the apparent content validity in regards to the cited referenced study items and the intended items of this study. 
The item responses generally follow a 5-point Likert-type scale (with some items being reverse coded) fitted to one of two possible ranges: 1 . extremely satisfied extremely dissatisfied, or 2. strongly agree - strongly disagree with the final response coding ranging from 1 - very favorable to 5 - very unfavorable. The human subjects shall evaluate the favorableness concerning the quality of work life prior to the time of task execution. The eight (8) indexed variables consisted of the average quality of work life favorableness of the representative item responses, which ranged between four (4) and ten (10) items per indexed variable across both questionnaires. These indexed variables was chosen to be represented as scaled variables, in lieu of nominal or ordinal variables since they were indeed indexed variables representing specific averaged responses. The validity of representing averaged item responses as scaled variables with the AMOS structural equation modeling process has been substantiated by Byrne (2001) when the number of averaged items is greater than four and the maximum likelihood discrepancy estimation is utilized.

To summarize, the questionnaire data associated with the quality of work life latent independent variable shall be collected according to the human subject/wave number and consist of the indexed Table 6 variables:

Table 6. Quality of Work Life Latent Independent Variables

Teamwork: $\quad$ scale measure: $(1-5)$

Supervision: scale measure: $(1-5)$

Empowerment: scale measure: $(1-5)$

Job Satisfaction: scale measure: $(1-5)$

Learning: $\quad$ scale measure: $(1-5)$

Autonomy: $\quad$ scale measure: $(1-5)$

Status: $\quad$ scale measure: $(1-5)$

Efficacy: scale measure: (1 - 5) 


\section{Data Analysis:}

The quantitative analysis revolves around the validity, reliability, correlational, and

causal analysis of three (3) separate latent variables, each having a different instrument of measurement. The longitudinal pseudopanel study provides the opportunity for a fourwave data collection period. The data was collected as to control for the wave number allowing the study to evaluate wave-to-wave relationships.

\section{Statistical Descriptive Statistics:}

The first series of statistical tests involve examining the data for abnormalities, and includes the evaluations of sufficient sample size, overall data reliability, multicollinearity, and multivariate normality. The software SPSS (Statistical Package for the Social Sciences) shall be utilized for evaluating the variable descriptive statistics involved with the study instruments.

The issue of having a sufficiently large sample size has been defined in several fashions in regards to structural equation modeling. Some researchers have defined a sufficiently large sample size as being 5:1 to 20:1 the number of estimable model parameters (Palomares, Ferreras, \& Delibes 1998). Other researchers (Tomer \& Pugesek 2003) have defined that ratios less than $4: 1$ should be avoided since the estimation of parameters is distorted in small samples as indicated in simulation studies.

Overall reliability of the "observed" data is evaluated by assessing Cronbach's alpha $(\alpha)$ which is a single indexed function of the sample covariance matrix $(\mathbf{S})$ and the number of observed variables. Maxim (1999) has proposed that a value of $\alpha=0.8$ be considered the minimum value of "reasonably reliable" data in this application. 
Multicollinearity is described as a condition when one or more independent (observed exogenous) variables are highly correlated $(\rho \geq 0.70)$ with one or more of the other independent (observed exogenous) variables (Mueller 1995). Multicollinearity is undesirable since path (regression) coefficients are not just a function of the correlations of the independent variables and dependent variables, but of the independent variable correlations among themselves (Maruyama 1998).

The condition of multivariate normality is central to the structural equation modeling process (Mueller 1995, Kaplan 2000, \& Dilalla 2000). Multivariate normality requires the assumption that "each variable is normally distributed when holding all other variables constant, each pair of variables is bivariate normal holding all other variables constant, et cetera, and the relation between any pair of variables is linear" (Dilalla 2000). The testing of multivariate normality is achieved by the evaluation of multivariate skewness $(<2.0)$ and kurtosis $(<7.0)$ defining the acceptable respective values $($ Tomer $\&$ Pugesek 2003). While the normal variable distribution is desired in principle, this condition is scarce in practice since the real data in social and behavioral sciences tend to be skewed and have marginal heterogeneous kurtosis (Yuan \& Bentler 2000).

\section{Structural Equation Modeling of the Causal Model:}

The central research objective of this study is to quantitatively evaluate the relationships that exist between the latent variables of system outcomes, human cognition, and quality of work life associated with an agile production system. These three latent variables have predominantly been evaluated separately, and by distinct scientific disciplines: namely, system outcomes have been studied by management and 
industrial engineering researchers, human cognition by psychology and cognitive system engineering researchers, and finally the quality of work life has been evaluated by sociology researchers. It is by virtue of having been evaluated by different scientific disciplines, that each of these latent variables also has different metrics associated with their evaluation. Therefore, the methodology used for this study provides an "evaluative synthesis" of the three different metrics (and scientific disciplines) in an inclusive procedure that is designed to provide a valid and reliable composite measurement tool. The evaluative measurement tool used for this "evaluative synthesis" is structural equation modeling; specifically the software AMOS (Analysis of MOment Structures).

Structural equation modeling has been defined "as a class of methodologies that seeks to represent hypotheses about the means, variances, and covariances of observed data in terms of a smaller number of structural parameters defined by a hypothesized underlying model" (Kaplan 2000). Structural equation modeling provides a strong process of simultaneous assessment of hypothesized cause-effect relationships between variables (observed or latent) that are contained in a hypothesized composite model that is designed to evaluate patterns of statistical dependencies (Dilalla 2000; Maruyama 1998; and Hershberger, Marcoulides, \& Parramore 2003). The structural equation model (Figure 9) consists of two forms: a. the structural form that graphically indicates the functional relationship between the illustrated latent variables of systems outcomes, human cognition, and quality of work life. The variable at the end of the arrow is assumed to be affected by the variable at the beginning of the path. The second form of a structural equation model is the measurement form which communicates the form of measurement (not structural) relationship between the observed variables (manifest or 
indexed) and the latent variables. Model correlational relationships are graphically

depicted by two-way arrows and numerically describe the covariance that exists between two variables (Mueller 1995; Kaplan 2000; and Hershberger, Marcoulides, \& Parramore 2003).

The process of using structural equation modeling may be viewed in the following methodological steps (Kelloway 1998 \& Maxim 1999):

1. Model Specification: Developing the structural and measurement forms of the model.

2. Model Identification: Evaluating the difference between the number of elements in the associated sample covariance matrix and the number of estimable model parameters, which equals the model degrees of freedom (d.f.). When the d.f. $>0$, then the model is overidentified and an infinite number of solutions exist. When the d.f. $=0$, then the model is just-identified, or saturated and only one solution exists. When the d.f. $<0$ no solution can be determined.

3. Examine Data for Abnormalities: Evaluating the existence of missing data, outliers, etc.

4. Model Parameter Estimation: The use of numerical methods to estimate a solution for the model parameters that is within an acceptable fitting criterion or function. This iterative process first "guesses" the trial model parameters, then calculates the trial covariance matrix which is compared to the actual observed covariance matrix. If the difference between the two covariance matrices is within the fitting criterion the process stops, if the difference in covariance matrices is too large, new model parameter values are evaluated and the iterative process continues. The fitting criterion usually takes the mathematical form of ordinary least squares, generalized least squares, or a maximum likelihood function.

5. Evaluate Model Goodness of Fit: The overall model null hypothesis is that the estimated model covariance matrix equals the observed sample covariance matrix. The statistical significance of rejecting this null hypothesis, as well as the size of the fit is the determining characteristics of this stage. A more thorough treatment of this subject shall be presented in Question 2. 
6. Model Respecification: The minor modifications to a model to improve to validity or fit, such as the inclusion of parameters for correlated error terms. Go to Step 4.

7. Interpret Results: Does the overall model disconfirm the overall null hypothesis? Are the model parameters for the structural paths statistically significant? Are individual indicators sufficiently reliable? Do the overall results for both the structural and measurement forms of the model make theoretical sense?

The primary statistical test associated with this study is the evaluation of the hypothesized structural equation model goodness of fit. The structural equation modeling process evaluates the statistical significance of rejecting the null hypothesis that the estimated model covariance matrix $\left(\sum\right)$ equals the observed sample covariance matrix (S), therefore Ho: $\sum$ = S (Maxim 1999; Kaplan 2000; \& Kelloway 1998). The validity of assessing the "equality" of the two matrices has been contested (Arbuckle \& Wothke 1999). There exists many methods to test this hypothesis, or the reasonable "closeness" of this hypothesis, but there exists a lack of consensus on the application of a particular method (Sümer 2003 \& Maxim 1999) within structural equation modeling. A common practice in the assessment of the structural equation modeling process is to evaluate several goodness of fit methods or measures ... not a single one (Mueller 1995).

The most common goodness of fit indices (including reasonable fit criteria applicable for use with the maximum-likelihood approximation) is presented in Table 7 (Dilalla 2000, Sümer 2003, \& Maxim 1999). 
Goodness of Fit Indices

Degree of Freedom

Chi-square statistic.

Chi-square statistic/d.f.

Goodness of Fit Index

Adjusted Goodness of Fit Index

Parsimony Goodness of Fit Index

Root Mean Square Error of Approximation

Comparative Fit Index

Normed Fit Index

Tucker-Lewis Index

Incremental Fit Index
Reasonable

Fit Criteria

$2: 1$ to $5: 1$

$>0.90$

$>0.90$

$>0.50$

$<0.08$

$>0.90$

$>0.90$

$>0.90$

$>0.90$

The chi-square statistic/d.f. index is based on the minimum sample value of discrepancy and is considered an absolute fit index, therefore rejecting the null hypothesis if the estimated model covariance matrix does not "equal" the observed sample covariance matrix. In a practical sense, these two matrices will never "equal" each other, therefore the concept of a "reasonable fit criteria" is presented in Table 7. The chi-squared statistic/d.f.test (2:1 to 5:1 indicating acceptable fit) is the most prevalent testing method (utilizing a function of $\sum, \mathbf{S}$, d.f, and sample size) used but it tends to reject the null hypothesis more strongly as the number of samples increases.

Additional absolute fit indices include the goodness of fit index, adjusted goodness of fit index, and parsimony goodness of fit index. The goodness of fit index and the adjusted goodness of fit index tend to decline as model complexity increases (Ping 2004, Muthhen \& Satorra 1995). The goodness of fit index evaluates the relative amount of the 
observed variances and covariances accounted for and by the model (Hoyle 2000), and the adjusted goodness of fit index makes an adjustment for the d.f. associated with the model. The root mean square error of approximation is an absolute fit index that adds a penalty for including too many parameters in the hypothesized model by evaluating the discrepancy between the observed and implied covariance matrices per d.f. (Hoyle 2000). The parsimony goodness of fit index is a modification of the goodness of fit index that adjusts according to the d.f. available for testing the model (Arbuckle \& Wothke 1999).

The comparative fit indices of the comparative fit index, normed fit index, tuckerlewis index, and the incremental fit index compare the absolute fit of the hypothesized model to an alternate (or baseline) model having no variable path coefficients or covariances (assumed complete variable independence). The intention of this class of indices is to evaluate the relative degree of "badness of fit", since the alternate model is always a very bad approximation. The reasonable fit criteria for all of these indices is ">0.90" (Dilalla 2000). The tucker-lewis index was of specific interest to this study because of its usefulness in comparing samples of unequal sizes (Byrne 1991).

The examination of the parameter and covariance estimates is also important in the goodness of fit assessment. The calculated model path coefficients provide predictions (regression weights) between variables which can provide insight into the relative weighting significance of the variables, and the review of the squared multiple correlations $\left(\mathrm{R}^{2}\right)$ yield the proportion of the variance described by the latent variables. This parameter and covariance information is the result of the structural equation modeling process, and is directly biased by the design of the hypothesized structural equation model. 
The examination of the standardized residual covariance matrix indicates that the standardized residuals may be interpreted as "t-" or " $\mathrm{z}$-" values, and large standardized residuals (> 3) would suggest that a significant goodness of fit improvements may be obtained by assigning a parameter to the associated residuals (Maxim 1999).

This step serves as the final step in the structural equation model analysis with the following questions being answered: Does the overall model disconfirm the overall null hypothesis? Are the model parameters for the structural paths statistically significant? Are individual indicators sufficiently reliable? Do the overall results for both the structural and measurement forms of the model make theoretical sense and does the overall model yield a valid and reliable instrument?

The overall interpretation of the structural equation modeling process is the assessment of overall instrument reliability and validity. Reliability refers to how consistently an instrument measures what it is designed to measure. A problem occurs in the quantification of the traditional single item reliability measurement in structural equation modeling since these reliability values do not allow for correlated measurement errors (Mueller 1995). The observed variable coefficients of determination $\left(\mathrm{R}^{2}\right)$ which describes the proportion of variance described by the latent variables has been accepted as the measurement of reliability within the structural equation modeling process (Maxim 1999 \& Mueller 1995) for individual variable assessment.

Traditional validity definitions suffer in light of the structural equation modeling process as well. Assumptions concerning a given scale measuring only one underlying construct and the fact that latent constructs are not explicitly incorporated present an obstacle for the traditional validity definitions. Maxim (1999) and Mueller (1995) have 
described a validity measurement akin to criterion validity that describes the correspondence between a measure and its variable as the standardized path coefficients (referred to as validity coefficients) between an observed variable and its latent variable.

In summary, statistical procedures are used to examine the data for abnormalities, evaluate the model goodness of fit, and interpret the overall modeling results associated with the structural equation modeling process. A practical and explanatory example of the structural equation modeling statistical considerations is illustrated in Question 3.

Structural equation modeling provides a useful approach to evaluating multivariate models and has been used by the social sciences for over 25 years. Recent studies regarding firm performance (Rogers 2004), organizational and management research (Williams, Edwards, \& Vandenberg 2003), working conditions (Whitbeck, Simons, Conger, Wickrama, Ackley, \& Elder 1997), occupational conditions (Wickrama, Lorenz, Conger, Matthews, \& Elder 1997), and quality of life (Ross \& Van Willigen 1997) have utilized structural equation modeling approaches and have subject matter loosely related to my dissertation subject matter. These studies, or summaries of studies, utilized predominately observed variables resulting from questionnaire data. The use of structural equation modeling in this study provides an "evaluative synthesis" of quality of work life questionnaire data, cognitive task analysis data, and empirical data of system outcomes concerning cost, schedule, and quality. 


\section{RESULTS AND DISCUSSION}

\section{Causal Model Structural Validity Analysis:}

The evaluation of a proposed structural equation model identified in the first hypothesis followed the previously discussed seven-step process (Kelloway 1998 \& Maxim 1999). This process was simplified and summarized by use of a structural equation model evaluation form that is illustrated in Appendix E.

\section{Model Specification:}

The first activity was to develop the structural and measurement forms of the model. There exist three distinct activities in the development and specification of the model (Mueller 1995): 1. a specific structure between the latent exogenous and endogenous constructs must be hypothesized, 2. it must be decided how to measure the exogenous latent variables, and 3. a measurement model for the endogenous latent construct must be determined. Figure 11 presents the proposed model that will be used for evaluation.

The eight representative matrices required to define the structural equation model are defined (Kelloway 1998 \& Mueller 1995) as: $\boldsymbol{\beta}, \boldsymbol{\Gamma}, \boldsymbol{\Phi}, \boldsymbol{\Psi}, \boldsymbol{\Lambda}_{\mathbf{x}}, \boldsymbol{\Lambda}_{\mathbf{y}} \boldsymbol{\Theta}_{\mathbf{x}}$, and $\boldsymbol{\Theta}_{y}$, where the structural form of the model includes the evaluation of $\boldsymbol{\beta}, \boldsymbol{\Gamma}, \Lambda_{\mathbf{x}}$, and $\boldsymbol{\Lambda}_{\mathbf{y}}$, and the measurement form of the model includes the derivation of $\boldsymbol{\Phi}, \boldsymbol{\Psi}, \boldsymbol{\Theta}_{\mathbf{x}}$, and $\boldsymbol{\Theta}_{y}$. The structural equation model requirement for these eight matrices is presented as a necessary 
condition, with the derivation of these eight matrices beginning in classical path analysis and confirmatory factor analysis.

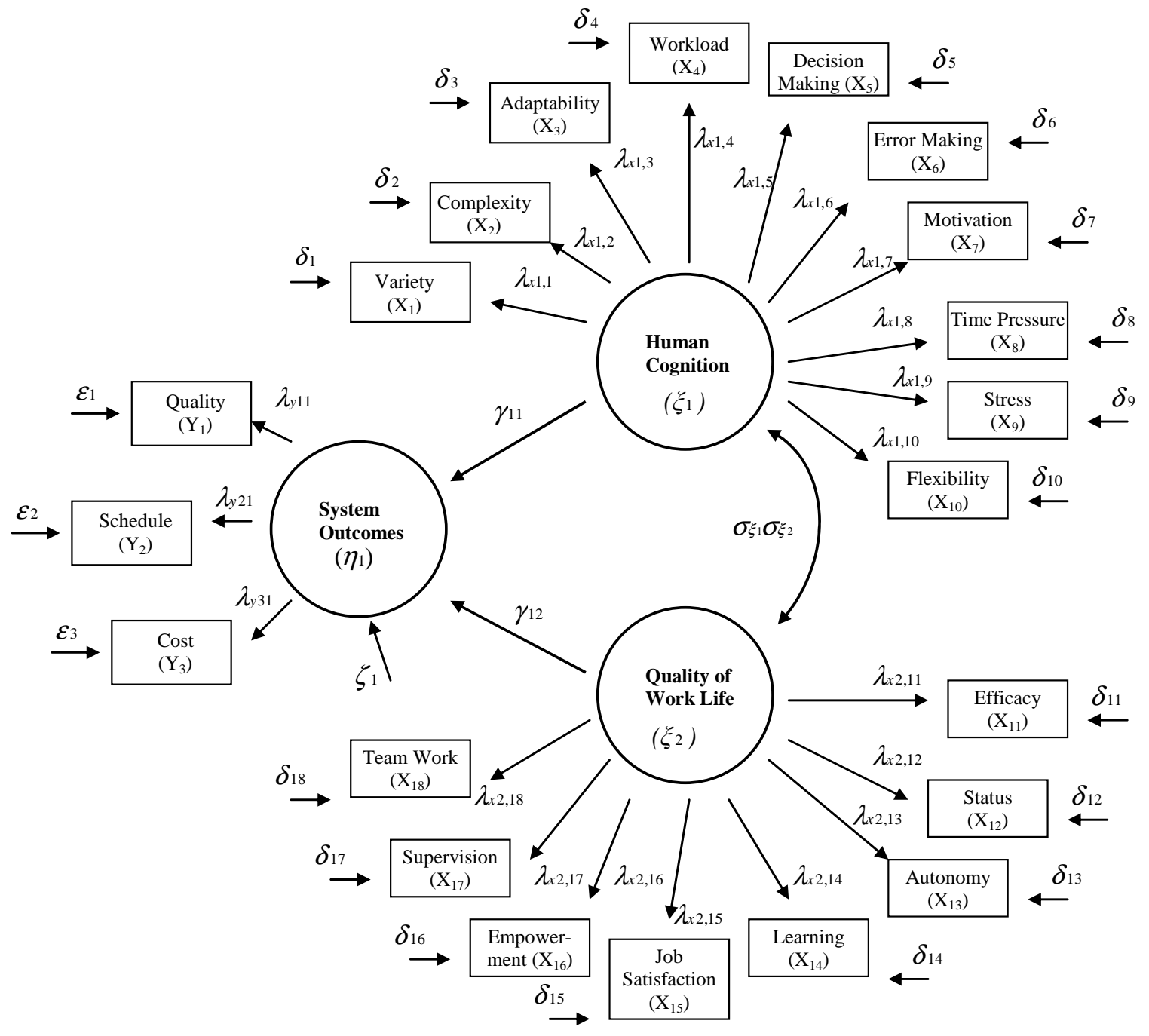

Figure 11. Proposed Human-Work Domain Structural Equation Model

The structural equation model matrix representation relating to the endogenous latent variable can be expressed as: 


$$
\boldsymbol{\eta}=\mathbf{B} \boldsymbol{\eta}+\boldsymbol{\Gamma} \xi+\zeta
$$

The matrix $\mathbf{B}$ defines the structural coefficients relating the endogenous latent variables to each other, but in this case there is only one endogenous latent variable and no resulting causal relationship (i.e. path) between any endogenous latent variables, B equals zero. The $\boldsymbol{\Gamma}$ matrix defines the structural coefficients relating the endogenous latent variables to the exogenous latent variables. The resultant vector equation deduced from the above matrix representation is:

$$
\left[\eta_{1}\right]=[0]\left[\eta_{1}\right]+\left[\begin{array}{ll}
\gamma_{11} & \gamma_{12}
\end{array}\right]\left[\begin{array}{l}
\xi_{1} \\
\xi_{2}
\end{array}\right]+\left[\zeta_{1}\right]
$$

resulting in the specific equation:

$$
\eta_{1}=\gamma_{11} \xi_{1}+\gamma_{12} \xi_{2}+\zeta_{1}
$$

The structural equation model matrix representation relating the exogenous observed variables can be expressed as:

$$
\mathbf{X}=\Lambda_{\mathbf{x}} \xi+\delta
$$

The matrix $\boldsymbol{\Lambda}_{\mathbf{x}}$ defines the factor loadings relating the exogenous observed variables to the exogenous latent variables. The resultant vector equation deduced from the above matrix representation is: 


$$
\left[\begin{array}{l}
X_{1} \\
X_{2} \\
X_{3} \\
X_{4} \\
X_{5} \\
X_{6} \\
X_{7} \\
X_{8} \\
X_{9} \\
X_{10} \\
X_{11} \\
X_{12} \\
X_{13} \\
X_{14} \\
X_{15} \\
X_{16} \\
X_{17} \\
X_{18}
\end{array}\right]=\left[\begin{array}{ll}
\lambda_{x 1,1} & \\
\lambda_{x 1,2} & \\
\lambda_{x 1,3} & \\
\lambda_{x 1,4} & \\
\lambda_{x 1,5} & \\
\lambda_{x 1,6} & \\
\lambda_{x 1,7} & \\
\lambda_{x 1,8} & \\
\lambda_{x 1,9} & \\
\lambda_{x 1,10} & \\
& \lambda_{x 2,11} \\
& \lambda_{x 2,12} \\
& \lambda_{x 2,13} \\
& \lambda_{x 2,14} \\
& \lambda_{x 2,15} \\
& \lambda_{x 2,16} \\
& \lambda_{x 2,17} \\
& \lambda_{x 2,18}
\end{array}\right]\left[\begin{array}{l}
\xi_{1} \\
\xi_{2}
\end{array}\right]+\left[\begin{array}{l}
\delta_{1} \\
\delta_{2} \\
\delta_{3} \\
\delta_{4} \\
\delta_{5} \\
\delta_{6} \\
\delta_{7} \\
\delta_{8} \\
\delta_{9} \\
\delta_{10} \\
\delta_{11} \\
\delta_{12} \\
\delta_{13} \\
\delta_{14} \\
\delta_{15} \\
\delta_{16} \\
\delta_{17} \\
\delta_{18}
\end{array}\right]
$$

resulting in the specific equations:

$$
\begin{array}{ll}
X_{1}=\lambda_{x 1,1} \xi_{1}+\delta_{1} & X_{11}=\lambda_{x 2,11} \xi_{2}+\delta_{11} \\
X_{2}=\lambda_{x 1,2} \xi_{1}+\delta_{2} & X_{12}=\lambda_{x 2,12} \xi_{2}+\delta_{12} \\
X_{3}=\lambda_{x 1,3} \xi_{1}+\delta_{3} & X_{13}=\lambda_{x 2,13} \xi_{2}+\delta_{13} \\
X_{4}=\lambda_{x 1,4} \xi_{1}+\delta_{4} & X_{14}=\lambda_{x 2,14} \xi_{2}+\delta_{14} \\
X_{5}=\lambda_{x 1,5} \xi_{1}+\delta_{5} & X_{15}=\lambda_{x 2,15} \xi_{2}+\delta_{15} \\
X_{6}=\lambda_{x 1,6} \xi_{1}+\delta_{6} & X_{16}=\lambda_{x 2,16} \xi_{2}+\delta_{16} \\
X_{7}=\lambda_{x 1,7} \xi_{1}+\delta_{7} & X_{17}=\lambda_{x 2,17} \xi_{2}+\delta_{17} \\
X_{8}=\lambda_{x 1,8} \xi_{1}+\delta_{8} & X_{18}=\lambda_{x 2,18} \xi_{2}+\delta_{18} \\
X_{9}=\lambda_{x 1,9} \xi_{1}+\delta_{9} & \\
X_{10}=\lambda_{x 1,10} \xi_{1}+\delta_{10} &
\end{array}
$$

The structural equation model matrix representation relating the endogenous observed variables can be expressed as:

$$
\mathbf{Y}=\Lambda_{\boldsymbol{y}} \boldsymbol{\eta}+\boldsymbol{\varepsilon}
$$


The matrix $\boldsymbol{\Lambda}_{y}$ defines the factor loadings relating the endogenous observed variables to the endogenous latent variables. The resultant vector equation deduced from the above matrix representation is:

$$
\left[\begin{array}{l}
Y_{1} \\
Y_{2} \\
Y_{3}
\end{array}\right]=\left[\begin{array}{c}
\lambda_{y 11} \\
\lambda_{y 21} \\
\lambda_{y 31}
\end{array}\right]\left[\eta_{1}\right]+\left[\begin{array}{c}
\varepsilon_{1} \\
\varepsilon_{2} \\
\varepsilon_{3}
\end{array}\right]
$$

resulting in the specific equations:

$$
\begin{aligned}
& Y_{1}=\lambda_{y 11} \eta_{1}+\varepsilon_{1} \\
& Y_{2}=\lambda_{y 21} \eta_{1}+\varepsilon_{2} \\
& Y_{3}=\lambda_{y 31} \eta_{1}+\varepsilon_{3}
\end{aligned}
$$

The next activity is to develop the measurement formulations concerning the overall structural equation model, such as:

Exogenous latent variable covariance: $\Phi=\left[\begin{array}{cc}\sigma_{\xi_{1}}^{2} & \\ \sigma_{\xi_{1}} \sigma_{\xi_{2}} & \sigma_{\xi_{2}}^{2}\end{array}\right]$

Endogenous latent error: $\left.\boldsymbol{\Psi}=\mid \sigma_{\zeta_{1}}^{2}\right\rfloor$

Endogenous observed error: $\Theta_{y}=\left[\begin{array}{lll}\sigma_{\varepsilon_{1}}^{2} & & \\ & \sigma_{\varepsilon_{2}}^{2} & \\ & & \boldsymbol{\sigma}_{\boldsymbol{\varepsilon}^{3}}^{2}\end{array}\right]$ 
Exogenous observed error is represented by:

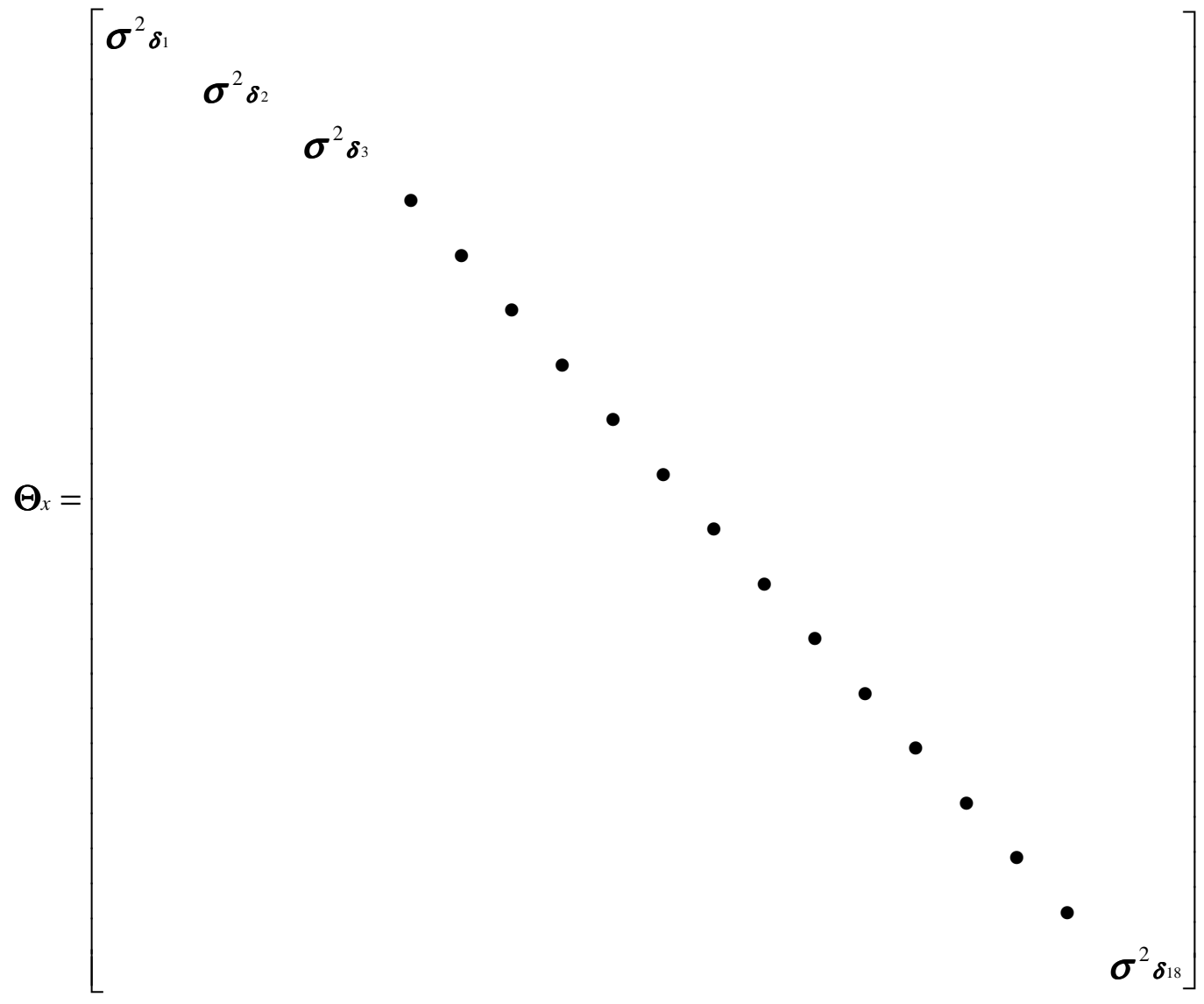

\section{Model Identification:}

Model identification revolves the calculation of the model degrees of freedom (d.f.) as a function of the number of elements in the sample covariance matrices minus the number of requested estimable model parameters. A necessary condition of structural equation modeling is that d.f. $>0$ resulting in an overidentified model, or that the d.f. $=0$ and a just-identified, or saturated model exists. When a model has a d.f. $<0$ no solution can be determined.

The 21 observed variables of Figure 11 (Quality, Schedule, Cost, Variety, Complexity, Adaptability, Workload, Decision Making, Error Making, Motivation, Time 
Pressure, Stress, Flexibility, Efficacy, Status, Autonomy, Learning, Job Satisfaction, Empowerment, Supervision, and Team Work) yield a covariance matrix that has 231 distinct elements (including the sample means as described in Arbuckle \& Wothke 1999) as indicated in Appendix G. The determination of the estimable parameters includes the selection, or constraining of certain parameters to a unit value of one (1) or the equating of particular parameter covariances (Maxim 1999, Hoyle 2000). This constraint of parameters aid in the identification of the model by reducing the number of estimable parameters while not influencing the determination of the standardized parameter regression weights (Arbuckle \& Wothke 1999). The parameters of $\boldsymbol{\lambda}_{x 1,1}, \lambda_{x 2,11}, \boldsymbol{\delta}_{1-} \boldsymbol{\delta}_{18}$ $\lambda_{y 11}, \boldsymbol{\varepsilon}_{1}, \boldsymbol{\varepsilon}_{2}, \boldsymbol{\varepsilon}_{3}$, and $\boldsymbol{\zeta}_{1}$ were constrained to a unit value of one. The resultant number of distinct estimable model parameters (including 19 variable means, 25 variable variances, and 1 covariance) is 45. Therefore, the structural equation model in Figure 2. has 231 $45=186$ degrees of freedom (d.f.), and is considered overidentified.

\section{Data Abnormality Evaluation:}

The first evaluation in the examination of the data is the determination of sufficient sample size. Previously discussed sample size guidelines defined a sufficiently large sample size would be considered as 5:1 to 20:1 the number of estimable model parameters (Palomares, Ferreras, \& Delibes 1998) and that ratios less than 4:1 should be avoided (Tomer \& Pugesek 2003). Therefore, since Appendix G indicates that the structural equation model has 45 estimable model parameter the sample size range of 225 - 900 would be considered sufficiently large, and the actual study of $n=205$ is somewhat less than appropriate for the 5:1 ratio, but is within the 4:1 ratio (180). 
The evaluation of missing data resulted in no missing data concerning the 21 indexed variables. There were rare accounts of questionnaire items not being completed, but since all questionnaire items were collapsed into averaged indexed variables, these rare omissions did not provide any special considerations.

The statistical data examination was conducted using the SPSS software (reference Appendix F for descriptive statistics). The overall reliability of the 21 indexed variables following the wave 4 data collection $(n=205)$ yielded a Cronbach's alpha $\alpha=.782(.814$ standardized), which is only slightly lower than the value of 0.8 considered the minimum value of "reasonably reliable" (Maxim 1999). The data represented by this alpha $\alpha$ value when rounded could be considered "reasonably reliable", especially when evaluated in terms of the sample size. The data appeared to be consistent during the study, with the Cronbach's alpha $\alpha$ steadily increasing with each progressive wave (Table 8 ) as the

Table 8. Cronbach's Alpha $\alpha$ Progression During Wave Data Collection

\begin{tabular}{|c|c|c|c|c|c|c|c|c|c|}
\hline \multirow[b]{2}{*}{$\begin{array}{c}\text { Wave } \\
\text { Number: }\end{array}$} & & \multicolumn{8}{|c|}{ Chronbach's Alpha (Actual/Standardized): } \\
\hline & $\begin{array}{l}\text { Accumulated } \\
\text { Sample Size: }\end{array}$ & \multicolumn{2}{|c|}{$\begin{array}{c}\text { Total of } 21 \text { Indexed } \\
\text { Variables: } \\
\end{array}$} & \multicolumn{2}{|c|}{$\begin{array}{c}\text { System Outcomes } \\
\text { (3 Variables): }\end{array}$} & \multicolumn{2}{|c|}{$\begin{array}{c}\text { Human Cognition } \\
\text { (10 Variables): }\end{array}$} & \multicolumn{2}{|c|}{$\begin{array}{c}\text { Quality of Work Life } \\
\text { (8 Variables): }\end{array}$} \\
\hline 1 & 49 & 0.388 & 0.621 & 0.541 & 0.106 & 0.217 & -0.191 & 0.901 & 0.903 \\
\hline 2 & 101 & 0.395 & 0.748 & 0.571 & -0.013 & 0.630 & 0.626 & 0.915 & 0.915 \\
\hline 3 & 153 & 0.768 & 0.813 & -1.450 & -0.978 & 0.810 & 0.844 & 0.927 & 0.927 \\
\hline 4 & 205 & 0.782 & 0.814 & -1.011 & -0.762 & 0.827 & 0.856 & 0.926 & 0.926 \\
\hline
\end{tabular}


sample size increases. The evaluation of the total of 21 indexed variables as a combined scale indicated a progression in reliability as represented by the increase in Cronbach's alpha $\alpha$ from 0.388 to 0.782 . The reliability consideration of human cognition $(0.217$ to 0.827 ) and Quality of work life (0.901 to 0.926$)$ also enhanced as the sample size continued to increase in size. The system outcomes' Cronbach's alpha $\alpha$ on the other hand indicated considerable weakness as a three-variable scale. This particular weakness shall be discussed more thoroughly in the following sections of this thesis.

Multicollinearity is described as a condition when one or more independent (observed exogenous) variables are highly correlated $(\rho \geq 0.70)$ with one or more of the other independent (observed exogenous) variables (Mueller 1995). In the review of the Appendix F Inter-Item Correlation Matrix, several exogenous variable inter-item correlations exceed 0.70: ADAP/VARI(0.752), STAT/SUPE(0.714), JOBS/EMPO(0.747), LEAR/EMPO(0.750), and LEAR/JOBS(0.717). These values indicate that those variables are highly correlated, yet they are just slightly greater than criteria $(\rho \geq 0.70)$. In practical terms the assessment of the cognitive task analysis activity attributes resulting in the indexed variables of worker adaptability and task variety would appear collinear which is logical since the worker could be assessed as adapting in an environment of variety. The other correlations are predominantly centered around the quality of work life indexed variables of job satisfaction, empowerment, and learning which indicate that it may be advisable to collapse the variables into a combined variable or possibly consider deleting the variable from the model after reviewing all evaluation factors. In any case, the identified variables are suspect of multicollinearity. 
Multivariate normality is preferred condition of the data associated with structural equation modeling. It is a condition that a particular variable distribution is normally distributed when holding all other variables constant (Dilalla 2000). While the normal variable distribution is desired in principle, this condition is scarce in practice since the real data in social and behavioral sciences tend to be skewed and have marginal heterogeneous kurtosis (Yuan \& Bentler 2000). The review of the Appendix G statistics indicate the skewness criteria of $(>=2.00)$ was exceeded by the following variables: COMP(3.170), DECI(4.019), GOAL(2.267), TIME(2.263), and STRE(3.288).

Therefore, those identified variables are suspect of not exhibiting multivariate normality. In addition, the kurtosis criteria of $(>=7.00)$ also signifies three of the previously suspected variables of COMP(11.201), DECI(16.780), and STRE(10.070) as being also suspected of not exhibiting multivariate normality in regards to kurtosis.

In summary, the examination of the data indicates no conditions of missing or outlier data. The sample size is lacking to be considered sufficiently large but does not dip below the 4:1 criterion, and there may also be some problems associated with multicollinearity. The potential problem is that the data may in fact indicate less than desired reliability, and that five of the variables may have problematic skewness or kurtosis characteristics that may invalidate the multivariate normality assumption of the structural equation modeling process.

\section{Parameter Estimation:}

The structural equation modeling software, AMOS was used to evaluate and calculate parameter estimates for the model first presented in Figure 11 as the proposed 
structural equation model. Figure 12 is the graphical representation of the AMOS standardized structural equation model solution.

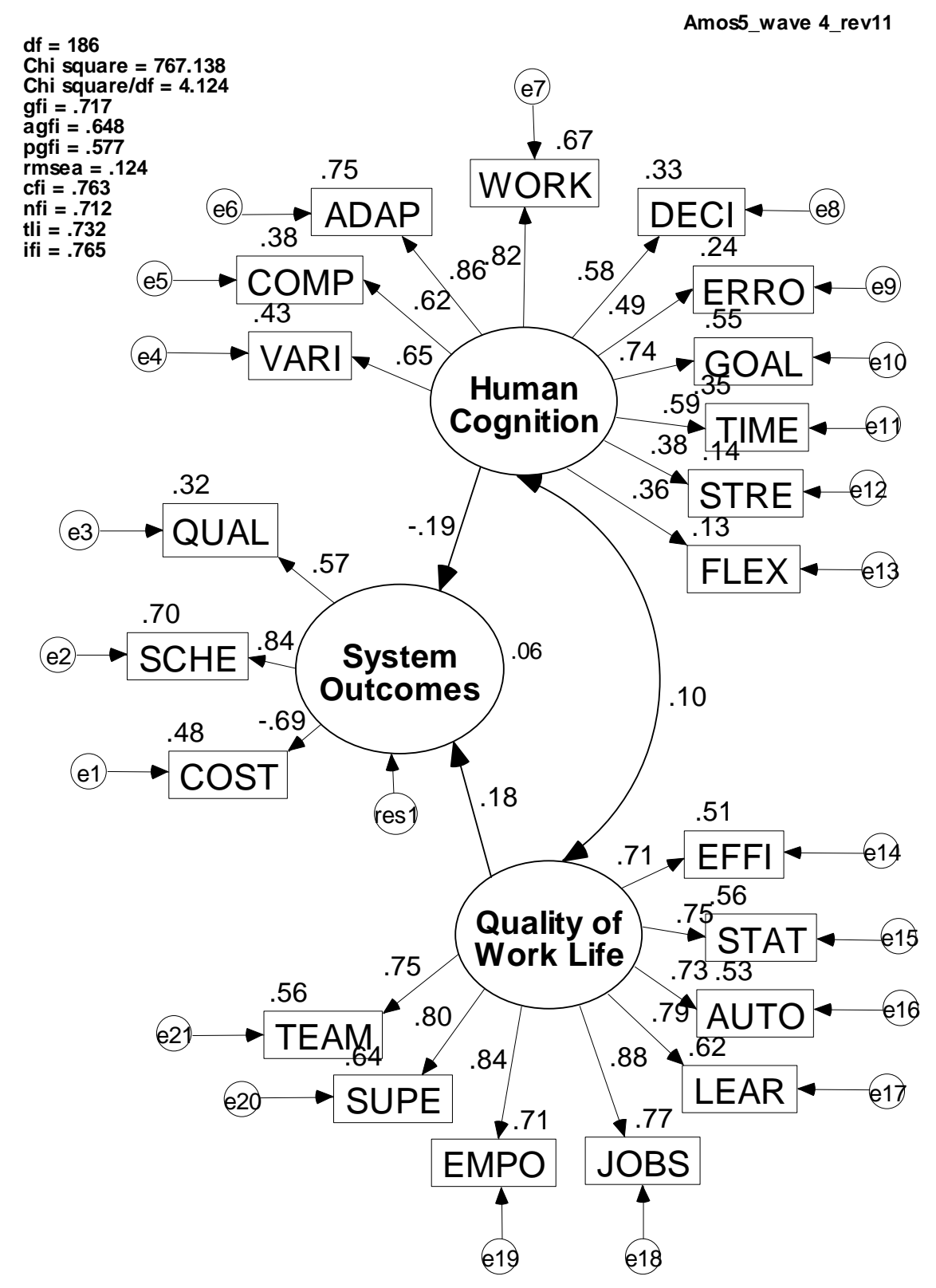

Figure 12. Model A: Proposed (AMOS Standardized) Human-Work Domain Causal Model

$$
(\mathrm{n}=205)
$$


Figure 12 presents the estimated standardized path regression weights and variable squared multiple correlations for the structural equation model, utilizing a maximumlikelihood estimation function (including a fitting criterion of 0.0001) within the AMOS software. The standardized parameter estimates equating to the path parameters of Figure 12 is summarized as:

$$
\begin{array}{llll}
\lambda_{x 1,1}=0.65 & & & \\
\lambda_{x 1,2}=0.62 & \lambda_{x 2,11}=0.71 & & \\
\lambda_{x 1,3}=0.86 & \lambda_{x 2,12}=0.75 & & \lambda_{y 11}=0.57 \\
\lambda_{x 1,4}=0.82 & \lambda_{x 2,13}=0.73 & & \lambda_{y 21}=0.84 \\
\lambda_{x 1,5}=0.58 & \lambda_{x 2,14}=0.79 & \gamma_{11}=-0.19 & \lambda_{y 21}=-0.69 \\
\lambda_{x 1,6}=0.49 & \lambda_{x 2,15}=0.88 & \gamma_{12}=0.18 & \\
\lambda_{x 1,7}=0.74 & \lambda_{x 2,16}=0.84 & & \\
\lambda_{x 1,8}=0.59 & \lambda_{x 2,17}=0.80 & & \\
\lambda_{x 1,9}=0.38 & \lambda_{x 2,18}=0.75 & & \\
\lambda_{x 1,10}=0.36 & & &
\end{array}
$$

\section{Goodness of Fit Evaluation:}

The overall model goodness of fit null hypothesis is that the estimated model covariance matrix "equals" the observed sample covariance matrix, Ho: $\sum=\mathbf{S}$ (Maxim 1999, Kaplan 2000, \& Kelloway 1998), although the validity of assessing the "equality" of the two matrices has been contested (Arbuckle \& Wothke 1999). There exist numerous debated methods of evaluating the null hypothesis. The problem with applying an accepted single goodness of fit measure has been discussed previously therefore, the 
common practice of evaluating several goodness of fit measures shall be applied in this evaluation.

The most common goodness of fit indices (including reasonable fit criteria applicable for use with the maximum-likelihood approximation) (Dilalla 2000, Sümer 2003, \& Maxim 1999) are compared to the Appendix G AMOS structural equation modeling output and presented in Table 9.

Table 9: Goodness of Fit Summary: Model A

\begin{tabular}{lcc}
\multicolumn{1}{l}{ Goodness of Fit Indices } & $\begin{array}{l}\text { Reasonable } \\
\text { Fit Criteria }\end{array}$ & $\begin{array}{l}\text { AMOS } \\
\text { Results }\end{array}$ \\
\cline { 2 - 3 } Degrees of Freedom & --- & 186 \\
Chi-square statistic & --- & 767.1 \\
Chi-square statistic/d.f. $\left(\boldsymbol{\chi}_{2} / d f\right)$ & $2: 1$ to $5: 1$ & $4.1: 1$ \\
Goodness of Fit Index (GFI) & $>0.90$ & 0.72 \\
Adjusted Goodness of Fit Index (AGFI) & $>0.90$ & 0.65 \\
Parsimony Goodness of Fit Index (PGFI) & $>0.50$ & 0.58 \\
Root Mean Square Error of Approx. (RMSEA) & $<0.08$ & 0.12 \\
Comparative Fit Index (CFI) & $>0.90$ & 0.76 \\
Normed Fit Index (NFI) & $>0.90$ & 0.71 \\
Tucker-Lewis Index (TLI) & $>0.90$ & 0.73 \\
Incremental Fit Index (IFI) & $>0.90$ & 0.77
\end{tabular}

The $\chi_{2} / d f$ value indicates a reasonable fit. The absolute fit indices GFI, AGFI, PGFI, and the RMSEA are absolute fit indices, which with the exception of the PGFI, indicate an ill-fitting model. The comparative fit indices of the CFI, NFI, TLI, and the IFI also indicate an ill-fitting model. 
The examination of the parameter estimates is also important in the goodness of fit assessment. The structural path coefficients of Figure 12 indicate predictions on the acted upon or effected variables, which is consistent with the proposed model. The structural path coefficient HUMAN COGNITION $\rightarrow$ SYSTEM OUTCOMES $\left(\gamma_{11}=-0.19, \mathrm{p}<.03\right)$ is interpreted as an increase in the cognitive loading (reverse coded) of the worker results in a direct effect (19\%) on the improvement in the system outcomes. The structural path coefficient QUALITY OF WORK LIFE $\rightarrow$ SYSTEM OUTCOMES $\left(\gamma_{12}=0.18, \mathrm{p}<.03\right)$ is interpreted as an increase in the perceived quality of work life experienced by the worker results in a direct effect (18\%) on the improvement in the system outcomes. All measurement path coefficients are statistically significant at $(\mathrm{p}<.001)$. The review of the squared multiple correlations indicate that $32 \%$ of the QUAL variance is attributed to the model, as is $70 \%$ of the SCHE variance. The FLEX and STRE variables had squared multiple correlations of 0.13 and 0.14 respectively, substantially lower than the other observed variables. The COST variable appears to be concerning, since it path coefficient is negative $\left(\lambda_{y 21}=-0.69\right)$. This variable proved to be difficult to measure, since it was not only dependent on an individual worker's hourly cost consideration, but the fact that the task may have been behind schedule resulting in more time for completion. A review with the supervisors responsible with providing this empirical data discovered that conceptual definition of the variable of COST was not defined accurately enough during this study, and therefore the variable's validity became substantively suspect.

The examination of the standardized residual covariance matrix indicates that several covariances associated with the COMP and FLEX variables appear to be relatively high. 
These standardized residuals may be interpreted as t- or z-values, and large standardized residuals (> 3) would suggest that a significant goodness of fit improvements may be obtained by assigning a parameter to the associated residuals (Maxim 1999). This potential standard residual discrepancy may merit further proposed model refinements.

In summary, the proposed structural equation model A did not reasonably fit the observed data, due substantially to the fact that the majority of the model fit criteria was not achieved, the observed variables FLEX and STRE had low reliability estimates, and the COST variable exhibited study definition and measurement inconsistencies.

\section{Model Respecification:}

This exploratory factor analytic step is intended to take lessons learned from the previous five steps and make modifications or enhancements to the proposed model in order to improve the model goodness of fit with respect to the observed sample data. A substantial aid to this activity is the modification indices as illustrated in the AMOS results of Appendix G. The modification indices serve as "modeling suggestions" to lower the chi-squared values, such as suggesting the establishment of correlations between variables, or constraining variances and regression weights to a particular constant (Arbuckle \& Wothke 1999; Byrne 2001). The review of the Model A modification index indicated that a $\Delta \boldsymbol{\chi}_{2}=135$ could be achieved by specifying covariance between the Figure 12 residuals $\mathrm{E} 6 \leftrightarrow \mathrm{E} 4$ and $\mathrm{E} 8 \leftrightarrow \mathrm{E} 5$. These covariance terms are indeed meaningful since as a worker encounters a degree of task variability, it is logical to anticipate the worker adapting to the task. Similarly, as the task complexity increases, it follows that the worker's level of decision-making would also be affected. 
The model respecification was approached in two phases. First, the Model B (Figure 13) was constructed that removed the variables COST, STRE, and FLEX that have been identified as not being substantive or relevant. Second, Model C was constructed from Model B with the additions of the residual covariances E6 $\leftrightarrow \mathrm{E} 4$ and E8 $\leftrightarrow \mathrm{E} 5$ as suggested previously. Model B (Figure 13) exhibits model goodness of fit improvements over Model A (Figure 12).

Noticeable improvements where noted in the absolute goodness of fit indices $\left(\boldsymbol{\chi}_{2} / d f\right.$, GFI, AGFI, PGFI, and RMSEA), while substantial improvements where indicated in the comparative fit indices (CFI, NFI, TLI, and IFI). All structural and measurement path coefficients were significant at $(\mathrm{p}<.05)$. While improvements were present, Model B ill-fitted the observed data, since the fit criteria (except PGFI) did not meet the accepted minimum values. 


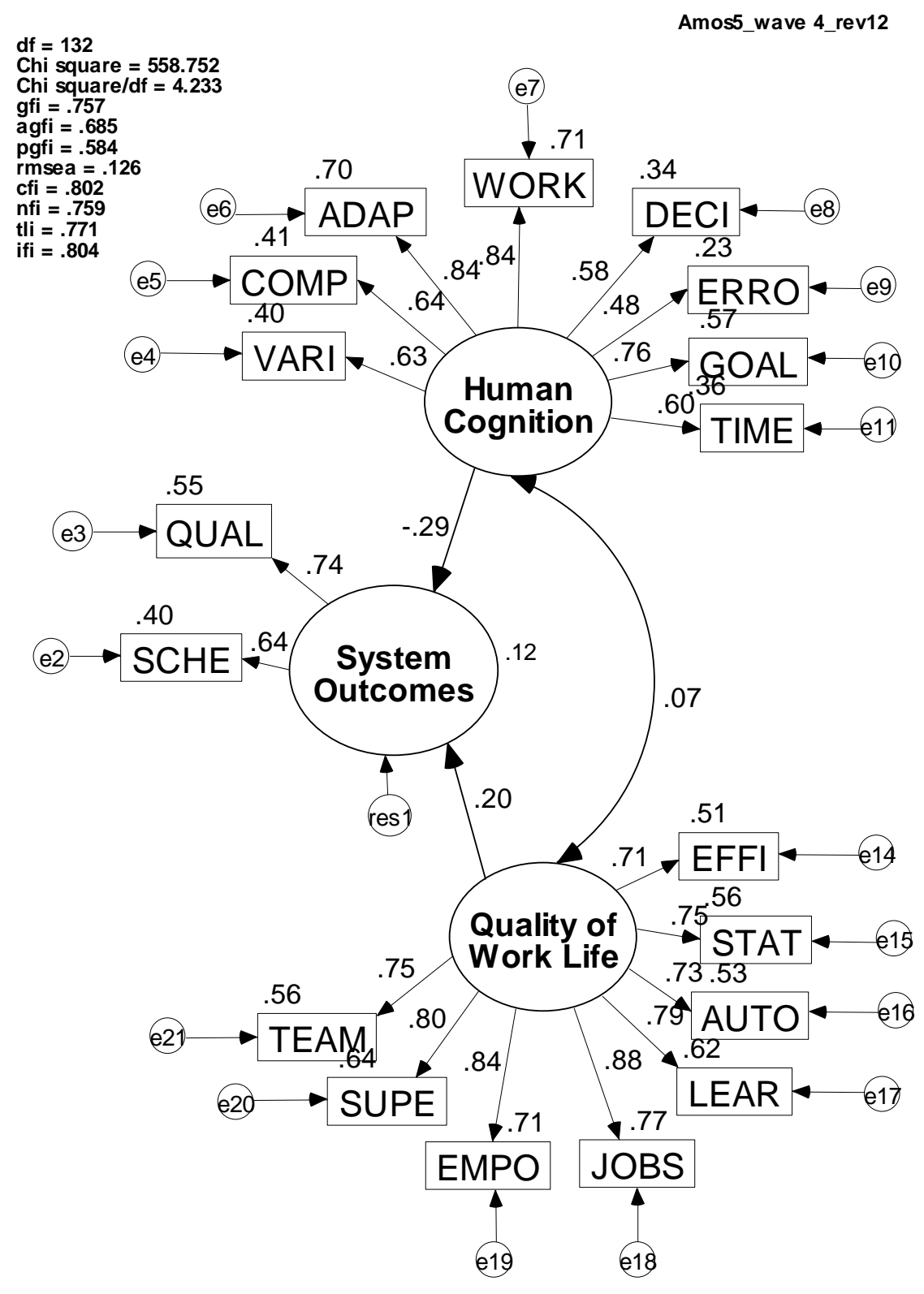

Figure 13. Model B: Respecified (AMOS Standardized)

Human-Work Domain Causal Model

$$
(\mathrm{n}=205)
$$

Model C (Figure 14) incorporated residual covariances E6 $\leftrightarrow \mathrm{E} 4$ and E8 $\leftrightarrow \mathrm{E} 5$ which substantially improved the model goodness of fit criteria, while remaining both 


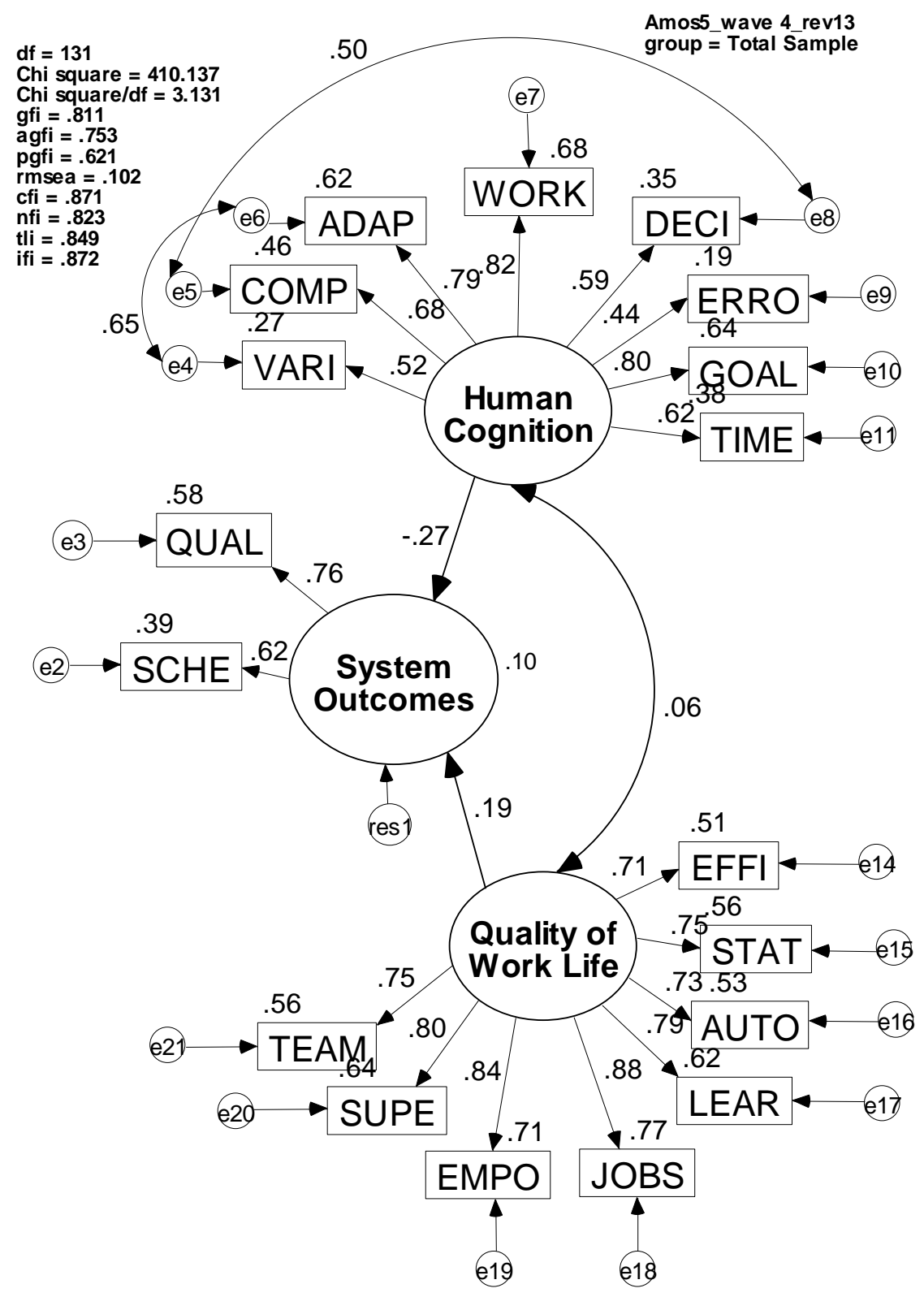

Figure 14. Model C: Respecified (AMOS Standardized, with covarying error) Human-Work Domain Causal Model

$$
(\mathrm{n}=205)
$$


substantive and significant. The covariances appear as correlations in the standardized model of Figure 14. It is apparent that the modification index was correct in the indication that significant goodness of fit improvements could be made with the specification of the covariances. Strong correlations exist between E4 $\leftrightarrow 6(\boldsymbol{\rho}=.65)$ and $\mathrm{E} 5 \leftrightarrow \mathrm{E} 8(\rho=.50)$ and the modeling of these covariances substantially improved the model fit. It is interesting to note that the specified residual covariances $\mathrm{E} 6 \leftrightarrow \mathrm{E} 4$ and $\mathrm{E} 8 \leftrightarrow \mathrm{E} 5$ are significant at $(\mathrm{p}<.001)$, but the specified covariance HUMAN COGNITION $\leftrightarrow$ QUALITY OF WORK LIFE is not significant at any reasonable level.

The standardized path coefficients of Figure 14 are summarized as:

$$
\begin{array}{llll}
\lambda_{x 1,1}=0.52 & \lambda_{x 2,11}=0.71 & & \\
\lambda_{x 1,2}=0.68 & \lambda_{x 2,12}=0.75 & & \\
\lambda_{x 1,3}=0.79 & \lambda_{x 2,13}=0.73 & & \\
\lambda_{x 1,4}=0.82 & \lambda_{x 2,14}=0.79 & \gamma_{11}=-0.27 & \lambda_{y 11}=0.76 \\
\lambda_{x 1,5}=0.59 & \lambda_{x 2,15}=0.88 & \gamma_{12}=0.19 & \lambda_{y 21}=0.62 \\
\lambda_{x 1,6}=0.44 & \lambda_{x 2,16}=0.84 & & \\
\lambda_{x 1,7}=0.80 & \lambda_{x 2,17}=0.80 & & \\
\lambda_{x 1,8}=0.62 & \lambda_{x 2,18}=0.75 & &
\end{array}
$$

The goodness of fit indices for Model C is summarized in Table 10, and while all the fit criteria indices does not indicate a "reasonable fit" they do indicate a consistent convergence for a good fit with respect to the sample size and data reliability previously discussed. 
$\underline{\text { Goodness of Fit Indices }}$

Degree of Freedom

Chi-square statistic

Chi-square statistic/d.f. $\left(\chi_{2} / d f\right)$

Goodness of Fit Index (GFI)

Adjusted Goodness of Fit Index (AGFI)

Parsimony Goodness of Fit Index (PGFI)

Root Mean Square Error of Approx. (RMSEA)

Comparative Fit Index (CFI)

Normed Fit Index (NFI)

Tucker-Lewis Index (TLI)

Incremental Fit Index (IFI)
Reasonable AMOS

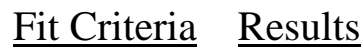

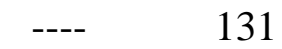

--- $\quad 410.1$

$2: 1$ to $5: 1 \quad 3.1: 1$

$>0.90 \quad 0.81$

$>0.90 \quad 0.75$

$>0.50 \quad 0.62$

$<0.08 \quad 0.10$

$>0.90 \quad 0.87$

$>0.90 \quad 0.82$

$>0.90 \quad 0.85$

$>0.90 \quad 0.87$

The $\chi_{2} / d f$ value indicates a reasonable fit, and is substantially improved over the hypothesized Model A (3.1 compared to 4.1) The absolute fit indices GFI(.81) and AGFI(.75) are close to the minimum value indicating a "reasonable fit", while PGFI(.62) exceeds the minimum fit criteria. The RMSEA(.10) while exceeding the "reasonable fit" criteria marginally, does equal the maximum value that Arbuckle \& Wothke (1999) describe as "not want(ing) to employ a model with a RMSEA greater than 0.1". The comparative fit indices of the CFI, NFI, TLI, and IFI are reasonably close enough to the fit criteria to be considered to represent a "reasonable fit".

The structural path coefficient HUMAN COGNITION $\rightarrow$ SYSTEM OUTCOMES $\left(\gamma_{11}=-0.27, \mathrm{p}<.005\right)$ is interpreted as an increase in the cognitive loading (reverse coded) of the worker results in a direct effect (27\%) on the improvement in the system outcomes. The structural path coefficient QUALITY OF WORK LIFE $\rightarrow$ SYSTEM 
OUTCOMES $\left(\boldsymbol{\gamma}_{12}=0.19, \mathrm{p}<.03\right)$ is interpreted as an increase in the perceived quality of work life experienced by the worker results in a direct effect $(19 \%)$ on the improvement in the system outcomes. All measurement path coefficients are statistically significant at $(\mathrm{p}<.001)$. The review of the squared multiple correlations indicate that $58 \%$ of the QUAL variance is attributed to the model, as is $39 \%$ of the SCHE variance. The VARI and ERRO variables had squared multiple correlations of .27 and .19 respectively, noticeably lower than the other observed variables.

The examination of the standardized residual covariance matrix indicates that two covariances $\mathrm{COMP} \leftrightarrow \mathrm{EMPO}$ and $\mathrm{COMP} \leftrightarrow \mathrm{AUTO}$ are only slightly greater than 3 . These standardized residuals may be interpreted as t- or z-values, and large standardized residuals (> 3) would suggest that a significant goodness of fit improvements may be obtained by assigning a parameter to the associated residuals (Maxim 1999). These two covariances do not necessarily merit a substantial goodness of fit improvement.

In summary, the structural equation Model $\mathrm{C}$ does marginally fit the observed data, and does have a sufficiently large sample size $(n=205>5 \times 40=200)$ since the number of model estimable parameters (Appendix G) for Model C (40) is less than Model A (45).

\section{Interpretation of Modeling Results:}

This step serves as the final step in the analysis since the model respecification had taken place, with the following questions being answered: Does the overall model disconfirm the overall null hypothesis? Are the model parameters for the structural paths statistically significant? Are individual indicators sufficiently reliable? Do the overall results for both the structural and measurement forms of the model make theoretical 
sense? The process of evaluating these questions has already been illustrated through the previous steps, but shall be summarized here.

The null hypothesis Ho: $\sum=\mathbf{S}$, where the estimated model covariance matrix equals the observed sample covariance matrix has been confirmed ... the estimated Model C covariance matrix is "reasonably fit" with the observed sample covariance matrix. Table 11 illustrates the summary information of Models A, B, and C that was developed during

Table 11. Model Respecification Summary Information

\begin{tabular}{|c|c|c|c|c|c|c|c|c|}
\hline \multirow{3}{*}{$\frac{\text { Model }}{\text { No. }}$} & \multirow{3}{*}{\begin{tabular}{|c|}
$\frac{\text { Model }}{\text { Description }}$ \\
Proposed Model
\end{tabular}} & \multirow{3}{*}{$\frac{\underline{\text { Sample }}}{\text { Size: }}$} & \multicolumn{6}{|c|}{ Standardized/Unstandardized Estimates } \\
\hline & & & \multicolumn{2}{|c|}{$\frac{\text { Path Coefficient }}{\gamma_{11}}$} & \multicolumn{2}{|c|}{$\frac{\text { Path Coefficient }}{\gamma_{12}}$} & \multicolumn{2}{|c|}{$\frac{\text { Corr/Covar }}{\sigma \xi_{1} \sigma \xi_{2}}$} \\
\hline & & & -0.190 & -0.010 & 0.180 & 0.230 & 0.100 & 0.280 \\
\hline Model B & & 205 & -0.290 & -0.030 & 0.200 & 0.330 & 0.070 & 0.210 \\
\hline Model C & Final Model & 205 & -0.270 & -0.030 & 0.190 & 0.320 & 0.060 & 0.130 \\
\hline
\end{tabular}

\begin{tabular}{|c|c|c|c|c|c|c|c|c|c|c|c|c|c|}
\hline \multirow[b]{2}{*}{$\frac{\text { Model }}{\text { No. }}$} & \multirow[b]{2}{*}{$\begin{array}{l}\text { Model } \\
\text { Description }\end{array}$} & \multirow[b]{2}{*}{$\begin{array}{l}\text { Sample } \\
\text { Size: }\end{array}$} & \multicolumn{11}{|c|}{ Goodness of Fit Indices } \\
\hline & & & $\chi_{2}$ & $d f$ & $\chi_{2} / d f$ & GFI & AGFI & PGFI & RMSEA & CFI & NFI & TLI & IFI \\
\hline Model A & Proposed Model & 205 & 767.14 & 186 & 4.12 & 0.717 & 0.648 & 0.577 & 0.124 & 0.763 & 0.712 & 0.732 & 0.765 \\
\hline Model B & & 205 & 558.75 & 132 & 4.23 & 0.757 & 0.685 & 0.584 & 0.126 & 0.802 & 0.759 & 0.771 & 0.804 \\
\hline Model C & Final Model & 205 & 410.14 & 131 & 3.13 & 0.810 & 0.753 & 0.616 & 0.102 & 0.871 & 0.823 & 0.849 & 0.872 \\
\hline
\end{tabular}

the model respecification process. The respecification of the proposed Model A which included the deletion of three (3) variables (COST, STRE, and FLEX) and the addition of two (2) model covariances (E4↔E6 and E5 $\leftrightarrow \mathrm{E} 8)$ substantially improved the goodness of fit indices without invalidating the design integrity of the study hypothesizes and yielded 
Model C as the final model. All Model C structural and measurement model path coefficients are substantive and significant.

The fundamental sample data reliability can be evaluated by analyzing Cronbach's alpha $(\alpha)$ for the various observed and indexed variables assessed according to the latent variables they represent. Table 12 summarizes the resultant Cronbach's alpha $(\alpha)$ for the applicable latent variables during the model respecification process. The negative alpha $(\alpha)$ for SYSTEM OUTCOMES scale of Model A indicates the valence problem of the COST data collection process which has been previously discussed, and thus deleted from the structural equation model. The final Model C, SYSTEM OUTCOMES alpha $(\alpha)=.633, \mathrm{n}=205)$ was lower than the accepted minimally reliable value of .8 , which reflects the difficulty in acquiring quality and consistent data concerning specific worker's task performance.

Table 12. Respecification Cronbach's Alpha $(\alpha)$ Summary Information

\begin{tabular}{|c|c|c|c|c|c|c|c|c|c|c|}
\hline \multirow[b]{2}{*}{$\frac{\text { Model }}{\text { No. }}$} & \multirow[b]{2}{*}{$\begin{array}{l}\text { Model } \\
\text { Description }\end{array}$} & & \multicolumn{8}{|c|}{ Chronbach's Alpha (Actual/Standardized): } \\
\hline & & $\begin{array}{l}\text { Accumulated } \\
\text { Sample Size: }\end{array}$ & \multicolumn{2}{|c|}{$\begin{array}{c}\text { Total of } 18 \text { Indexed } \\
\text { Variables: }\end{array}$} & \multicolumn{2}{|c|}{$\begin{array}{l}\text { System Outcomes } \\
\text { (2 Variables): }\end{array}$} & \multicolumn{2}{|c|}{$\begin{array}{l}\text { Human Cognition (8 } \\
\text { Variables): }\end{array}$} & \multicolumn{2}{|c|}{$\begin{array}{c}\text { Quality of Work Life } \\
\text { (8 Variables): }\end{array}$} \\
\hline Model A & $\begin{array}{l}\text { Proposed } \\
\text { Model }\end{array}$ & 205 & $0.782^{\mathrm{a}}$ & $0.814^{\mathrm{a}}$ & $-1.011^{b}$ & $-0.762^{b}$ & $0.827^{\mathrm{C}}$ & $0.856^{\mathrm{c}}$ & 0.926 & 0.926 \\
\hline Model B & & 205 & 0.766 & 0.825 & 0.633 & 0.639 & 0.827 & 0.864 & 0.926 & 0.926 \\
\hline Model C & Final Model & 205 & 0.766 & 0.825 & 0.633 & 0.639 & 0.827 & 0.864 & 0.926 & 0.926 \\
\hline Note: & $\begin{array}{ll}\text { a } & \text { 21-variable } \\
\text { b } & 3 \text {-variable } \\
& \\
{ }^{c} & 10 \text {-variable }\end{array}$ & & & & & & & & & \\
\hline
\end{tabular}


The QUALITY OF WORK LIFE scale indicate a very high reliability $(\alpha=.926, \mathrm{n}=205)$ which is consistent with the instrument design where specific questionnaire items were utilized from existing instruments (Appendix A) which had already been substantiated as being valid and reliable. The HUMAN COGNITION scale exhibited an acceptable level of reliability $(\alpha=.827, \mathrm{n}=205)$, where the eight (8) indexed variables were the result of a developed cognitive task analysis performed by this researcher. The overall reliability of the 18-indexed variable scale can be considered "reasonably reliable" (Maxim 1999), since $(\alpha=.766, \mathrm{n}=205)$, when rounded, equals the accepted value of 0.8 .

The final global consideration in the interpretation of the structural equation modeling process is the assessment of overall instrument reliability and validity. Reliability refers to how consistently an instrument measures what it is designed to measure. A problem occurs in the quantification of the traditional single item reliability measurement in structural equation modeling since these reliability values do not allow for correlated measurement errors (Mueller 1995). The observed variable coefficients of determination $\left(\mathrm{R}^{2}\right)$ which describes the proportion of variance described by the latent variables has been accepted as the measurement of reliability within the structural equation modeling process (Maxim 1999 \& Mueller 1995). Typical reliability values of $(.50-.70)$ is exhibited in the independent endogenous variables, while the reliability values concerning the variables VARI (0.27) and ERRO (0.19) appears relatively low and could warrant further investigation. The dependent endogenous variables QUAL and SCHE result in reliability values of (.58) and (.39) respectively. Traditional validity definitions suffer in light of the structural equation modeling process as well. Assumptions concerning a given scale measuring only one underlying construct and the 
fact that latent constructs are not explicitly incorporated present an obstacle for the traditional validity definitions. Maxim (1999) and Mueller (1995) have described a validity measurement akin to criterion validity that describes the correspondence between a measure and its variable as the standardized path coefficients (referred to as validity coefficients) between an observed variable and its latent variable. These standardized path (or validity) coefficients are graphically depicted for Model C on Figure 14.

In summary, the structural equation model, Model $\mathrm{C}$ does reasonably represent the sample data.

\section{Multi-group Invariance Analysis:}

The previous analysis concerning the causal model structure revolved around the first hypothesis of this study, the relational characteristics that exist between system outcomes, human cognition, and the perceived quality of work life of a worker in an agile production environment. Multi-group invariance analysis evaluates the second hypothesis of this study ... the situational relationships concerning the time duration immersed in a task and the context of the task. The structural equation, multi-group evaluation of the validated Model C model was utilized in this situational model invariance (or equivalence) analysis. Specifically, the invariance testing of the latent variable structural path coefficients HUMAN COGNITION $\rightarrow$ SYSTEM OUTCOMES $\left(\boldsymbol{\gamma}_{11}\right)$ and QUALITY OF WORK LIFE $\rightarrow$ SYSTEM OUTCOMES $\left(\boldsymbol{\gamma}_{12}\right)$ was the objective of this analysis. The consideration of multi-company, multi-wave, multiperiod, multi-activity, and multi-worker invariance testing scenarios were considered plausible second hypothesis study variations. 
Byrne (2001) describes the process of evaluating the summative $\chi_{2}$ statistics for each baseline group, as compared to the structural equation model simultaneous (integrated) multi-group $\chi_{2}$ statistic for a measure of model factorial significance. "Given that $\chi_{2}$ statistics are summative, the overall $\chi_{2}$ value for the multi-group model should equal the sum of the $\chi_{2}$ values obtained when the baseline model is tested separately for each group (with no cross-group constraints imposed." Therefore, the statistical significance between the summative and simultaneous multi-group models resides in the evaluation of the difference in $\chi_{2}$ values $\left(\Delta \chi_{2}\right)$ between the two models. "This difference is itself $\chi_{2}$-distributed, with degrees of freedom ( $d f$ ) equal to the difference in the model degrees of freedom ( $\Delta d f)$ and can be thus be tested statistically" (Byrne 1993). Therefore an insignificant $\Delta \boldsymbol{\chi}_{2}$ indicates invariance, or equivalence, of specific multigroup structural model parameters that were constrained to be equal across groups during the simultaneous structural equation solution evaluation.

It should be noted that the previous sampling size validation concerning the original evaluation of the causal model structural analysis, also applies to the multi-group analysis. The stated sample size for the below listed groups usually falls below the minimum sample size required for acceptable reliable structural equation modeling practices, therefore the presented multi-group analysis can only be considered directional, not statistical, in practicality. In order to have been considered a reliable statistical evaluation the minimum sample size in any particular group would have been approximately $(\mathrm{n}=200)$. 


\section{Testing for Invariance Across Study Companies:}

The evaluation of the second hypothesis where the relationship between the latent variables is situational in nature, varying in both temporal and contextual aspects, is first evaluated at the company level. There were two companies involved with this study, and the testing for the structural path coefficients $\left(\boldsymbol{\gamma}_{11}\right.$ and $\left.\boldsymbol{\gamma}_{12}\right)$ invariance was considered a hierarchical first choice in testing the hypothesis of situational task contexts.

Table 13 presents the results of the summative and simultaneous model evaluation.

First COMPANY 1 and COMPANY 2 was evaluated individually utilizing the Model C

Table 13. Testing for Invariance Across Study Companies

\begin{tabular}{|c|c|c|c|c|c|c|c|c|}
\hline \multirow{3}{*}{$\frac{\underline{\text { Model }}}{\text { No. }}$} & \multirow{3}{*}{$\begin{array}{c}\frac{\text { Model }}{\text { Description }} \\
\text { Company } 1\end{array}$} & \multirow{3}{*}{$\begin{array}{c}\frac{\text { Sample }}{\text { Size: }} \\
57\end{array}$} & \multicolumn{6}{|c|}{ Standardized/Unstandardized Estimates } \\
\hline & & & \multicolumn{2}{|c|}{$\frac{\text { Path Coefficient }}{\gamma_{11}}$} & \multicolumn{2}{|c|}{$\frac{\text { Path Coefficient }}{\gamma_{12}}$} & \multicolumn{2}{|c|}{$\frac{\text { Corr/Covar }}{\sigma \xi_{1} \sigma \xi_{2}}$} \\
\hline & & & -0.240 & -0.050 & 0.060 & 0.100 & -0.200 & -0.260 \\
\hline Model C & Company 2 & 148 & -0.310 & -0.030 & 0.180 & 0.320 & 0.130 & 0.330 \\
\hline Model C & $\begin{array}{c}\text { Simultaneous } \\
\text { Analysis }\end{array}$ & 205 & ---- & -0.030 & ---- & 0.251 & --- & --- \\
\hline
\end{tabular}

\begin{tabular}{|c|c|c|c|c|c|c|c|c|c|c|c|c|c|}
\hline \multirow[b]{2}{*}{$\frac{\text { Model }}{\text { No. }}$} & \multirow[b]{2}{*}{$\frac{\text { Model }}{\text { Description }}$} & \multirow[b]{2}{*}{$\begin{array}{l}\text { Sample } \\
\text { Size: }\end{array}$} & \multicolumn{11}{|c|}{ Goodness of Fit Indices } \\
\hline & & & $\chi_{2}$ & $d f$ & $\boldsymbol{\chi}_{2} / d f$ & GFI & AGFI & PGFI & RMSEA & CFI & NFI & TLI & IFI \\
\hline Model C & Company 1 & 57 & 259.97 & 131 & 1.98 & 0.693 & 0.599 & 0.531 & 0.133 & 0.804 & 0.679 & 0.771 & 0.810 \\
\hline Model C & Company 2 & 148 & 322.71 & 131 & 2.46 & 0.803 & 0.743 & 0.615 & 0.100 & 0.884 & 0.821 & 0.864 & 0.885 \\
\hline & & & 582.68 & 262 & & & & & & & & & \\
\hline Model C & $\begin{array}{c}\text { Simultaneous } \\
\text { Analysis }\end{array}$ & 205 & 584.47 & 264 & 2.21 & 0.769 & 0.701 & 0.594 & 0.077 & 0.861 & 0.777 & 0.839 & 0.864 \\
\hline
\end{tabular}

structural equation model and allowing the company specific optimized structural path coefficients ( $\boldsymbol{\gamma}_{11}$ and $\boldsymbol{\gamma}_{12}$ ) to take on any particular values. The standardized and 
unstandardized structural path coefficients ( $\boldsymbol{\gamma}_{11}$ and $\boldsymbol{\gamma}_{12}$ ), as well as the correlation and covariance values for HUMAN COGNITION $\leftrightarrow$ QUALITY OF WORK LIFE ( $\sigma_{\xi_{1}} \sigma_{\xi_{2}}$ ) are presented. Note that the structural path coefficients $\left(\boldsymbol{\gamma}_{11}\right.$ and $\left.\boldsymbol{\gamma}_{12}\right)$ for the simultaneous analysis does not contain standardized values for the path coefficients since those are dependent on the particular data contained in each company sample. The optimized simultaneous multi-group simultaneous unstandardized structural path coefficients yielded $\boldsymbol{\gamma}_{11}=-0.030$ and $\boldsymbol{\gamma}_{12}=0.251$.

To evaluate the invariance of these structural path coefficients across the two companies the following statistical evaluation is conducted. The summative overall $\chi_{2}$ value of the two companies evaluated for the baseline model $\left(\chi_{2}=582.68, d f=262\right)$ was compared with the simultaneous analysis which yielded $\chi_{2}=584.47, d f=264$. The $\chi_{2}$ difference of these two multi-group models yielded $\Delta \chi_{2}=1.79, \Delta d f=2$, which was not significant $(\mathrm{p}<.05)$. Therefore, the structural path coefficients $\left(\boldsymbol{\gamma}_{11}\right.$ and $\left.\boldsymbol{\gamma}_{12}\right)$ are invariant (equivalent) across the two study companies, implying that the relationships between the latent variables do not vary across companies or the highest level of context variety of the study.

The evaluation of the goodness of fit indices (with appropriate validity concerns in light of the previous sample size reliability discussion) indicates several interesting features of the multi-group analysis. First, the indices of the simultaneous analysis tend to represent a "weighted" value between the two individual baseline models. Second, the indices generally indicate a more ill-fitting model than the Model C $(n=205)$ as indicated in Table 10. This malfitting state is partially facilitated by the less than desired sample size of the multi-group analysis, as well as the less than optimum modeling of the 
two-company multi-group model. The GFI, AGFI, and PGFI of the multi-group model indicates a lesser fit in regards to the Model $\mathrm{C}(\mathrm{n}=205)$ as indicated in Table 10 which is consistent with the fact that these indices tend to decline as the model complexity increases. It is puzzling that the $\chi_{2} / d f$ and RMSEA values of the multi-group model indicated an improvement to model fit over the Model C $(n=205)$, but again the suspicion of the sample size validity cautions against drawing a strong conclusion.

\section{Testing for Invariance Across Task Activities:}

In order to further evaluate the latent variable situational relationship proposed by the second hypothesis concerning the context of the tasks, it is hypothesized that the relationship between the latent variables is different for different tasks and as a worker changes tasks in an agile production environment the system outcomes will be affected by the different HUMAN COGNITION and QUALITY OF WORK LIFE attributes either placed on, or perceived by the worker. Table 14 identifies the twelve (12) summary level activities observed during this study and provides a crosstabulation of these twelve (12) activities with respect to the specific study company ( $n=205)$.

These twelve (12) activities were tested for structural path coefficients ( $\boldsymbol{\gamma}_{11}$ and $\left.\boldsymbol{\gamma}_{12}\right)$ invariance utilizing the same multi-group procedure as was conducted for the previous company invariance evaluation. It should be noted that only four (4) of the twelve (12) activities were shared between the two (2) study companies. 


\section{Table 14. Activity * Company Crosstabulation}

ACTIVITY * COMPANY Crosstabulation

\begin{tabular}{|c|c|c|c|c|c|}
\hline & & & \multicolumn{2}{|c|}{ COMPANY } & \multirow[b]{2}{*}{ Total } \\
\hline & & & 1.0 & 2.0 & \\
\hline \multirow[t]{48}{*}{$\overline{\text { ACTIVITY }}$} & \multirow[t]{4}{*}{ Mech. Fabrication } & Count & 0 & 41 & 41 \\
\hline & & \% within ACTIVITY & $.0 \%$ & $100.0 \%$ & $100.0 \%$ \\
\hline & & $\%$ within COMPANY & $.0 \%$ & $27.7 \%$ & $20.0 \%$ \\
\hline & & $\%$ of Total & $.0 \%$ & $20.0 \%$ & $20.0 \%$ \\
\hline & \multirow[t]{4}{*}{ Elect. Panel Fabrication } & Count & 10 & 0 & 10 \\
\hline & & \% within ACTIVITY & $100.0 \%$ & $.0 \%$ & $100.0 \%$ \\
\hline & & $\%$ within COMPANY & $17.5 \%$ & $.0 \%$ & $4.9 \%$ \\
\hline & & $\%$ of Total & $4.9 \%$ & $.0 \%$ & $4.9 \%$ \\
\hline & \multirow[t]{4}{*}{ Mech. Assembly } & Count & 0 & 8 & 8 \\
\hline & & \% within ACTIVITY & $.0 \%$ & $100.0 \%$ & $100.0 \%$ \\
\hline & & $\%$ within COMPANY & $.0 \%$ & $5.4 \%$ & $3.9 \%$ \\
\hline & & $\%$ of Total & $.0 \%$ & $3.9 \%$ & $3.9 \%$ \\
\hline & \multirow[t]{4}{*}{ Elect. Panel Assembly } & Count & 22 & 0 & 22 \\
\hline & & \% within ACTIVITY & $100.0 \%$ & $.0 \%$ & $100.0 \%$ \\
\hline & & $\%$ within COMPANY & $38.6 \%$ & $.0 \%$ & $10.7 \%$ \\
\hline & & $\%$ of Total & $10.7 \%$ & $.0 \%$ & $10.7 \%$ \\
\hline & \multirow[t]{4}{*}{ Supervision } & Count & 1 & 10 & 11 \\
\hline & & \% within ACTIVITY & $9.1 \%$ & $90.9 \%$ & $100.0 \%$ \\
\hline & & $\%$ within COMPANY & $1.8 \%$ & $6.8 \%$ & $5.4 \%$ \\
\hline & & $\%$ of Total & $.5 \%$ & $4.9 \%$ & $5.4 \%$ \\
\hline & \multirow[t]{4}{*}{ Machine Operation } & Count & 0 & 33 & 33 \\
\hline & & \% within ACTIVITY & $.0 \%$ & $100.0 \%$ & $100.0 \%$ \\
\hline & & $\%$ within COMPANY & $.0 \%$ & $22.3 \%$ & $16.1 \%$ \\
\hline & & $\%$ of Total & $.0 \%$ & $16.1 \%$ & $16.1 \%$ \\
\hline & \multirow[t]{4}{*}{ Material Transport } & Count & 0 & 1 & 1 \\
\hline & & \% within ACTIVITY & $.0 \%$ & $100.0 \%$ & $100.0 \%$ \\
\hline & & $\%$ within COMPANY & $.0 \%$ & $.7 \%$ & $.5 \%$ \\
\hline & & $\%$ of Total & $.0 \%$ & $.5 \%$ & $.5 \%$ \\
\hline & \multirow[t]{4}{*}{ Inspection } & Count & 3 & 4 & 7 \\
\hline & & \% within ACTIVITY & $42.9 \%$ & $57.1 \%$ & $100.0 \%$ \\
\hline & & $\%$ within COMPANY & $5.3 \%$ & $2.7 \%$ & $3.4 \%$ \\
\hline & & $\%$ of Total & $1.5 \%$ & $2.0 \%$ & $3.4 \%$ \\
\hline & \multirow[t]{4}{*}{ Maintenance } & Count & 0 & 10 & 10 \\
\hline & & \% within ACTIVITY & $.0 \%$ & $100.0 \%$ & $100.0 \%$ \\
\hline & & $\%$ within COMPANY & $.0 \%$ & $6.8 \%$ & $4.9 \%$ \\
\hline & & $\%$ of Total & $.0 \%$ & $4.9 \%$ & $4.9 \%$ \\
\hline & \multirow[t]{4}{*}{ Office Support } & Count & 19 & 4 & 23 \\
\hline & & \% within ACTIVITY & $82.6 \%$ & $17.4 \%$ & $100.0 \%$ \\
\hline & & $\%$ within COMPANY & $33.3 \%$ & $2.7 \%$ & $11.2 \%$ \\
\hline & & $\%$ of Total & $9.3 \%$ & $2.0 \%$ & $11.2 \%$ \\
\hline & \multirow[t]{4}{*}{ Shipping \& Receiving } & Count & 2 & 16 & 18 \\
\hline & & \% within ACTIVITY & $11.1 \%$ & $88.9 \%$ & $100.0 \%$ \\
\hline & & $\%$ within COMPANY & $3.5 \%$ & $10.8 \%$ & $8.8 \%$ \\
\hline & & $\%$ of Total & $1.0 \%$ & $7.8 \%$ & $8.8 \%$ \\
\hline & \multirow[t]{4}{*}{ Painting } & Count & 0 & 21 & 21 \\
\hline & & \% within ACTIVITY & $.0 \%$ & $100.0 \%$ & $100.0 \%$ \\
\hline & & $\%$ within COMPANY & $.0 \%$ & $14.2 \%$ & $10.2 \%$ \\
\hline & & $\%$ of Total & $.0 \%$ & $10.2 \%$ & $10.2 \%$ \\
\hline \multirow{4}{*}{\multicolumn{2}{|c|}{ Total }} & Count & 57 & 148 & 205 \\
\hline & & $\%$ within ACTIVITY & $27.8 \%$ & $72.2 \%$ & $100.0 \%$ \\
\hline & & $\%$ within COMPANY & $100.0 \%$ & $100.0 \%$ & $100.0 \%$ \\
\hline & & $\%$ of Total & $27.8 \%$ & $72.2 \%$ & $100.0 \%$ \\
\hline
\end{tabular}


Table 15 presents the results of the summative and simultaneous model evaluation.

First the applicable ACTIVITY was evaluated individually utilizing the Model C

structural equation model and allowing the activity specific optimized structural path

coefficients $\left(\boldsymbol{\gamma}_{11}\right.$ and $\left.\boldsymbol{\gamma}_{12}\right)$ to take on any particular values. It is import to note that seven

Table 15. Testing for Invariance Across Task Activities

\begin{tabular}{|c|c|c|c|c|c|c|c|c|}
\hline \multirow{3}{*}{$\frac{\underline{\text { Model }}}{\underline{\text { No. }}}$} & \multirow{3}{*}{$\begin{array}{c}\text { Model } \\
\text { Description } \\
\text { Activity } 1 \\
\text { Mech Fab }\end{array}$} & \multirow{3}{*}{\begin{tabular}{|c|} 
Sample \\
Size: \\
41
\end{tabular}} & \multicolumn{6}{|c|}{ Standardized/Unstandardized Estimates } \\
\hline & & & \multicolumn{2}{|c|}{$\frac{\text { Path Coefficient }}{\gamma_{11}}$} & \multicolumn{2}{|c|}{$\frac{\text { Path Coefficient }}{\gamma_{12}}$} & \multicolumn{2}{|c|}{$\frac{\text { Corr/Covar }}{\sigma \xi_{1} \sigma \xi_{2}}$} \\
\hline & & & -0.160 & -0.020 & -0.010 & -0.020 & 0.100 & 0.150 \\
\hline Model C & $\begin{array}{c}\text { Activity } 4 \\
\text { Panel Assy }\end{array}$ & 22 & -0.700 & -0.050 & -0.060 & -0.140 & -0.130 & -0.060 \\
\hline Model C & $\begin{array}{l}\text { Activity } 6 \\
\text { Operator }\end{array}$ & 33 & -0.290 & -0.030 & 0.450 & 1.910 & -0.240 & -0.340 \\
\hline Model C & $\begin{array}{c}\text { Activity } 10 \text { Office } \\
\text { Support }\end{array}$ & 23 & -0.160 & -0.020 & -0.090 & -2.290 & 0.240 & 0.030 \\
\hline Model C & $\begin{array}{c}\text { Activity } 12 \\
\text { Painting }\end{array}$ & 21 & -0.060 & 0.000 & 0.370 & 0.380 & 0.100 & 1.260 \\
\hline Model C & $\begin{array}{c}\text { Simultaneous } \\
\text { Analysis }\end{array}$ & 140 & --- & -0.033 & --- & 0.166 & --- & --- \\
\hline
\end{tabular}

\begin{tabular}{|c|c|c|c|c|c|c|c|c|c|c|c|c|c|}
\hline \multirow[b]{2}{*}{$\begin{array}{l}\text { Model } \\
\text { No. }\end{array}$} & \multirow[b]{2}{*}{ Description } & \multirow[b]{2}{*}{$\begin{array}{l}\text { Sample } \\
\text { Size: }\end{array}$} & \multicolumn{11}{|c|}{ Goodness of Fit Indices } \\
\hline & & & $\chi_{2}$ & $d f$ & $\boldsymbol{x}_{2} / d f$ & GFI & AGFI & PGFI & RMSEA & CFI & NFI & TLI & IFI \\
\hline Model C & $\begin{array}{c}\text { Activity } 1 \\
\text { Mech Fab }\end{array}$ & 41 & 199.45 & 131 & 1.52 & 0.692 & 0.598 & 0.530 & 0.114 & 0.800 & 0.597 & 0.766 & 0.812 \\
\hline Model C & $\begin{array}{c}\text { Activity } 4 \\
\text { Panel Assy }\end{array}$ & 22 & 280.26 & 131 & 2.14 & 0.535 & 0.393 & 0.410 & 0.233 & 0.508 & 0.386 & 0.425 & 0.541 \\
\hline Model C & $\begin{array}{l}\text { Activity } 6 \\
\text { Operator }\end{array}$ & 33 & 230.68 & 131 & 1.76 & 0.649 & 0.541 & 0.497 & 0.154 & 0.659 & 0.482 & 0.601 & 0.683 \\
\hline Model C & $\begin{array}{c}\text { Activity } 10 \text { Office } \\
\text { Support }\end{array}$ & 23 & 325.11 & 131 & 2.48 & 0.524 & 0.379 & 0.402 & 0.260 & 0.513 & 0.411 & 0.432 & 0.539 \\
\hline Model C & $\begin{array}{c}\text { Activity } 12 \\
\text { Painting }\end{array}$ & 21 & 308.12 & 131 & 2.35 & 0.483 & 0.326 & 0.370 & 0.260 & 0.578 & 0.462 & 0.507 & 0.599 \\
\hline & & & 1343.62 & 655 & & & & & & & & & \\
\hline Model C & $\begin{array}{c}\text { Simultaneous } \\
\text { Analysis }\end{array}$ & 140 & 1366.10 & 663 & 2.06 & 0.585 & 0.465 & 0.454 & 0.089 & 0.601 & 0.460 & 0.540 & 0.623 \\
\hline
\end{tabular}


(7) of the activities experienced an error while attempting to fit the model, due to the sample moment matrix not being positive definite and the sample size being too small (n $\leq 18$ ). The standardized and unstandardized structural path coefficients ( $\boldsymbol{\gamma}_{11}$ and $\left.\boldsymbol{\gamma}_{12}\right)$, as well as the correlation and covariance values for HUMAN COGNITION $\leftrightarrow$ QUALITY OF WORK LIFE $\left(\boldsymbol{\sigma}_{\xi_{1}} \boldsymbol{\sigma}_{\xi_{2}}\right)$ are presented for the five (5) activities that did not experience an AMOS software error. The optimized simultaneous multi-group simultaneous unstandardized structural path coefficients yielded $\gamma_{11}=-0.033$ and $\gamma_{12}=0.166$.

The summative overall $\boldsymbol{\chi}_{2}$ value of the applicable activities evaluated for the baseline model ( $\left.\boldsymbol{\chi}_{2}=1342.62, d f=655\right)$ was compared with the simultaneous analysis which yielded $\chi_{2}^{2}=1366.10, d f=663$. The $\chi_{2}$ difference of these two multi-group models yielded $\Delta \chi_{2}=22.48, \Delta d f=8$, which was significant $(\mathrm{p}<.05)$. Therefore, the structural path coefficients $\left(\boldsymbol{\gamma}_{11}\right.$ and $\left.\boldsymbol{\gamma}_{12}\right)$ are non-invariant (non-equivalent) across the five (5) analyzed activities, implying that the relationships between the latent variables do vary across activities. Interesting, although not statistically significant, indications of the differing path coefficients can be seen pertaining to the specific baseline activity model evaluations. The PANEL ASSY activity yields a structural path coefficient $\boldsymbol{\gamma}_{11}=-0.70$, which indicates a very large improvement in system outcomes occurs as the cognitive loading of the worker increases; whereas with PAINTING there is a very small improvement $\left(\boldsymbol{\gamma}_{11}=-0.06\right)$ in system outcomes as the cognitive loading of the worker increases. MACHINE OPERATIONS yields a structural path coefficient $\boldsymbol{\gamma}_{12}=0.45$, which indicates a very large improvement in system outcomes occurs as the worker perceives increasing favorableness in the quality of work life, unlike the OFFICE 
SUPPORT where decreasing systems outcome performance $\left(\boldsymbol{\gamma}_{12}=-0.90\right)$ is experienced with increasing favorableness in the quality of work life attribute.

The evaluation of the goodness of fit indices (continuing the validity concerns due to sample size reliability) indicates that the activity multi-group model is generally more illfitting than the company multi-group model, and is substantial substandard to the Model $\mathrm{C}(\mathrm{n}=205)$ as indicated in Table 10. The GFI, AGFI, and PGFI of the activity multigroup model indicates a lesser fit in regards to the Model C $(n=205)$ as indicated in Table 10 which is consistent with the fact that these indices tend to decline as the model complexity increases. Just as in the case of the company multi-group model, the $\chi_{2} / d f$ and RMSEA values of the activity multi-group model indicated an improvement to model fit over the Model C $(n=205)$, keeping sample size as a noted issue.

\section{Testing for Invariance Across Data Collection Waves:}

The evaluation of second hypothesis where the relationship between the latent variables is situational in nature, varying in both time duration and context of the task is next evaluated at the data collection wave level. There were four (4) waves of data collection involved with this study, and the testing for the structural path coefficients ( $\boldsymbol{\gamma}_{11}$ and $\boldsymbol{\gamma}_{12}$ ) invariance across these four (4) waves of data collection was deemed essential in characterizing the situational relationships involving this time duration component of the hypothesis.

Table 16 presents the results of the summative and simultaneous model evaluation. First the four (4) waves were evaluated individually utilizing the Model C structural 
equation model and allowing the wave specific optimized structural path coefficients ( $\boldsymbol{\gamma}_{11}$ and $\gamma_{12}$ ) to take on any particular values. The standardized and unstandardized structural path coefficients $\left(\boldsymbol{\gamma}_{11}\right.$ and $\left.\boldsymbol{\gamma}_{12}\right)$, as well as the correlation and covariance values for HUMAN COGNITION $\leftrightarrow$ QUALITY OF WORK LIFE $\left(\boldsymbol{\sigma}_{\xi_{1}} \boldsymbol{\sigma}_{\xi_{2}}\right)$ are presented. The optimized simultaneous multi-group simultaneous unstandardized structural path coefficients yielded $\gamma_{11}=-0.041$ and $\gamma_{12}=0.337$.

Table 16. Testing for Invariance Across Data Collection Waves

\begin{tabular}{|c|c|c|c|c|c|c|c|c|}
\hline \multirow{3}{*}{$\frac{\frac{\text { Model }}{\text { No. }}}{\text { Model C }}$} & \multirow{3}{*}{$\frac{\begin{array}{c}\text { Model } \\
\text { Description }\end{array}}{\text { Wave } 1}$} & \multirow{3}{*}{$\begin{array}{c}\text { Sample } \\
\text { Size: } \\
49\end{array}$} & \multicolumn{6}{|c|}{ Standardized/Unstandardized Estimates } \\
\hline & & & \multicolumn{2}{|c|}{$\frac{\text { Path Coefficient }}{\gamma_{11}}$} & \multicolumn{2}{|c|}{$\frac{\text { Path Coefficient }}{\gamma_{12}}$} & \multicolumn{2}{|c|}{$\frac{\text { Corr/Covar }}{\sigma \xi_{1} \sigma \xi_{2}}$} \\
\hline & & & -0.360 & -0.290 & 0.410 & 0.770 & 0.670 & 0.200 \\
\hline Model C & Wave 2 & 52 & -0.320 & -0.130 & 0.140 & 0.260 & 0.020 & 0.010 \\
\hline Model C & Wave 3 & 52 & -0.250 & -0.030 & 0.020 & 0.030 & 0.090 & 0.210 \\
\hline Model C & Wave 4 & 52 & 0.110 & 0.020 & 0.420 & 0.890 & -0.040 & -0.050 \\
\hline Model C & $\begin{array}{c}\text { Simultaneous } \\
\text { Analysis }\end{array}$ & 205 & ---- & -0.041 & ---- & 0.337 & --- & --- \\
\hline
\end{tabular}

\begin{tabular}{|c|c|c|c|c|c|c|c|c|c|c|c|c|c|}
\hline \multirow[b]{2}{*}{$\begin{array}{l}\text { Model } \\
\text { No. }\end{array}$} & \multirow[b]{2}{*}{$\begin{array}{c}\text { Model } \\
\text { Description }\end{array}$} & \multirow[b]{2}{*}{$\begin{array}{l}\text { Sample } \\
\text { Size: }\end{array}$} & \multicolumn{11}{|c|}{ Goodness of Fit Indices } \\
\hline & & & $\chi_{2}$ & $d f$ & $\boldsymbol{x}_{2} / d f$ & GFI & AGFI & PGFI & RMSEA & CFI & NFI & TLI & IFI \\
\hline Model C & Wave 1 & 49 & 229.39 & 131 & 1.75 & 0.687 & 0.591 & 0.526 & 0.125 & 0.718 & 0.543 & 0.671 & 0.735 \\
\hline Model C & Wave 2 & 52 & 218.58 & 131 & 1.70 & 0.709 & 0.620 & 0.543 & 0.114 & 0.836 & 0.682 & 0.809 & 0.843 \\
\hline Model C & Wave 3 & 52 & 239.97 & 131 & 1.83 & 0.678 & 0.579 & 0.519 & 0.128 & 0.841 & 0.714 & 0.814 & 0.846 \\
\hline \multirow[t]{2}{*}{ Model C } & Wave 4 & 52 & 254.14 & 131 & 1.94 & 0.672 & 0.572 & 0.515 & 0.136 & 0.791 & 0.658 & 0.756 & 0.799 \\
\hline & & & 942.08 & 524 & & & & & & & & & \\
\hline Model C & $\begin{array}{c}\text { Simultaneous } \\
\text { Analysis }\end{array}$ & 205 & 954.29 & 530 & 1.80 & 0.687 & 0.596 & 0.533 & 0.063 & 0.804 & 0.656 & 0.773 & 0.811 \\
\hline
\end{tabular}


To evaluate the invariance of these structural path coefficients across the four waves of data collection the following statistical evaluation is conducted. The summative overall $\chi^{2}$ value of the four waves evaluated for the baseline model ( $\chi^{2}=942.08$, $d f=524)$ was compared with the simultaneous analysis which yielded $\chi_{2}=954.29$, $d f=530$. The $\boldsymbol{\chi}_{2}$ difference of these two multi-group models yielded $\Delta \boldsymbol{\chi}_{2}=12.21$, $\Delta d f=6$, which was not significant $(\mathrm{p}<.05)$. Therefore, the structural path coefficients $\left(\boldsymbol{\gamma}_{11}\right.$ and $\left.\boldsymbol{\gamma}_{12}\right)$ are invariant (equivalent) across the four (4) waves of data collection, implying that the relationships between the latent variables do not vary across waves of data collection as a indicator of time duration sensitivity during this eight (8) month study.

The evaluation of the goodness of fit indices (continuing the validity concerns due to sample size reliability) indicates that the wave multi-group model is generally more illfitting, and is substantial substandard to the Model $\mathrm{C}(\mathrm{n}=205)$ as indicated in Table 10. The GFI, AGFI, and PGFI of the activity multi-group model indicates a lesser fit in regards to the Model C $(n=205)$ as indicated in Table 10 which is consistent with the fact that these indices tend to decline as the model complexity increases. Just as in the case of the other multi-group models, the $\chi_{2} / d f$ and RMSEA values of the wave multigroup model indicated an improvement to model fit over the Model C $(\mathrm{n}=205)$, keeping sample size as a noted issue.

\section{Testing for Invariance Across Data Collection Periods:}

Research bias and the negative aspects of the Hawthorne effect are important considerations during this planned study, especially the executed cognitive task analysis 
portion of this study. The testing for these researcher imposed effects can be evaluated if the situational relationship between the latent variables is evaluated at the data collection period level. The data collection period is defined as a sequential nominal measure as to when the worker underwent study data collection activities, as an example, a worker could have been included in wave 3 of the planned data collection for the first time in which case the worker would have experience the first period of data collection. There would be a maximum of four (4) periods of data collection that a worker could have been involved with this study, and the testing for the structural path coefficients ( $\boldsymbol{\gamma}_{11}$ and $\left.\boldsymbol{\gamma}_{12}\right)$ invariance across these four (4) periods of data collection could indicate a study induced characteristic such as an increasing comfort with being reviewed by the researcher, or a complacent attitude towards the importance of the study procedures, or even the data collection learning curve experienced by the researcher.

Table 17 presents the results of the summative and simultaneous model evaluation. First, the four (4) periods were evaluated individually utilizing the Model C structural equation model and allowing the period specific optimized structural path coefficients $\left(\gamma_{11}\right.$ and $\left.\gamma_{12}\right)$ to take on any particular values. The standardized and unstandardized structural path coefficients ( $\boldsymbol{\gamma}_{11}$ and $\boldsymbol{\gamma}_{12}$ ), as well as the correlation and covariance values for HUMAN COGNITION $\leftrightarrow$ QUALITY OF WORK LIFE ( $\left.\boldsymbol{\sigma}_{\xi_{1}} \boldsymbol{\sigma}_{\xi_{2}}\right)$ are presented. The optimized simultaneous multi-group simultaneous unstandardized structural path coefficients yielded $\boldsymbol{\gamma}_{11}=0.002$ and $\boldsymbol{\gamma}_{12}=0.448$. 


\begin{tabular}{|c|c|c|c|c|c|c|c|c|}
\hline \multirow{3}{*}{$\frac{\underline{\text { Model }}}{\underline{\text { No. }}}$} & \multirow{3}{*}{$\frac{\begin{array}{c}\text { Model } \\
\text { Description }\end{array}}{1 \text { Period }}$} & \multirow{3}{*}{\begin{tabular}{|c|} 
Sample \\
Size: \\
74
\end{tabular}} & \multicolumn{6}{|c|}{ Standardized/Unstandardized Estimates } \\
\hline & & & \multicolumn{2}{|c|}{$\frac{\text { Path Coefficient }}{\gamma_{11}}$} & \multicolumn{2}{|c|}{$\frac{\text { Path Coefficient }}{\gamma_{12}}$} & \multicolumn{2}{|c|}{$\frac{\text { Corr/Covar }}{\sigma \xi_{1} \sigma \xi_{2}}$} \\
\hline & & & 0.070 & 0.000 & 0.220 & 0.450 & -0.030 & -0.100 \\
\hline Model C & 2 Periods & 52 & -0.150 & -0.050 & 0.260 & 0.520 & -0.040 & -0.030 \\
\hline Model C & 3 Periods & 41 & -0.170 & -0.050 & 0.150 & 0.170 & 0.070 & 0.090 \\
\hline Model C & 4 Periods & 38 & 0.020 & 0.010 & 0.470 & 0.890 & -0.070 & -0.070 \\
\hline Model C & $\begin{array}{c}\text { Simultaneous } \\
\text { Analysis }\end{array}$ & 205 & ---- & 0.002 & --- & 0.448 & --- & --- \\
\hline
\end{tabular}

\begin{tabular}{|c|c|c|c|c|c|c|c|c|c|c|c|c|c|}
\hline \multirow[b]{2}{*}{$\begin{array}{c}\text { Model } \\
\text { No. }\end{array}$} & \multirow[b]{2}{*}{$\begin{array}{c}\text { Model } \\
\text { Description }\end{array}$} & \multirow[b]{2}{*}{$\begin{array}{l}\text { Sample } \\
\text { Size: }\end{array}$} & \multicolumn{11}{|c|}{ Goodness of Fit Indices } \\
\hline & & & $\chi_{2}$ & $d f$ & $\boldsymbol{\chi}_{2} / d f$ & GFI & AGFI & PGFI & RMSEA & CFI & NFI & TLI & IFI \\
\hline Model C & 1 Period & 74 & 223.75 & 131 & 1.71 & 0.766 & 0.695 & 0.587 & 0.098 & 0.856 & 0.719 & 0.831 & 0.860 \\
\hline Model C & 2 Periods & 52 & 248.29 & 131 & 1.90 & 0.685 & 0.589 & 0.525 & 0.132 & 0.814 & 0.683 & 0.783 & 0.820 \\
\hline Model C & 3 Periods & 41 & 218.08 & 131 & 1.67 & 0.645 & 0.537 & 0.494 & 0.129 & 0.837 & 0.683 & 0.810 & 0.843 \\
\hline \multirow[t]{2}{*}{ Model C } & 4 Periods & 38 & 258.31 & 131 & 1.97 & 0.619 & 0.503 & 0.474 & 0.162 & 0.737 & 0.595 & 0.693 & 0.748 \\
\hline & & & 948.43 & 524 & & & & & & & & & \\
\hline Model C & $\begin{array}{c}\text { Simultaneous } \\
\text { Analysis }\end{array}$ & 205 & 951.57 & 527 & 1.81 & 0.691 & 0.598 & 0.532 & 0.063 & 0.815 & 0.673 & 0.785 & 0.822 \\
\hline
\end{tabular}

To evaluate the invariance of these structural path coefficients across the four periods of data collection the following statistical evaluation is conducted. The summative overall $\boldsymbol{\chi}_{2}$ value of the four periods evaluated for the baseline model $\left(\boldsymbol{\chi}_{2}=\right.$ 948.43, $d f=524$ ) was compared with the simultaneous analysis which yielded $\boldsymbol{\chi}_{2}=$ 951.57, $d f=527$. The $\boldsymbol{\chi}_{2}$ difference of these two multi-group models yielded $\Delta \boldsymbol{\chi}_{2}=$ 3.14, $\Delta d f=3$, which was not significant $(\mathrm{p}<.05)$. Therefore, the structural path coefficients ( $\boldsymbol{\gamma}_{11}$ and $\left.\boldsymbol{\gamma}_{12}\right)$ are invariant (equivalent) across the four (4) periods of data 
collection, implying that the relationships between the latent variables do not vary across periods of data collection as a indicator of time duration sensitivity during this eight (8) month study.

The evaluation of the goodness of fit indices (continuing the validity concerns due to sample size reliability) indicates that the period multi-group model is generally more illfitting, and is substantial substandard to, the Model C $(\mathrm{n}=205)$ as indicated in Table 10. The GFI, AGFI, and PGFI of the period multi-group model indicates a lesser fit in regards to the Model $C(n=205)$ as indicated in Table 10 which is consistent with the fact that these indices tend to decline as the model complexity increases. Just as in the case of the other multi-group models, the $\boldsymbol{\chi}_{2} / d f$ and RMSEA values of the multi-group model indicated an improvement to model fit over the Model C $(n=205)$, again keeping sample size as a validity consideration.

\section{Testing for Invariance Across Workers:}

A more specific analysis of the time at task exposure sensitivity includes the evaluation of thirty (30) individual workers who worked the same activity during three (3) data collection periods. Table 18 presents the results of the summative and simultaneous model evaluation. First, the three (3) worker-periods were evaluated individually utilizing the Model C structural equation model and allowing the workerperiod specific optimized structural path coefficients $\left(\boldsymbol{\gamma}_{11}\right.$ and $\left.\boldsymbol{\gamma}_{12}\right)$ to take on any particular values. The standardized and unstandardized structural path coefficients ( $\boldsymbol{\gamma}_{11}$ and $\gamma_{12}$ ), as well as the correlation and covariance values for HUMAN COGNITION $\leftrightarrow$ QUALITY OF WORK LIFE ( $\left.\boldsymbol{\sigma}_{\xi_{1}} \boldsymbol{\sigma}_{\xi_{2}}\right)$ are presented. The optimized simultaneous multi- 
group simultaneous unstandardized structural path coefficients yielded $\gamma_{11}=-0.070$ and

$\gamma_{12}=0.700$.

Table 18. Testing for Invariance Across Workers (30 workers maintained same task for 3 periods)

\begin{tabular}{|c|c|c|c|c|c|c|c|c|}
\hline \multirow{3}{*}{$\frac{\frac{\text { Model }}{\text { No. }}}{\text { Model C }}$} & \multirow{3}{*}{$\frac{\text { Model }}{\text { Description }}$} & \multirow{3}{*}{$\frac{\underline{\text { Sample }}}{\underline{\text { Size: }}}$} & \multicolumn{6}{|c|}{ Standardized/Unstandardized Estimates } \\
\hline & & & \multicolumn{2}{|c|}{$\frac{\text { Path Coefficient }}{\gamma_{11}}$} & \multicolumn{2}{|c|}{$\frac{\text { Path Coefficient }}{\gamma_{12}}$} & \multicolumn{2}{|c|}{$\frac{\text { Corr/Covar }}{\sigma \xi_{1} \sigma \xi_{2}}$} \\
\hline & & & 0.420 & 0.140 & 0.190 & 0.590 & 0.060 & 0.030 \\
\hline Model C & $\begin{array}{c}\text { Worker-Period } \\
2\end{array}$ & 30 & -0.230 & -0.100 & 0.490 & 1.650 & -0.140 & -0.060 \\
\hline Model C & $\begin{array}{c}\text { Worker-Period } \\
3\end{array}$ & 30 & -0.060 & -0.020 & 0.380 & 0.540 & 0.160 & 0.180 \\
\hline Model C & $\begin{array}{l}\text { Simultaneous } \\
\text { Analysis }\end{array}$ & 90 & --- & -0.070 & ---- & 0.700 & --- & --- \\
\hline
\end{tabular}

\begin{tabular}{|c|c|c|c|c|c|c|c|c|c|c|c|c|c|}
\hline \multirow[b]{2}{*}{$\frac{\text { Model }}{\text { No. }}$} & \multirow[b]{2}{*}{ Description } & \multirow[b]{2}{*}{$\begin{array}{l}\text { Sample } \\
\text { Size: }\end{array}$} & \multicolumn{11}{|c|}{ Goodness of Fit Indices } \\
\hline & & & $\chi_{2}$ & $d f$ & $\boldsymbol{x}_{2} / d f$ & GFI & AGFI & PGFI & RMSEA & CFI & NFI & TLI & IFI \\
\hline Model C & $\begin{array}{c}\text { Worker-Period } \\
1\end{array}$ & 30 & 239.11 & 131 & 1.83 & 0.620 & 0.504 & 0.475 & 0.169 & 0.603 & 0.438 & 0.536 & 0.633 \\
\hline Model C & $\begin{array}{c}\text { Worker-Period } \\
2\end{array}$ & 30 & 216.88 & 131 & 1.66 & 0.617 & 0.501 & 0.473 & 0.150 & 0.806 & 0.636 & 0.773 & 0.815 \\
\hline \multirow[t]{2}{*}{ Model C } & $\begin{array}{c}\text { Worker-Period } \\
3\end{array}$ & 30 & 224.15 & 131 & 1.71 & 0.586 & 0.459 & 0.449 & 0.157 & 0.792 & 0.627 & 0.757 & 0.802 \\
\hline & & & 680.14 & 393 & & & & & & & & & \\
\hline Model C & $\begin{array}{c}\text { Simultaneous } \\
\text { Analysis }\end{array}$ & 90 & 688.40 & 397 & 1.73 & 0.604 & 0.488 & 0.467 & 0.092 & 0.749 & 0.575 & 0.710 & 0.762 \\
\hline
\end{tabular}

To evaluate the invariance of these structural path coefficients across the three worker- periods of data collection the following statistical evaluation is conducted. The summative overall $\chi_{2}$ value of the three (3) worker-periods evaluated for the baseline model $\left(\chi_{2}=680.14, d f=393\right)$ was compared with the simultaneous analysis which 
yielded $\chi_{2}=688.40, d f=397$. The $\chi_{2}^{2}$ difference of these two multi-group models yielded $\Delta \chi_{2}=8.26, \Delta d f=4$, which was not significant $(\mathrm{p}<.05)$. Therefore, the structural path coefficients ( $\boldsymbol{\gamma}_{11}$ and $\boldsymbol{\gamma}_{12}$ ) are invariant (equivalent) across the three (3) worker-periods of data collection, implying that the relationships between the latent variables do not vary across worker-periods (i.e. workers) as a indicator of time exposure sensitivity during this eight (8) month study. It is interesting to note that while there appears to be no relationship to the time exposed to the task (as measured during this eight (8) month study), the analysis implies that the unstandardized structural path coefficient QUALITY OF WORK LIFE $\rightarrow$ SYSTEM OUTCOMES $\left(\gamma_{12}=0.70\right)$ of the worker-period multi-group analysis is substantially larger in magnitude than the other multi-group comparisons, as well as the overall Model C $\left(\boldsymbol{\gamma}_{12}=0.32\right)$. This implies that the time exposed to the task situational characteristics postulated in the second hypothesis may exist for the quality of work life attributes, but only being detectable during a longer evaluative time frame (longer than the eight (8) month study).

The evaluation of the goodness of fit indices (continuing the validity suspicions due to sample size reliability) indicates that the worker-period multi-group model is generally more ill-fitting, and is substantial substandard to the Model C $(n=205)$ as indicated in Table 10. The GFI, AGFI, and PGFI of the activity multi-group model indicates a lesser fit in regards to the Model C $(n=205)$ as indicated in Table 10 which is consistent with the fact that these indices tend to decline as the model complexity increases. Just as in the case of the other multi-group models, the $\chi_{2} / d f$ and RMSEA values of the multigroup model indicated an improvement to model fit over the Model C $(\mathrm{n}=205)$, keeping sample size as an issue. 


\section{SUMMARY AND CONCLUSIONS}

This research has been formatted as a response to previous researchers' call for quantitative, longitudinal studies of human performance such as: recognizing the need for a "mid-range" socio-technical system theory (Majchrzak \& Borys 2001), evaluating the compatibility of "work demands" and "work energizers" (Genaidy \& Karwowski, in press), and the substantiation of such concepts as the "balance theory" of work design and its linkages between the physical and psychosocial work attributes (Carayon \& Smith 2000). The result of this research presents a derivation from abstraction to the application of a practical evaluative process. In short, systems outcomes are indicated to be the causal result of the human cognitive attributes involved with performing a task, as well as the worker's perceived quality of work life attributes in an agile production system.

The dissertation research began with the ecological cognitive framework (Figure 6) that was developed in order to synthesize the abstractions and concerns of current sociotechnical literature concerning human performance in an agile production environment. The framework encapsulates referred cited factors relating to organizational performance, as well as the interdependence of the work environment and the worker. The resulting human-work domain structural equation model was developed and evaluated through the 
process of confirmatory factor analysis and yielded a somewhat ill-fitting model. The human-work domain casual model (Figure 14) is the result of the exploratory factor analysis where practical and theoretical model enhancements were implemented that provided a quantifiable and testable construct to evaluate the human-work domain within the ecological cognitive framework.

This human-work domain causal model (Figure 14) was well-defined, depicting the factorial latent variable relationship between HUMAN COGNITION $\rightarrow$ SYSTEM OUTCOME $\left(\gamma_{11}=-0.27\right)$, as well as the factorial latent variable relationship between the workers' perceived QUALITY OF WORK LIFE $\rightarrow$ SYSTEM OUTCOMES $\left(\boldsymbol{\gamma}_{12}=0.19\right)$, therefore providing substantive, theoretical, and significant credence to this human-work domain causal relationship and supporting the first hypothesis of study. It is important to note that there was no statistical significant correlation between the latent variables of human cognition and quality of work life, while there were significant modeling error covariances concerning task variety $\leftrightarrow$ worker adaptability and task complexity $\leftrightarrow$ decision-making. The overall reliability of this model can be explained by the variable squared multiple correlation $\left(\mathrm{R}^{2}\right)$ that indicate that $58 \%$ of the quality variance is attributed to the model, as is $39 \%$ of the schedule variance.

The second hypothesis of this study revolved around the temporal and contextual situational relationships that are contained in the human-work domain model, specifically the varying model relationships in regard to the time exposed to, and the context of, the worker's task. To test this hypothesis the analysis involved the structural equation modeling process of multi-group factorial invariance testing, where the total sample population is distilled into individual groups (i.e. companies, data collection waves, data 
collection periods, activities, or workers) and simultaneously evaluated as distinct groups fitting a constrained factorial structural equation model. It should be noted that while the first hypothesis analysis included an adequate sample size, the distillation of the sample population into smaller group populations affords this second hypothesis multi-group evaluation result to be directional and substantive, but lacking (at least questionable) overall modeling statistical significance due to sample size. The structural path coefficients HUMAN COGNITION $\rightarrow$ SYSTEM OUTCOMES $\left(\boldsymbol{\gamma}_{11}\right)$ and QUALITY OF WORK LIFE $\rightarrow$ SYSTEM OUTCOMES ( $\gamma_{12}$ ) were the only constrained model elements, since the structural model covariance HUMAN COGNITION $\leftrightarrow$ QUALITY OF WORK LIFE ( $\boldsymbol{\sigma}_{\xi_{1}} \boldsymbol{\sigma}_{\xi_{2}}$ ) indicated a non-significant result in the primary model (Model C). The primary significance test criterion was the $\Delta \boldsymbol{\chi}_{2}$ between the competing baseline and simultaneous analyzed particular multi-group models.

The first multi-group factorial invariance test involved the review of the two (2) study companies in order to evaluate the fundamental differences that may exist in these different work environments, the highest level of task context variety of the study. The factorial structural model was invariant (equivalent, with no significant differences) across the two (2) companies. A finer resolution of task context involved the multi-group analysis of the activities themselves, and at this point the factorial structural model was non-invariant (non-equivalent, with significant differences) across the activities. Substantial differences could be seen in the individual activity structural path coefficients (Table 15), to the extreme that the activity of painting did not indicate any causal relationship with human cognition, but exhibited a strong positive causal relationship with the quality of work life construct. The activity of panel assembly on the other hand, 
indicated a strong (strongest of all analyzed activities) positive relationship with human cognition, while actually yielding a strong negative relationship with the quality of work life construct. These findings confirm the second hypothesis where the structural relationships represented in the human-work domain model are task context dependent.

The time exposure element of the second hypothesis was evaluated in three (3) consecutively finer resolution reviews: data collection waves, data collection periods, and finally across workers. The analysis across data collection waves was defined to be a longitudinal review across the eight (8) month study duration, and the period analysis was comparable to the wave evaluation except it corrected for the entry of new workers and the departure of previous workers from the study. The factorial structural model was invariant (equivalent, with no significant differences) across both data collection waves and data collection periods, indicating that time exposure was not a significant factor during this study. In order to delve deeper into the issue of time exposure sensitivity to a particular task, a review of the data indicated that a total thirty (30) workers had performed a particular activity for three (3) data collection periods. This information was evaluated as a multi-group analysis, with the results again indicating the factorial structural model was invariant (equivalent, with no significant differences) across the worker-periods. While, it can be concluded that these findings do not confirm the second hypothesis where the structural relationships represented in the human-work domain model are time exposure dependent ... for this eight (8) month longitudinal study, a longer time horizon may be called for. The findings of the worker-period multi-group analysis implies that the time exposed to the task situational characteristics postulated in the second hypothesis may exist for the quality of work life attributes, but only being 
detectable during a longer evaluative time frame (longer than the eight (8) month study), as evident in the unstandardized structural path coefficient QUALITY OF WORK LIFE $\rightarrow$ SYSTEM OUTCOMES $\left(\gamma_{12}=0.70\right)$ of the worker-period multi-group analysis is substantially larger in magnitude than the other multi-group comparisons, as well as the overall Model C $\left(\gamma_{12}=0.32\right)$, but not indicating any significant difference during the study time frame.

The study results indicate that the situational context of the task does indeed affect the relationship of the human-work domain structural model, while the time exposed to the task relational characteristics (especially the quality of work life attributes) may only be detected in time frames longer than this eight (8) month study.

There exists several known limitations of this study. First, the limited sample size of the multi-group invariance testing procedure, depending on the particular group in question, requires a cautious view in considering the results of the second hypothesis. The results indicate a direction of conclusion, although the conclusion can not be statistically substantiated. Second, the cognitive task analysis developed specifically by this researcher for the data collection of the human cognition indexed variables has not been fully validated. The human cognition construct, as well as the cognitive task analysis data collection procedure was synthesized from various cited researchers such as Stanton \& Stevenage (1998), Militello \& Hutton (1998), and Karwowski \& Marris (1999) among others. Third, researcher induced effects such as researcher training period, researcher bias in conducting the cognitive task analysis, and possible Hawthorne effects (Maxim 1999) exhibited by the workers while being observed by this researcher, could have possibly been present ... yet undetected and evaluatively uncontrolled. Lastly, the 
manifest variable of COST was not defined sufficiently by this researcher, and as a result the data collected was not consistent and had to be removed from the model evaluative process.

Future work in the area of the prescribed human-work domain model included addressing the identified study limitations presented (i.e. increasing multi-group sample size, further research and validation of this study's cognitive task analysis procedure, reducing possible researcher effects, and clarifying the definition of the COST variable). Increasing the multi-group sample size would facilitate the use of a more restrictive (more model path coefficients or covariances defined to be invariant) and statistically significant multi-group structural equation evaluation process. Increasing the sample size would also allow a cross-validation process which would further enhance the validity of the structural equation modeling process. The use of video data collection of the cognitive task analysis raw data would aid in the minimization of researcher (Hawthorne) effects while providing a time efficient means of gathering data.

The quantitative process of this research provides a consistent platform of evaluation to topics which have historically proved difficult to qualitatively discuss, not to mention quantify. The research methodology of combining empirical data, cognitive task analysis data, and questionnaire data into an evaluative format facilitating the structural equation modeling of the complex psychosocial process that exists in today's agile production system may aid our understanding of the human-work domain, thus allowing considerations for what Parasuraman (2003) described as “joint cognitive systems". An example of an identified benefit of this research is the application of predictive algorithms that could simulate the human performance of an individual (or 
groups of individuals) that exhibit a particular set of human cognition and quality of work life attributes in an agile production environment where the cognitive demands of the task have been identified and accurately modeled. This simulation would aid the congruent understanding and performance optimization of the human worker, technology, and infrastructure inherent to the agile production system. 


\section{REFERENCES}

Amabile, T. M., Hill, K. G., Hennessey, B. A., \& Tighe, E. M. (1994). The Work Preference Inventory: Assessing Intrinsic and Extrinsic Motivational Orientations. Journal of Personality and Social Psychology. 66, No 5, 950-967.

Arbuckle, J.L., and Wothke, W. (1999). AMOS 4.0 User's Guide. Chicago, IL: SmallWaters Corporation.

Azani, C. H. (1999). An Integrative Methodology for the Strategic Management of Advanced Integrated Manufacturing Systems. In Sarkis, J. \& Parsaei, H. R. Eds. Advanced Manufacturing Systems: Strategic Management and Implementation. The Netherlands: Gordon and Breach Science Publishers. 21-41.

Badham, R., \& Ehn, P. (2000). Tinkering with Technology: Human Factors, Work Redesign, and Professionals in Workplace Innovation. Human Factors and Ergonomics in Manufacturing. 10, No 1, 61-82.

Barnard, P. J., \& May, J. (2000). Towards a Theory-Based Form of Cognitive Task Analysis of Broad Scope and Applicability. In Schraagen, J. M., Chipman, S. F., \& Shalin, V. L. Eds. Cognitive Task Analysis. Mahwah, NJ: Lawrence Erlbaum Associates. 147-164.

Bedny, G., Karwowski, W., \& Bedny, M. (2001). The Principle of Unity of Cognition And Behavior: Implications of Activity Theory for the Study of Human Work. International Journal of Cognitive Ergonomics. 5, No 4, 401-420.

Bedny, G., Karwowski, W., Kwon, YG. (2001). A Methodology of Systemic-Structural Analysis and Design of Manual-Based Manufacturing Operations. Human Factors And Ergonomics in Manufacturing. 11, No 3, 233-253.

Bi, S., \& Salvendy, G. (1994). Analytical Modeling and Experimental Study of Human Workload in Scheduling of Advanced Manufacturing Systems. The International Journal of Human Factors in Manufacturing. 4, No 2, 205-234.

Brezocnik, M., Balic, J. \& Brezocnik, Z. (2003). Emergence of Intelligence in Next-Generation Manufacturing Systems. Robotics and Computer Integrated Manufacturing. 19, 55-63. 
Byrne, B. (2001). Structural Equation Modeling With AMOS: Basic Concepts, Applications, and Programming. Mahwah, NJ: Lawerance Erlbaum Associates.

Byrne, B. (1993). The Maslach Burnout Inventory: Testing for Factorial Validity And Invariance across Elementary, Intermediate, and Secondary Teachers. Journal Of Occupational and Organizational Psychology. 66, 197-212.

Byrne, B. (1991). The Maslach Burnout Inventory: Testing for Factorial Validity And Invariance across Elementary, Intermediate, and Secondary Teachers. Multivariate Behavioral Research. 26, No. 4, 583-605.

Cañas, J. J., Quesada, J. F., Antolí, A., \& Fajardo, I. (2003). Cognitive Flexibility And Adaptability to Environmental Changes in Dynamic Complex Problem-Solving Tasks. Ergonomics. 46, No 5, 482-501.

Carayon, P., \& Smith, M. J. (2000). Work Organization and Ergonomics. Applied Ergonomics. 31, Issue 6, 649-662.

Carstensen, P.H., \& Schmidt, K. (2002). Self-Governing Production Groups: Towards Requirements for IT Support. In Marik, V., Camarinha-Matos, L.M., \& Afsarmanesh, H. Eds. Knowledge and Technology Integration in Production and Services: Balancing Knowledge and Technology in Product and Service Life Cycle. Boston, Mass: Kluwer Academic Publishers. 49-60.

Cordery, J., Sevastos, P., Mueller, W., \& Parker, S. (1993). Correlates of Employee Attitudes Toward Functional Flexibility. Human Relations. 46, No 6, 705-723.

Daniels, K., \& Guppy, A. (1994). Occupational Stress, Social Support, Job Control, And Psychological Well-Being. Human Relations. 47, No 12, 1523-1544.

Decker, P. J., \& Borgen, F. H. (1993). Dimensions of Work Appraisal: Stress, Strain, Coping, Job Satisfaction, and Negative Affectivity. Journal of Counseling Psychology. 40, No 4, 470-478.

De Toni, A., \& Tonchia, S. (1998). Manufacturing Flexibility: A Literature Review. International Journal of Production Research. 36, No 6, 1587-1617.

Dilalla, L.F. (2000). Structural Equation Modeling: Uses and Issues. In Tinsley, H.E.A., and Brown, S.D. Eds. Handbook of Applied Multivariate Statistics and Mathematical Modeling. New York, NY: Academic Press. 439-464.

Donavan, M. A., Drasgow, F., \& Munson, L. J. (1998). The Perceptions of Fair Interpersonal Treatment Scale: Development and Validation of a Measure of Interpersonal Treatment in the Workplace. Journal of Applied Psychology. 83, No 5, 683-692. 
Duffy, V. G., \& Salvendy, G. (1999). The Impact of Organizational Ergonomics on Work Effectiveness: With Special Reference to Concurrent Engineering in Manufacturing Industries. Ergonomics, 42, No 4, 614-637.

Eisenberger, R., Cummings, J., Armeli, S., \& Lynch, P. (1997). Perceived Organizational Support, Discretionary Treatment, and Job Satisfaction. Journal of Applied Psychology. 82, No 5, 812-820.

Eklund, J. (2000). Development Work for Quality and Ergonomics. Applied Ergonomics. 31, Issue 6, 641-648.

Endsley, M. R., \& Kaber, D. B. (1999). Level of Automation Effects on Performance, Situation Awareness and Workload in a Dynamic Control Task. Ergonomics. 42, No 3, 462-492.

Fang, X., \& Salvendy, G. (2001). A Personal Perspective on Behavior and Information Technology: A 20-Year Progress and Future Trend. Behavior \& Information Technology. 20, No 5, 357-366.

Fenwick, R., \& Tausig, M. (1994). The Macroeconomic Context of Job Stress. Journal Of Health and Social Behavior. 35, No 3, 266-282.

Furnham, A., Brewin, C. R., \& O’Kelly, H. (1994). Cognitive Style and Attitudes to Work. Human Relations. 47, No 12, 1509-1521.

Genaidy, A. M., \& Karwowski, W. (in press). Human Performance in Lean Production Environment: Critical Assessment and Research Framework. Human Factors and Ergonomics in Manufacturing.

Genaidy, A., Karwowski, W., \& Shoaf, C. (2002). The Fundamentals of Work System Compatibility Theory: An Integrated Approach to Optimization of Human Performance at Work. Theoretical Issues in Ergonomics Science. 3, No 4, 346-368.

Gielo-Perczak, K., \& Karwowski, W. (2003). Ecological Models of Human Performance Based on Affordance, Emotion, and Intuition. Ergonomics. 46, No 1-3, 310-326.

Grammig, T. (2003). Sociotechnical Relations and Development Assistance. Technological Forecasting and Social Change. 70, Issue 6, 501-523.

Griffith, T. L., \& Dougherty, D. J. (2002). Beyond Socio-technical Systems: Introduction to the Special Issue. Journal of Engineering and Technology Management. 19, Issue 2, 205-216. 
Haynes, A. (1999). Effects of World Class Manufacturing on Shop Floor Workers. Journal of European Industrial Training. 23, No 6, 300-309.

Havn, E. (1994). Reflecting on Work Practice: The Role of People and Organizations. In Karwowski, W., \& Salvendy, G. Eds. Organization and Management of Advanced Manufacturing. New York, NY: John Wiley \& Sons, Inc. 239-253.

Hendrick, H. W. (2002). An Overview of Macroergonomics. In Hendrick, H. W. \& Kleiner, B. M., Eds. Macroergonomics: Theory, Methods, and Applications. Human Factors and Ergonomics. 1-23.

Hershberger, S.L., Marcoulides, G.A., and Parramore, M.M. (2003). Structural Equation Modeling: An Introduction. In Pugesek, B.H., Tomer, A., and von Eye, A. Eds. Structural Equation Modeling: Applications in Ecology and Evolutionary Biology. Cambridge: University Press. 3-41.

Hoyle, R.H. (2000). Confirmatory Factor Analysis. In Tinsley, H.E.A., and Brown, S.D. Eds. Handbook of Applied Multivariate Statistics and Mathematical Modeling. New York, NY: Academic Press. 465-497.

Jiang, P. D. Z., \& Fung, R. Y. K. (2003). An Adaptive Agile Manufacturing Control Infrastructure Based on TOPNs-CS Modeling. The International Journal of Advanced Manufacturing Technology. Online: 18 June 2003.

Jones, P. M., \& Jacobs, J. L. (2000). Cooperative Problem Solving in Human-Machine Systems: Theory, Models, and Intelligent Associate Systems. IEEE Transactions on Systems, Man, and Cybernetics-Part C. 30, No 4, 397-407.

Kaber, D. B., Onal, E., \& Endsley, M. R. (2000). Design of Automation for Telerobots And the Effect on Performance, Operator Situation Awareness, and Subjective Workload. Human Factors and Ergonomics in Manufacturing. 10, No 4, 409-430.

Kaghan, W. N., \& Bowker, g. C. (2001). Out of the Machine Age?: Complexity, Sociotechnical Systems and Actor Network Theory. Journal of Engineering and Technology Management. 18, Issues 3-4, 253-269.

Kaplan, D. (2000). Structural Equation Modeling: Foundations and Extensions. London: Sage Publications.

Karasek, R., \& Theorell, T. (1990). Healthy Work: Stress, Productivity, and the Reconstruction of Working Life. New York, NY: Basic Books, Inc.

Karwowski, W. \& Marras. (1999). The Occupational Ergonomics Handbook. New York, NY: CRC Press. Chapter 16. 
Karwowski, W., Salvendy, G., Badham, R., Brodner, P., Clegg, C., Hwang, S. L., Iwasawa, J., Kidd, P. T., Kobayashi, N., Koubek, R., LaMarsh, J., Naganachi, M., Naniwada, M., Salzman, H., Seppala, P., Schallock, B., Sheridan, T., \& Warschat, J. (1994). Integrating People, Organization, and Technology in Advanced

Manufacturing: A Position Paper Based on the Joint View of Industrial Managers, Engineers, Consultants, and Researchers. The International Journal of Human Factors in Manufacturing. 4, No 1, 1-19.

Karwowski, W., Siemionow, W., \& Gielo-Perczak, K. (2003). Physical

Neuroergonomics: The Human Brain in Control of Physical Work Activities.

Theoretical Issues in Ergonomics Science. 4, Nos 1-2, 175-199.

Kelloway, E.K. (1998). Using LISREL for Structural Equation Modeling: A

Researcher's Guide. London: Sage Publications.

Kidd, P. T. (1994). Agile Manufacturing: Forging New Frontiers. Reading, MA: Addison-Wesley Publishing Company.

Klein, G., Kaempf, G. L., Wolf, S., Thorsden, M., \& Miller, T. (1997). Applying Decision Requirements to User-centered Design. International Journal of Human-Computer Studies. 46, 1-15.

Klein, G., \& Militello, L. (2001). Some Guidelines for Conducting a Cognitive Task Analysis. In Salas, E., Ed. Advances in Human Performance and Cognitive Engineering Research. Kidlington, UK: Elsevier Science Ltd. 1, 163-199.

Koberg, C. S., Detienne, D. R., \& Heppard, K. A., (2003). An Empirical Test of Environmental, Organizational, and Process Factors Affecting Incremental and Radical Innovation. The Journal of High Technology Management Research. 14, Issue 1, 21-45.

Kuusi, O., \& Meyer, M. (2002). Technological Generalizations and LeitbilderThe Anticipation of Technological Opportunities. Technological Forecasting and Social Change. 69, Issue 6, 625-639.

Leach, D. J., Jackson, P. R., \& Wall, T. D. (2001). Realizing the Potential of Empowerment: The Impact of a Feedback Intervention of the Performance of Complex Technology. Ergonomics. 44, No 9, 870-886.

Lee, S-K., \& Lee, WG. (2001). Coping with Job Stress in Industries: A Cognitive Approach. Human Factors and Ergonomics in Manufacturing. 11, No 3, 255-268.

Lennon, M. C. (1994). Women, Work, and Well-Being: The Importance of Work Conditions. Journal of Health and Social Behavior. 35, No 3, 235-247. 
Le Saux, E., Lenca, P., \& Picouet, P. (2002). Dynamic Adaptation of Rules Bases Under Cognitive Constraints. European Journal of Operational Research.

136, Issue 2, 299-309.

Lewis, M. W., \& Boyer, K. K. (2002). Factors Impacting AMT Implementation: An Integrative and Controlled Study. Journal of Engineering and Technology Management. 19, Issue 2, 111-130.

Luczak, H., Reuth, R., \& Schmidt, L. (2003). Development of Error-compensating UI For Autonomous Production Cells. Ergonomics. 46, No 1-3, 19-40.

Majchrzak, A., \& Borys, B. (2001). Generating Testable Socio-technical Systems Theory. Journal of Engineering and Technology Management. 18, Issues 3-4, 219-240.

Maruyama, G.M. (1998). Basics of Structural Equation Modeling. London: Sage Publications.

Maturana, F., Shen, W. \& Norrie, D. H. (1999). MetaMorph: An Adaptive AgentBased Architecture for Intelligent Manufacturing. International Journal of Production Research. 37, No 10, 2159-2173.

Maxim, P.S. (1999). Quantitative Research Methods in the Social Sciences. New York, NY: Oxford University Press. 104-166, 251-278.

Mikkelsen, A., Øgaard, T., Lindøe, P. H., \& Olsen, O. E. (2002). Job Characteristics and Computer Anxiety in the Production Industry. Computers in Human Behavior. 18, Issue 3, 223-239.

Militello, L. G., \& Hutton, R. J. B. (1998). Applied Cognitive Task Analysis (ACTA): A Practitioner's Toolkit for Understanding Cognitive Task Demands.

Ergonomics. 41, No 11, 1618-1641.

Miller, D. C. (1991). Handbook of Research Design and Social Measurement, Fifth Edition. Newbury Park, CA. Sage Publications, Inc., 450-468.

Moorman, R. H. (1991). Relationship between Organizational Justice and Organizational Citizenship Behaviors: Do Fairness Perceptions Influence Employee Citizenship? Journal of Applied Psychology. 76, No 6, 845-855.

Moorman, R. H. (1993). The Influence of Cognitive and Affective Based Job Satisfaction Measures on the Relationship between Satisfaction and Organizational Citizenship Behavior. Human Relations. 46, No 6, 759-776. 
Mueller, R.O. (1995). Basic Principles of Structural Equation Modeling: An Introduction to LISREL and EQS. New York, NY: Springer.

Muthen, B.O. and Satorra, A. (1995). Complex Sample Data in Structural Equation Modeling. Sociological Methodology. 25, 267-316.

Neerincx, M. A., van Doorne, H., \& Ruijsendaal, M. (2000). Attuning ComputerSupported Work to Human Knowledge and Processing Capacities in Ship Control Centers. In Schraagen, J. M., Chipman, S. F., \& Shalin, V. L. Eds. Cognitive Task Analysis. Mahwah, NJ: Lawrence Erlbaum Associates. 341-362.

O’Hare, D., Wiggins, M., Williams, A., \& Wong, W. (1998). Cognitive Task Analysis For Decision Centred Design and Training. Ergonomics. 41, No. 11, 1698-1718.

Ormerod, T. C, Richardson, J., \& Shepherd, A. (1998). Enhancing the Usability of a Task Analysis Method: A Notation and Environment for Requirements Specification. Ergonomics. 41, No 11, 1162-1663.

Palomares, F., Ferreras, P., and Delibes, M. (1998). Co-Existence between Iberian Lynx and Egyptian Mongooses: Estimating Interaction Strength by Structural Equation Modeling and Testing by an Observational Study. The Journal of Animal Ecology. 67. No.6, 967-978.

Parasuraman, R. (2003). Neuroergonomics: Research and Practice. Theoretical Issues In Ergonomics Science. 4, Nos 1-2, 5-20.

Parasuraman, R., Sheridan, T. B., \& Wickens, C. D. (2000). A Model for Types and Levels of Human Interaction with Automation. IEEE Transactions on Systems, Man, and Cybernetics-Part A. 30, No 3, 286-297.

Pejtersen, A.M., Albrechtsen, H., Cleal, B., Hansen, C.B., \& Hertzum, M. (2003). A Web-Based Multimedia Collaboratory: Empirical Work Studies in Film Archives. Ris $\varnothing-R-1284(E N)$. Ris $\varnothing$ National Laboratory. Roskilde.

Pejtersen, A.M. (2003). Ecological, Collaborative Information Systems: A CSE Approach to Knowledge Creation, Integration, and Sharing during Collaborative Decision-Making. Presentation at the Cognitive Systems Engineering Consortium (CSEC) in October 29-31, 2003. Dayton.

Ping, R.A. (2004). On Assuring Valid Measures for Theoretical Models Using Survey Data. Journal of Business Research. 57, Issue 2, 125-141.

Pliske, R.M., McCloskey, M.J., \& Klein, G. (2001). Decision Skills Training: Facilitating Learning from Experience. In Salas, E. \& Klein, G. Eds. Linking Expertise and Naturalistic Decision Making. Mahwah, NJ: Lawerance Erlbaum Associates. 37-53. 
Prastacos, G., Söderquist, K., Spanos, Y., \& Wassenhove. (2002). An Integrated Framework for Managing Change in the New Competitive Landscape.

European Management Journal. 20, Issue 1, 55-71.

Ranta, J. (1994). Evolution and Diffusion of Advanced Manufacturing Systems. In Karwowski, W., \& Salvendy, G. Eds. Organization and Management of Advanced Manufacturing. New York, NY: John Wiley \& Sons, Inc. 29-59.

Rasmussen, J. (2000). Human Factors in a Dynamic Information Society: Where Are We Heading? Ergonomics. 43, No 7, 869-879.

Rasmussen, J. (1994). Taxonomy for Work Analysis. In Salvendy, G. \& Karwowski, W. Eds. Design of Work and Development of Personnel in Advanced Manufacturing. New York, NY: Wiley Interscience.

Rasmussen, J. (1990). Use of Field Studies for Design of Work Stations for Integrated Manufacturing Systems. International Conference on Human Factors in Design for Manufacturability and Process Planning in August 1990. International Ergonomics Association. Honolulu.

Rasmussen, J., Pejtersen, A.M., Schmidt, K. (1990). Taxonomy for Cognitive Work Analysis. Ris $\varnothing-M-2871$. Ris $\varnothing$ National Laboratory. Roskilde.

Rasmussen, J. (1986). Information Processing and Human-Machine Interaction An Approach to Cognitive Engineering. Amsterdam: North Holland.

Repetti, R. L. (1987). Individual and Common Components of the Social Environment At Work and Psychological Well-Being. Journal of Personality and Social Psychology. 52, No 4, 710-720.

Rogers, E.W. (2004). The Effect of Perceptions of the Employment Game on Cooperative Knowledge Behavior in High-tech Firms. The Journal of High Technology Management Research. 15, Issue 1, 17-36.

Ross, C.E., and Van Willigen, M. (1997). Education and the Subjective Quality of Life. Journal of Health and Social Behavior. 38, No.3, 275-297.

Schmidt, K. (1990). Analysis of Cooperative Work: A Conceptual Framework. Ris $\varnothing-M-2890$. Ris $\varnothing$ National Laboratory. Roskilde.

Schmidt, K. (2000). Distributed Collective Practices: A CSCW Perspective. Conference on Distributed Collective Practices.. September 19-22, 2000. Paris.

Schultz, K. L., McClain, J. O., \& Thomas, L. J. (2003). Overcoming the Dark Side of Worker Flexibility. Journal of Operations Management. 21, Issue 1, 81-92. 
Seamster, T. L., Redding, R. E., \& Kaempf, G. L. (2000). A Skill-Based Cognitive Task Analysis Framework. In Schraagen, J. M., Chipman, S. F., \& Shalin, V. L. Eds. Cognitive Task Analysis. Mahwah, NJ: Lawrence Erlbaum Associates. 135-146.

Stanton, N. A., \& Ashleigh, M. J. (2000). A Field Study of Team Working in a New Human Supervisory Control System. Ergonomics. 43, No 8, 1190-1209.

Stanton, N. A., \& Stevenage, S. V. (1998). Learning to Predict Human Error: Issues Of Acceptability, Reliability, and Validity. Ergonomics. 41, No 11, 1737-1756.

Stock, G. N., \& McDermott, C. M. (2001). Organizational and Strategic Predictors of Manufacturing Technology Implementation Success: An Exploratory Study. Technovation. 21, Issue 10. 625-636.

Sümer, N. (2003). Personality and Behavioral Predictors of Traffic Accidents: Testing a Contextual Mediated Model. Accident, Analysis, \& Prevention. 35, Issue 6, 949-964.

Tiwari, M. K., \& Mondal, S. (2002). Application of an Autonomous Agent Network to Support the Architecture of a Holonic Manufacturing System. The International Journal of Advanced Manufacturing Technology. 20, 931-942.

Tomer, A., and Pugesek, B.H.. (2003). Structural Equation Modeling: An Introduction. In Pugesek, B.H., Tomer, A., and von Eye, A. Eds. Structural Equation Modeling: Applications in Ecology and Evolutionary Biology. Cambridge: University Press. 125-140.

Vicente, K. J. (1999). Cognitive Work Analysis: Toward Safe, Productive, and Healthy Computer-Based Work. Mahwah, NJ: Lawrence Erlbaum Associates.

Vicente, K. J. (2000). Work Domain Analysis and Task Analysis: A Difference That Matters. In Schraagen, J. M., Chipman, S. F., \& Shalin, V. L. Eds. Cognitive Task Analysis. Mahwah, NJ: Lawrence Erlbaum Associates. 101-118.

Vicente, K. J. (2001). Cognitive Engineering Research at Risø from 1962-1979. In Salas, E., Ed. Advances in Human Performance and Cognitive Engineering Research. Kidlington, UK: Elsevier Science Ltd. 1, 1-57.

Wagner, J. A. III, Leana, C. R., Locke, E. A. \& Schweiger, D. M. (1997). Cognitive And Motivational Frameworks in U.S. Research on Participation: A Meta-analysis Of Primary Effects. Journal of Organizational Behavior. 18, 49-65.

Wei, J. \& Salvendy, G. (2000). Development of The Purdue Cognitive Job Analysis Methodology. International Journal of Cognitive Ergonomics. 4, No 4, 277-295. 
Whitbeck, L.B., Simons, R.L., Conger, R.D., Wickrama, S.A.S., Ackley, K.A., and Elder, G.H. (1997). The Effects of Parents' Working Conditions and Family Economic Hardship on Parenting Behaviors and Childrens' Self-Efficacy. Social Psychology Quarterly. 60, No.4, 291-303.

Wickrama, K.A.S., Lorenz, F.O., Conger, R.D., Matthews, L., and Elder, G.H. (1997). Linking Occupational Conditions to Physical Health through Marital, Social, and Intrapersonal Processes. Journal of Health and Social Behavior. 38, No.4, 363-375.

Williams, L.J., Edwards, J.R., and Vandenberg, R.J. (2003). Recent Advances in Causal Modeling Methods for Organizational and Management Research. Journal of Management. 29, Issue 6, 903-936.

Wilson, J. R., Koubek, R. J., Salvendy, G., Sharit, J., \& Karwowski, W. (1994). Human Factors in Advanced Manufacturing: A Review and Reappraisal. In Karwowski, W., \& Salvendy, G. Eds. Organization and Management of Advanced Manufacturing. New York, NY: John Wiley \& Sons, Inc. 379-415.

Wilson, M. (2002). Six View of Embodied Cognition. Psychonomic Bulletin and Review. 9, No 4, 625-636.

Wobbe, W., \& Charles, T. (1994). Human Roles in Advanced Manufacturing Technology. In Karwowski, W., \& Salvendy, G. Eds. Organization and Management of Advanced Manufacturing. New York, NY: John Wiley \& Sons, Inc. 61-79.

Wong, W.B.L., Sallis, P.J., \& O'Hare, D. (1998). The Ecological Approach to Interface Design: Applying the Abstraction Hierarchy to Intentional Domains. In the Eigth Australian Conference on Computer-Human Interaction OzCHI'98. IEEE Computer Society Press. Adelaide.

Xie, B. \& Salvendy, G. (2000). Prediction of Mental Workload in Single and Multiple Tasks Environments. International Journal of Cognitive Ergonomics. 4, No 3, 213-242.

Yuan, K.H. and Bentler, P.M. (2000). Three Likelihood-Based Methods for Mean and Covariance Structure Analysis with Nonnormal Missing Data. Sociological Methodology. 30, 165-200. 
APPENDIX A. Quality of Work Life Questionnaire Items (3 pages) 
Team Work:

1. People feel like they belong where I work ${ }^{\mathrm{a}}$

2. I have a great deal in common with most people ${ }^{a}$

3. The people I work with help each other out when someone falls behind or gets in a

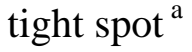

4. The people I work with get along well together ${ }^{a}$

5. My boss gets employees to work together as a team ${ }^{\text {a }}$

6. Coworkers help each other out ${ }^{b}$

7. Coworkers treat each other with respect ${ }^{b}$

8. To what degree are you satisfied with the chance to do things with other people ${ }^{c}$

9. To what degree are you satisfied with the chance to work alone ${ }^{\mathrm{c}}$

10. To what degree are you satisfied with the way my co-workers get along with each other $^{\mathrm{c}}$

Supervision:

1. Management does everything possible to prevent accidents in our work ${ }^{a}$

2. Management is doing its best to give us good working conditions ${ }^{\text {a }}$

3. Management here is really trying to build the organization and make it successful ${ }^{\mathrm{a}}$

4. I have a great deal of interest in this company and its future ${ }^{a}$

5. My boss has always been fair in his dealings with me ${ }^{a}$

6. Your supervisor considered your viewpoint ${ }^{\mathrm{d}}$

7. Your supervisor was able to suppress personal biases ${ }^{\mathrm{d}}$

8. Your supervisor took steps to deal with you in a truthful manner ${ }^{d}$

9. My organization really cares about my well-being ${ }^{\mathrm{e}}$

10. My organization would forgive an honest mistake on my part ${ }^{\mathrm{e}}$

11. Employees are treated with respect ${ }^{b}$

12. Employees are treated fairly ${ }^{\mathrm{b}}$

13. To what degree are you satisfied with my supervisor's competence in making decisions $^{\mathrm{c}}$

14. How much can you supervisor be relied on when things get tough at work ${ }^{\mathrm{f}}$

\section{Empowerment:}

1. My job gives me a chance to do what I do best ${ }^{\mathrm{a}}$

2. My boss sees that we have the things we need to do our jobs ${ }^{\text {a }}$

3. I have little opportunity to use my abilities in this organization ${ }^{\text {a }}$

4. I have the right equipment to do my job ${ }^{\mathrm{a}}$

5. Does your job give you a chance to do things you feel you do best ${ }^{a}$

6. To what degree are you satisfied with the chance to make the use of my abilities ${ }^{c}$

7. Job flexibility will lead to a chance to use all the skills you want to ${ }^{\mathrm{g}}$

8. Job flexibility will lead to being able to do more varied work on a day-to-day basis ${ }^{\mathrm{g}}$

\section{Job Satisfaction:}

1. I am satisfied with the work I do ${ }^{\text {a }}$

2. I am often bothered by sudden speedups or unexpected slack periods in my work ${ }^{\mathrm{a}}$ 
3. Changes are made here with little regard for the welfare of employees ${ }^{\text {a }}$

4. How well do your like the sort of work you are doing ${ }^{\text {a }}$

5. How do you feel about your work, does it rate as an important job with you ${ }^{a}$

6. I feel fairly well satisfied with my job ${ }^{\text {a }}$

7. Most of the time I have to force myself to go to work ${ }^{a}$

8. I am satisfied with my job for the time being ${ }^{a}$

9. I definitely dislike my work ${ }^{\mathrm{a}}$

10. I like my job better than the average worker does ${ }^{\text {a }}$

11. If a good friend of mine told me that he/she was interested in working in a job like mine I would strongly recommend it ${ }^{\mathrm{e}}$

12. All in all, I am very satisfied with my current job ${ }^{\mathrm{e}}$

13. Knowing what I know now, if I had to decide all over again whether to take my job, I would $^{\mathrm{e}}$

14. In general, my job measures up to the sort of job I wanted when I took it ${ }^{\mathrm{e}}$

15. Job flexibility will lead to greater stress ${ }^{\mathrm{g}}$

16. Job flexibility will lead to more job satisfaction ${ }^{\mathrm{g}}$

17. The work is usually very interesting ${ }^{f}$

18. I frequently think of quitting this job ${ }^{\mathrm{f}}$

19. I am generally satisfied with the kind of work I do in this job ${ }^{f}$

Learning:

1. I tend to get bored on the job ${ }^{\text {a }}$

2. My boss sees that employees are properly trained for their jobs ${ }^{\text {a }}$

3. I can learn a great deal on my present job ${ }^{\mathrm{a}}$

4. My job is usually interesting enough to keep me from getting bored ${ }^{a}$

5. I feel that my job is no more interesting than others I could get ${ }^{\mathrm{a}}$

6. My job requires that I keep learning new things ${ }^{\mathrm{h}}$

7. To what degree are you satisfied with the chance to do different things ${ }^{c}$

8. To what degree are you satisfied with the chance to try my own methods ${ }^{c}$

9. Job flexibility will lead to people having too much to learn ${ }^{\mathrm{g}}$

10. I want my work to provide me with opportunities for increasing my knowledge and skills ${ }^{\mathrm{j}}$

11. No matter what the outcome of a project, I am satisfied if I feel I gained a new experience $^{\mathrm{j}}$

12. The work is really challenging ${ }^{f}$

\section{Autonomy:}

1. I would like more freedom on the job ${ }^{a}$

2. I have too small a share in deciding matters that affect my work ${ }^{\text {a }}$

3. When I make plans, I am almost certain that I can make them work ${ }^{a}$

4. My boss is always breathing down our necks, he watches us too closely ${ }^{\text {a }}$

5. I have plenty of freedom on the job to use my own judgement ${ }^{\text {a }}$

6. My job requires a high level of skills ${ }^{h}$

7. My job requires that I do the same things over and over ${ }^{\mathrm{h}}$

8. I have a lot of say about what happens on my job ${ }^{\mathrm{h}}$

9. I am given a lot of freedom to decide how I do my own work ${ }^{\mathrm{h}}$ 
10. You decide on your own how to go about doing the work ${ }^{\mathrm{k}}$

11. To what degree are you satisfied with the freedom to use my own judgement ${ }^{\mathrm{c}}$

12. Job flexibility will lead to having more say in how you do your work ${ }^{\mathrm{g}}$

13. I'm more comfortable when I can set my own goals ${ }^{j}$

\section{Status:}

1. The future looks very bright to $\mathrm{me}^{\mathrm{a}}$

2. My boss gives us credit and praise for work well done ${ }^{a}$

3. The job security is good ${ }^{\mathrm{h}}$

4. Employees are praised for good work ${ }^{\mathrm{b}}$

5. Employees' hard work is appreciated ${ }^{\mathrm{b}}$

6. To what degree are you satisfied with the praise I get for doing my job ${ }^{c}$

7. I am strongly motivated by the recognition I can earn ${ }^{j}$

8. I want other people to find out how good I really can be at my work ${ }^{j}$

9. I believe that there is no point in doing a good job if nobody else knows about it ${ }^{j}$

\section{Efficacy:}

1. There is too little variety in my job ${ }^{\text {a }}$

2. My job means more to me than just money ${ }^{a}$

3. I seem to be marking time these days ${ }^{\text {a }}$

4. There is much purpose to what I am doing at present ${ }^{\mathrm{a}}$

5. Sometimes I feel that my job counts for very little in this organization ${ }^{a}$

6. I'm really doing something worthwhile in my job ${ }^{\mathrm{a}}$

7. Do you get any feeling of accomplishment from the work you are doing a

8. To what degree are you satisfied with the feeling of accomplishment I get ${ }^{\mathrm{c}}$

9. I want to find out how good I really can be at my work ${ }^{j}$

10. I'm less concerned with what work I do than what I get for it $^{\mathrm{j}}$

Notes: The above items were taken or modified from the following referenced literature.

a Miller, D. C. (1991)

b Donavan, M. A., Drasgow, F., \& Munson, L. J. (1998)

c Moorman, R. H. (1993)

d Moorman, R. H. (1991)

e Eisenberger, R., Cummings, J., Armeli, S., \& Lynch, P. (1997)

f Repetti, R. L. (1987)

g Cordery, J., Sevastos, P., Mueller, W., \& Parker, S. (1993)

h Fenwick, R., \& Tausig, M. (1994)

j Amabile, T. M., Hill, K. G., Hennessey, B. A., \& Tighe, E. M. (1994)

k Lennon, M. C. (1994) 
Appendix B. Quality of work life Questionnaire QWL-1 (2 pages) 
Identifier:

The Quality of Work Life Survey: QWL-1

Date:

The following survey ask you questions about your work. Please darken the circle that best represents your response.

Rate your level of satisfaction or dissatisfaction with the following typical workday situations.

\begin{tabular}{|c|c|c|c|c|c|c|}
\hline & & $\begin{array}{l}\text { Extremely } \\
\text { Satisfied }\end{array}$ & $\begin{array}{l}\text { Somewhat } \\
\text { Satisfied }\end{array}$ & Undecided & $\begin{array}{l}\text { Somewhat } \\
\text { Dissatisfied }\end{array}$ & $\begin{array}{c}\text { Extremely } \\
\text { Dissatisfied }\end{array}$ \\
\hline TW10 & $\begin{array}{l}\text { To what degree are you satisfied with the way } \\
\text { your co-workers get along with each other }\end{array}$ & 0 & 0 & O & O & O \\
\hline$\overline{\text { AT11 }}$ & $\begin{array}{l}\text { To what degree are you satisfied with the freedom } \\
\text { to use your own judgement }\end{array}$ & 0 & 0 & 0 & 0 & 0 \\
\hline EF08 & $\begin{array}{l}\text { To what degree are you satisfied with the feeling } \\
\text { of accomplishment you get }\end{array}$ & 0 & O & 0 & O & 0 \\
\hline LN08 & $\begin{array}{l}\text { To what degree are you satisfied with the chance } \\
\text { to try your own methods }\end{array}$ & 0 & O & O & O & O \\
\hline EP06 & $\begin{array}{l}\text { To what degree are you satisfied with the chance } \\
\text { to make the use of your abilities }\end{array}$ & O & O & O & 0 & O \\
\hline TW08 & $\begin{array}{l}\text { To what degree are you satisfied with the chance } \\
\text { to do things with other people }\end{array}$ & 0 & O & O & 0 & 0 \\
\hline
\end{tabular}

Rate your level of agreement or disagreement with the following typical workday situations.

\begin{tabular}{|c|c|c|c|c|c|c|}
\hline & & $\begin{array}{l}\text { Strongly } \\
\text { Disagree }\end{array}$ & Disagree & Undecided & Agree & $\begin{array}{l}\text { Strongly } \\
\text { Agree }\end{array}$ \\
\hline SP08 & $\begin{array}{l}\text { Your supervisor took steps to deal with you in a } \\
\text { truthful manner }\end{array}$ & O & O & O & O & O \\
\hline SP06 & Your supervisor considered your viewpoint & O & O & ○ & O & O \\
\hline LN12 & The work is really challenging & 0 & $\mathrm{O}$ & O & O & O \\
\hline TW04 & The people I work with get along well together & $\bigcirc$ & 0 & 0 & $\bigcirc$ & $\bigcirc$ \\
\hline$\overline{\text { EF05 }}$ & $\begin{array}{l}\text { Sometimes I feel that my job counts for very little } \\
\text { in this organization }\end{array}$ & O & $\mathrm{O}$ & O & O & O \\
\hline SP10 & $\begin{array}{l}\text { My organization would forgive an honest mistake } \\
\text { on my part }\end{array}$ & O & O & 0 & O & O \\
\hline LN06 & My job requires that I keep learning new things & O & O & $\bigcirc$ & O & O \\
\hline AT06 & My job requires a high level of skills & 0 & 0 & O & O & O \\
\hline$\overline{\text { EF02 }}$ & My job means more to me than just money & 0 & 0 & 0 & 0 & $\bigcirc$ \\
\hline$\overline{\mathrm{LN} 04}$ & $\begin{array}{l}\text { My job is usually interesting enough to keep me } \\
\text { from getting bored }\end{array}$ & O & $\mathrm{O}$ & O & O & O \\
\hline EP02 & $\begin{array}{l}\text { My boss sees that we have the things we need to } \\
\text { do our jobs }\end{array}$ & 0 & 0 & 0 & $\bigcirc$ & $\bigcirc$ \\
\hline LN02 & $\begin{array}{l}\text { My boss sees that employees are properly trained } \\
\text { for their jobs }\end{array}$ & O & 0 & 0 & $\bigcirc$ & O \\
\hline$\overline{\text { AT04 }}$ & $\begin{array}{l}\text { My boss is always breathing down our necks, he } \\
\text { watches us too closely }\end{array}$ & 0 & 0 & 0 & $\bigcirc$ & $\bigcirc$ \\
\hline JS07 & $\begin{array}{l}\text { Most of the time I have to force myself to go to } \\
\text { work }\end{array}$ & 0 & 0 & 0 & $\bigcirc$ & $\bigcirc$ \\
\hline SP02 & $\begin{array}{l}\text { Management is doing its best to give us good } \\
\text { working conditions }\end{array}$ & 0 & 0 & 0 & 0 & 0 \\
\hline JS16 & Job flexibility will lead to more job satisfaction & $\bigcirc$ & $\mathrm{O}$ & O & O & O \\
\hline
\end{tabular}

Page 1 of 2 
The Quality of Work Life Survey: QWL-1

The following survey ask you questions about your work. Please darken the circle that best represents your response.

Rate your level of agreement or disagreement with the following typical workday situations.

\begin{tabular}{|c|c|c|c|c|c|c|}
\hline & & $\begin{array}{l}\text { Strongly } \\
\text { Disagree }\end{array}$ & Disagree & Undecided & Agree & $\begin{array}{c}\text { Strongly } \\
\text { Agree }\end{array}$ \\
\hline EP08 & $\begin{array}{l}\text { Job flexibility will lead to being able to do more } \\
\text { varied work on a day-to-day basis }\end{array}$ & ○ & ○ & $\bigcirc$ & O & O \\
\hline JS14 & $\begin{array}{l}\text { In general, my job measures up to the sort of job I } \\
\text { wanted when I took it }\end{array}$ & O & O & ○ & O & O \\
\hline ST06 & I'm satisfied with the praise I get for doing my job & $\bigcirc$ & O & O & O & O \\
\hline EF06 & I'm really doing something worthwhile in my job & $\bigcirc$ & $\bigcirc$ & $\bigcirc$ & $\bigcirc$ & $\bigcirc$ \\
\hline AT13 & $\begin{array}{l}\text { I'm more comfortable when I can set my own } \\
\text { goals }\end{array}$ & $\bigcirc$ & $\bigcirc$ & $\bigcirc$ & $\bigcirc$ & $\bigcirc$ \\
\hline EF10 & $\begin{array}{l}\text { I'm less concerned with what work I do than what } \\
\text { I get for it }\end{array}$ & $\bigcirc$ & $\bigcirc$ & O & $\bigcirc$ & O \\
\hline ST08 & $\begin{array}{l}\text { I want other people to find out how good I really } \\
\text { can be at my work }\end{array}$ & $\bigcirc$ & $\bigcirc$ & $\bigcirc$ & $\bigcirc$ & $\bigcirc$ \\
\hline LN10 & $\begin{array}{l}\text { I want my work to provide me with opportunities } \\
\text { for increasing my knowledge and skills }\end{array}$ & ○ & ○ & O & $\bigcirc$ & $\bigcirc$ \\
\hline JS10 & I like my job better than the average worker does & $\bigcirc$ & $\bigcirc$ & O & O & O \\
\hline AT02 & $\begin{array}{l}\text { I have too small a share in deciding matters that } \\
\text { affect my work }\end{array}$ & O & ○ & ○ & O & ○ \\
\hline SP04 & $\begin{array}{l}\text { I have a great deal of interest in this company and } \\
\text { its future }\end{array}$ & $\bigcirc$ & O & 0 & $\bigcirc$ & $\bigcirc$ \\
\hline TW02 & I have a great deal in common with most people & $\bigcirc$ & $\bigcirc$ & ○ & O & O \\
\hline JS18 & I frequently think of quitting this job & $\bigcirc$ & O & O & $\bigcirc$ & $\bigcirc$ \\
\hline JS06 & I feel fairly well satisfied with my job & $\bigcirc$ & $\bigcirc$ & $\bigcirc$ & $\bigcirc$ & $\bigcirc$ \\
\hline ST09 & $\begin{array}{l}\text { I believe that there is no point in doing a good job } \\
\text { if nobody else knows about it }\end{array}$ & $\bigcirc$ & $\bigcirc$ & O & O & O \\
\hline JS02 & $\begin{array}{l}\text { I am often bothered by sudden speedups or } \\
\text { unexpected slack periods in my work }\end{array}$ & $\bigcirc$ & $\bigcirc$ & $\bigcirc$ & $\bigcirc$ & O \\
\hline AT09 & $\begin{array}{l}\text { I am given a lot of freedom to decide how I do my } \\
\text { own work }\end{array}$ & O & O & ○ & O & ○ \\
\hline JS04 & I like the sort of work I am are doing & O & O & ○ & $\bigcirc$ & O \\
\hline SP14 & $\begin{array}{l}\text { My supervisor can be relied on when things get } \\
\text { tough at work }\end{array}$ & O & O & O & $\bigcirc$ & O \\
\hline ST05 & Employees' hard work is appreciated & O & O & ○ & O & O \\
\hline SP12 & Employees are treated fairly & $\bigcirc$ & O & O & O & O \\
\hline ST04 & Employees are praised for good work & $\bigcirc$ & $\bigcirc$ & ○ & O & O \\
\hline EP05 & $\begin{array}{l}\text { My job give me a chance to do things I feel I do } \\
\text { best }\end{array}$ & $\bigcirc$ & $\bigcirc$ & $\bigcirc$ & $\bigcirc$ & $\bigcirc$ \\
\hline TW06 & Coworkers help each other out & O & $\bigcirc$ & O & $\bigcirc$ & O \\
\hline JS12 & All in all, I am very satisfied with my current job & $\bigcirc$ & O & $\bigcirc$ & ○ & O \\
\hline
\end{tabular}

Page 2 of 2 
Appendix C. Quality of work life Questionnaire QWL-2

(2 pages) 
Indentifier:

The Quality of Work Life Survey: QWL-2

Date:

The following survey ask you questions about your work. Please darken the circle that best represents your response.

Rate your level of satisfaction or dissatisfaction with the following typical workday situations.

\begin{tabular}{ll|c|c|c|c|} 
& & $\begin{array}{c}\text { Extremely } \\
\text { Satisfied }\end{array}$ & $\begin{array}{c}\text { Somewhat } \\
\text { Satisfied }\end{array}$ & Undecided & $\begin{array}{c}\text { Somewhat } \text { Dissatisfied } \\
\text { Dissatisfied }\end{array}$ \\
\hline TW09 $\begin{array}{c}\text { To what degree are you satisfied with the chance } \\
\text { to work alone }\end{array}$ & 0 & 0 & 0 & 0 \\
\hline $\begin{array}{l}\text { To what degree are you satisfied with the chance } \\
\text { to do different things }\end{array}$ & 0 & 0 & 0 & 0 \\
\hline SP13 & $\begin{array}{l}\text { To what degree are you satisfied with your } \\
\text { supervisor's competence in making decisions }\end{array}$ & 0 & 0 & 0 & 0 \\
\hline
\end{tabular}

Rate your level of agreement or disagreement with the following typical workday situations.

\begin{tabular}{|c|c|c|c|c|c|c|}
\hline & & $\begin{array}{l}\text { Strongly } \\
\text { Disagree }\end{array}$ & Disagree & Undecided & Agree & $\begin{array}{l}\text { Strongly } \\
\text { Agree }\end{array}$ \\
\hline SP07 & $\begin{array}{l}\text { Your supervisor is able to suppress personal } \\
\text { biases }\end{array}$ & O & ○ & $\bigcirc$ & $\bigcirc$ & O \\
\hline AT10 & $\begin{array}{l}\text { You decide on your own, how to go about doing } \\
\text { the work }\end{array}$ & ○ & ○ & O & ○ & $\bigcirc$ \\
\hline AT03 & $\begin{array}{l}\text { When I make plans, I am almost certain that I can } \\
\text { make them work }\end{array}$ & $\bigcirc$ & $\bigcirc$ & $\bigcirc$ & $\bigcirc$ & $\bigcirc$ \\
\hline EF01 & There is too little variety in my job & O & O & O & O & O \\
\hline EF04 & $\begin{array}{l}\text { There is much purpose to what I am doing at } \\
\text { present }\end{array}$ & $\bigcirc$ & $\bigcirc$ & $\bigcirc$ & $\bigcirc$ & $\bigcirc$ \\
\hline JS17 & The work is usually very interesting & O & ○ & O & O & O \\
\hline TW03 & $\begin{array}{l}\text { The people I work with help each other out when } \\
\text { someone falls behind or gets in a tight spot }\end{array}$ & $\bigcirc$ & $\bigcirc$ & $\bigcirc$ & $\bigcirc$ & $\bigcirc$ \\
\hline ST03 & The job security is good & $\bigcirc$ & $\bigcirc$ & $\bigcirc$ & $\bigcirc$ & $\bigcirc$ \\
\hline ST01 & The future looks very bright to me & $\bigcirc$ & $\bigcirc$ & $\bigcirc$ & $\bigcirc$ & $\bigcirc$ \\
\hline TW01 & People feel like they belong where I work & O & O & O & ○ & O \\
\hline LN11 & $\begin{array}{l}\text { No matter what the outcome of a project, I am } \\
\text { satisfied if I feel I gained a new experience }\end{array}$ & $\bigcirc$ & $\bigcirc$ & $\bigcirc$ & $\bigcirc$ & $\bigcirc$ \\
\hline SP09 & My organization really cares about my well-being & $\bigcirc$ & $\bigcirc$ & $\bigcirc$ & $\bigcirc$ & $\bigcirc$ \\
\hline AT07 & $\begin{array}{l}\text { My job requires that I do the same things over } \\
\text { and over }\end{array}$ & $\bigcirc$ & O & 0 & 0 & 0 \\
\hline EP01 & My job gives me a chance to do what I do best & $\bigcirc$ & $\bigcirc$ & $\bigcirc$ & $\bigcirc$ & $\bigcirc$ \\
\hline SP05 & $\begin{array}{l}\text { My boss has always been fair in his dealings with } \\
\text { me }\end{array}$ & $\bigcirc$ & 0 & 0 & 0 & 0 \\
\hline ST02 & $\begin{array}{l}\text { My boss gives us credit and praise for work well } \\
\text { done }\end{array}$ & O & $\bigcirc$ & $\bigcirc$ & O & $\bigcirc$ \\
\hline TW05 & $\begin{array}{l}\text { My boss gets employees to work together as a } \\
\text { team }\end{array}$ & 0 & 0 & 0 & 0 & 0 \\
\hline SP03 & $\begin{array}{l}\text { Management here is really trying to build the } \\
\text { organization and make it successful }\end{array}$ & $\bigcirc$ & $\bigcirc$ & $\bigcirc$ & O & $\bigcirc$ \\
\hline SP01 & $\begin{array}{l}\text { Management does everything possible to prevent } \\
\text { accidents in our work }\end{array}$ & $\bigcirc$ & $\bigcirc$ & $\bigcirc$ & $\bigcirc$ & $\bigcirc$ \\
\hline
\end{tabular}

Page 1 of 2 
The Quality of Work Life Survey: QWL-2

The following survey ask you questions about your work. Please darken the circle that best represents your response.

Rate your level of agreement or disagreement with the following typical workday situations.

\begin{tabular}{|c|c|c|c|c|c|c|}
\hline & & $\begin{array}{l}\text { Strongly } \\
\text { Disagree }\end{array}$ & Disagree & Undecided & Agree & $\begin{array}{l}\text { Strongly } \\
\text { Agree }\end{array}$ \\
\hline JS13 & $\begin{array}{l}\text { Knowing what I know now, if I had to decide all } \\
\text { over again whether to take my job, I would }\end{array}$ & O & O & $\bigcirc$ & $\bigcirc$ & $\bigcirc$ \\
\hline LN09 & $\begin{array}{l}\text { Job flexibility will lead to people having too much } \\
\text { to learn }\end{array}$ & O & $\bigcirc$ & $\bigcirc$ & O & $\bigcirc$ \\
\hline$\overline{\text { AT12 }}$ & $\begin{array}{l}\text { Job flexibility will lead to having more say in how } \\
\text { you do your work }\end{array}$ & O & $\bigcirc$ & $\bigcirc$ & O & O \\
\hline JS15 & Job flexibility will lead to greater stress & O & O & O & O & $\bigcirc$ \\
\hline EP07 & $\begin{array}{l}\text { Job flexibility will lead to a chance to use all the } \\
\text { skills you want to }\end{array}$ & O & $\mathrm{O}$ & O & $\mathrm{O}$ & O \\
\hline JS11 & $\begin{array}{l}\text { If a good friend of mine told me that he/she was } \\
\text { interested in working in a job like mine I would } \\
\text { strongly recommend it }\end{array}$ & O & $\mathrm{O}$ & O & O & O \\
\hline AT01 & I would like more freedom on the job & O & $\bigcirc$ & O & O & $\bigcirc$ \\
\hline EF09 & $\begin{array}{l}\text { I want to find out how good I really can be at my } \\
\text { work }\end{array}$ & $\mathrm{O}$ & O & O & O & $\mathrm{O}$ \\
\hline LN01 & I tend to get bored on the job & O & $\mathrm{O}$ & O & O & O \\
\hline EF03 & I seem to be marking time these days & O & O & O & $\mathrm{O}$ & $\bigcirc$ \\
\hline EP04 & I have the right equipment to do my job & $\bigcirc$ & $\bigcirc$ & $\bigcirc$ & O & $\bigcirc$ \\
\hline AT05 & $\begin{array}{l}\text { I have plenty of freedom on the job to use my own } \\
\text { judgement }\end{array}$ & O & O & O & $\mathrm{O}$ & O \\
\hline EP03 & $\begin{array}{l}\text { I have little opportunity to use my abilities in this } \\
\text { organization }\end{array}$ & O & $\bigcirc$ & O & O & $\mathrm{O}$ \\
\hline$\overline{\text { AT08 }}$ & I have a lot of say about what happens on my job & O & $\bigcirc$ & $\bigcirc$ & O & $\bigcirc$ \\
\hline LN05 & $\begin{array}{l}\text { I feel that my job is no more interesting than } \\
\text { others I could get }\end{array}$ & O & $\mathrm{O}$ & $\mathrm{O}$ & O & $\mathrm{O}$ \\
\hline JS09 & I definitely dislike my work & O & $\bigcirc$ & $\bigcirc$ & 0 & $\bigcirc$ \\
\hline LN03 & I can learn a great deal on my present job & O & O & O & O & $\bigcirc$ \\
\hline ST07 & $\begin{array}{l}\text { I am strongly motivated by the recognition I can } \\
\text { earn }\end{array}$ & 0 & 0 & 0 & 0 & 0 \\
\hline JS01 & I am satisfied with the work I do & O & O & O & O & $\bigcirc$ \\
\hline JS08 & I am satisfied with my job for the time being & 0 & $\bigcirc$ & O & O & O \\
\hline JS19 & $\begin{array}{l}\text { I am generally satisfied with the kind of work I do } \\
\text { in this job }\end{array}$ & 0 & 0 & 0 & 0 & 0 \\
\hline JS05 & My work rates as an important job with me & O & O & O & O & O \\
\hline SP11 & Employees are treated with respect & 0 & 0 & 0 & 0 & $\bigcirc$ \\
\hline EF07 & $\begin{array}{l}\text { I get a feeling of accomplishment from the work I } \\
\text { am doing }\end{array}$ & O & $\bigcirc$ & $\bigcirc$ & $\mathrm{O}$ & $\bigcirc$ \\
\hline TW07 & Coworkers treat each other with respect & O & $\mathrm{O}$ & O & O & $\mathrm{O}$ \\
\hline JS03 & $\begin{array}{l}\text { Changes are made here with little regard for the } \\
\text { welfare of employees }\end{array}$ & O & $\bigcirc$ & O & O & O \\
\hline
\end{tabular}

Page 2 of 2 
Appendix D. Cognitive Task Analysis Data Collection Form

(1 page) 


\begin{tabular}{|c|c|c|c|c|c|c|}
\hline & \begin{tabular}{|l|} 
Activity Attributes \\
\end{tabular} & Task: & Cues, Strateqy, \& Recovery & Error Mechanism/ Why Diffficult: & Consequences: & Step \\
\hline \multicolumn{7}{|l|}{ Activity Attribute Taxonomy } \\
\hline \multicolumn{7}{|l|}{ 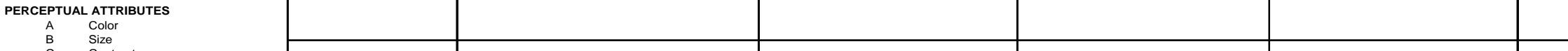 } \\
\hline & & & & & & \\
\hline $\begin{array}{cl}F & \text { Vigilance Decrement } \\
G & \text { AAtention } \\
\text { S Sittion }\end{array}$ & & & & & & \\
\hline & & & & & & \\
\hline \multicolumn{7}{|l|}{$\begin{array}{c}\text { PROCESSING ATTRRBIUTES } \\
\text { K } \begin{array}{c}\text { Reacll } \\
\text { Detection }\end{array}\end{array}$} \\
\hline \multicolumn{7}{|l|}{$\begin{array}{l}\text { Rate of Movement } \\
\text { Motor Control } \\
\text { Time Pressure }\end{array}$} \\
\hline \multicolumn{7}{|l|}{ 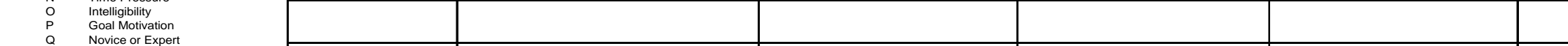 } \\
\hline \multicolumn{7}{|l|}{$\begin{array}{ll}\mathrm{R} & \text { Age } \\
\mathrm{S} & \text { Time Available for Viewing }\end{array}$} \\
\hline \multicolumn{7}{|l|}{$\begin{array}{l}\text { ACTION ATTRRBBUTES } \\
\text { TAction too short long }\end{array}$} \\
\hline \multicolumn{7}{|l|}{$\begin{array}{ll}\mathrm{u} & \text { Action mistimed } \\
\mathrm{v} & \text { Action in wrong direction } \\
\mathrm{w} & \text { Action to little/ much }\end{array}$} \\
\hline \multicolumn{7}{|l|}{ 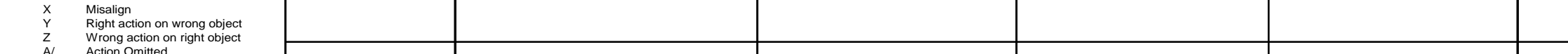 } \\
\hline \multicolumn{7}{|l|}{$\begin{array}{l}\text { A } \\
\text { B Action Omitted } \\
\text { Action Incomplete }\end{array}$} \\
\hline \multicolumn{7}{|l|}{ CHECKING ATTRIBUTES } \\
\hline \multicolumn{7}{|l|}{$\begin{array}{ll}\text { D/ } & \text { Checking Omitted } \\
\text { E/I } & \text { Checking Inomplete } \\
\text { F/ } & \text { Right check on wrong object }\end{array}$} \\
\hline & & & & & & \\
\hline \multicolumn{7}{|l|}{$\begin{array}{l}\text { RETRIEVAL ATTRIBUTES } \\
V \\
\text { Intormation not obtained }\end{array}$} \\
\hline $\begin{array}{l}\text { W/ } \\
\mathrm{K} /\end{array}$ & $\begin{array}{l}\text { Human Cognition } \\
\text { Indexed Variable: } \\
\end{array}$ & Accumulation of Activity Attribute Types: & $\begin{array}{l}\text { Normalized Accumulated Attribute } \\
\text { Percentage: } \\
\end{array}$ & $\begin{array}{l}\text { System Outcomes Tabulated } \\
\text { Variables: }\end{array}$ & Number of Observed Steps: & \\
\hline SELECTION ATTRIBUTTES & Task Variety & $A+B+C+D+E+F+G+H+1$ & 0.000 & & (1) & \\
\hline $\begin{array}{ll}\stackrel{L}{L} & \text { Selection omitted } \\
\text { M/ } & \text { Wrong selection made }\end{array}$ & $\begin{array}{l}\text { Task Complexity } \\
\text { Worker Adaxtability }\end{array}$ & 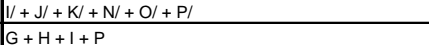 & 0.000 & $\begin{array}{l}\text { Quality yrrors }(0-5): \\
\text { Cost }(0-150 \%):\end{array}$ & $\begin{array}{l}\text { Wave No/ Date: } \\
\text { Location: }\end{array}$ & \\
\hline & Worker Flexibility & $L+M+Q+R$ & & Schedule Duration $(0-150 \%)$ : & Subject Name: & \\
\hline TRANSMISSION ATTRIBUTES & \begin{tabular}{|l|l|l|l} 
Mental Workload \\
Decisipn-Making
\end{tabular} & $\frac{J+K+O+S}{J+K}$ & 0.000 & & 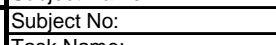 & \\
\hline $\begin{array}{l}\text { Intormation not transminited } \\
\text { Wrong information transmitted }\end{array}$ & $\begin{array}{l}\text { Decision-Making } \\
\text { Error-Making }\end{array}$ & 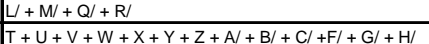 & & & Task Name: & \\
\hline PI Information transfer not complete & $\begin{array}{l}\text { Goal Motivation } \\
\text { Goulion }\end{array}$ & 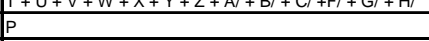 & 0.000 & & Data Name: & \\
\hline \multirow{2}{*}{ 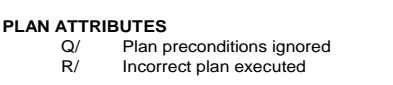 } & $\begin{array}{l}\text { Time Pressure } \\
\text { Stress Consideration }\end{array}$ & $\begin{array}{l}N+S+D /+E / \\
\text { visible psychological indication }\end{array}$ & & & \begin{tabular}{|l} 
(wave-subject) \\
Researcherci
\end{tabular} & \\
\hline & & visible psychological Indication & & & Page: & of \\
\hline
\end{tabular}


Appendix E. Structural Equation Model Evaluation Form (2 pages) 
Structural Equation Model Evaluation Form:

File Name:
Date:

Actual Sample Size:

Step 1. Model Specification:

Developing the structural and measurement forms of the model.

Step 2. Model Identification:

OK

d.f. $=$ no. of elements in sample cov matrix minus estimable model parameters

a. No. of elements in sample cov matrix -AMOS:

b. Estimable model parameters -AMOS:

c. d.f. (not less than zero) -AMOS:

Step 3. Examine Data for Adnormalities:

a. Sufficient Sample Size:

equals ( 4 to 20 ) X Step $2 b$. compared to Actual Sample Size:

b. Missing Data -SPSS:

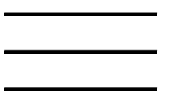

c. Reliability of Observed (independent) Data: Cronbach's Alpha of 0.8 "reasonably reliable": Actual Cronbach's Alpha -SPSS:

Actual Standardized Cronbach's Alpha -SPSS:

d. Multicolinearity of Observed (independent) Data:

List with values the inter-item correlations $(>=0.70)$-SPSS

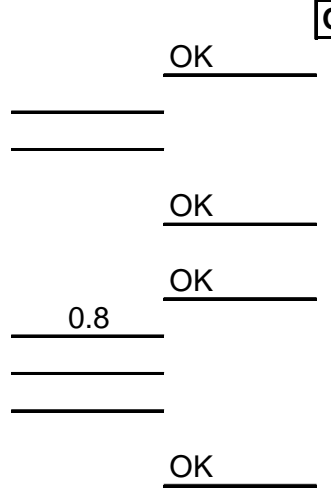

These items are suspect of multicolinearity.

e. Multivariate Skewness:

OK

List with values the Skewness ( $>=2.00)$-AMOS

These items are suspect of not exhibiting multivariate normality.

f. Multivariate Kurtosis:

List with values the Kurtosis (>=7.00) -AMOS

OK

These items are suspect of not exhibiting multivariate normality.

Step 4. Model Parameter Estimation:

a. Set up "Analysis Properties/ Estimation" -AMOS

Pick "Maximum Likelihood" as discrepancy function

up "Analysis Properties/ Numerical" - AMOS

Convergence Criteria, Crit 1 (0.001):

Convergence Criteria, Crit 2 (0.01):

Interation Limit $(10,000)$ :

c. List relevant standardized estimates with statistical significance indicated (standardized residual covariances or C.R. levels $>|1.96|(p=0.05)$ is significant) -AMOS

OK 
Step 5. Evaluate Model Goodness of Fit: Null Hypothesis is that estimated model covariance matrix equals the observed sample covariance matrix.

a. Evaluate Goodness of Fit Indices:

Index

Name:

Degree of freedom

Chi-square statistic

Chi-square statistic/d.f.

Goodness of Fit Index

Adjusted Goodness of Fit Index

Parsimony Goodness of Fit Index

Root Mean Sq. Error of Approx'n

Comparative Fit Index

Normed Fit Index

Tucker-Lewis Index

Incremental Fit Index

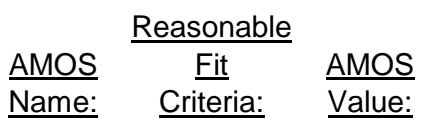

d.f.

CMIN

CMINDF

GFI

AGFI

PGFI

RMSEA

CFI

NFI

TLI

IFI
---

2:1 to $5: 1$

$>0.90$

$>0.90$

$>0.50$

$<0.08$

$>0.90$

$>0.90$

$>0.90$

$>0.90$
OK

AMOS

Cor

b. List relevant reliability estimates (squared multiple correlations) of the standardized path estimates -AMOS

OK

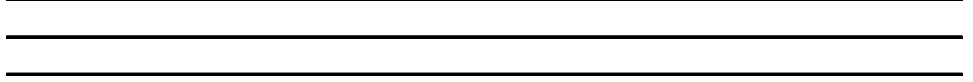

c. List relevant standardized residual covariance matrix items that indicate standardized residual covariances $>|3.00|$. Significant goodness of fit improvements may be obtained be assigning a parameter to the associated residual. -AMOS

OK



d. Accept or Reject Null Hypothesis (acceptance indicates good model fit):

Step 6. Model Respecification:

a. List relevant Modification Index suggestions with M.I. values that will tend to A or $\mathrm{R}$ lower the chi-square statistic. Make certain that the suggestions make theortical sense. -AMOS

$\underline{\mathrm{OK}}$

OK

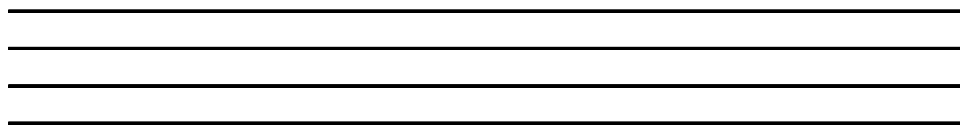

Step 7. Intrepret Results:

OK

a. Does overall model disconfirm the null hypothesis?

b. Are the model parameters for the structural paths statistically significant?

c. Are individual indicators sufficiently reliable?

d. Do the overall results for both the structural and measurement forms of the model make theoretical sense?

\begin{tabular}{l}
$\mathrm{Y}$ or $\mathrm{N}$ \\
\hline $\mathrm{Y}$ or $\mathrm{N}$ \\
\hline $\mathrm{Y}$ or $\mathrm{N}$ \\
\hline $\mathrm{Y}$ or $\mathrm{N}$ \\
\hline
\end{tabular}


Appendix F. SPSS Descriptive Statistics Output

For Model C

(3 pages) 
Case Processing Summary

\begin{tabular}{|ll|r|r|}
\hline & \multicolumn{1}{|c|}{$\mathrm{N}$} & \multicolumn{1}{c|}{$\%$} \\
\hline Cases & Valid & 205 & 100.0 \\
& Excluded & 0 & .0 \\
& Total & 205 & 100.0 \\
\hline
\end{tabular}

a. Listwise deletion based on all variables in the procedure.

Reliability Statistics

\begin{tabular}{|c|c|c|}
\hline $\begin{array}{c}\text { Cronbach's } \\
\text { Alpha }\end{array}$ & $\begin{array}{c}\text { Cronbach's } \\
\text { Alpha Based } \\
\text { on } \\
\text { Standardized } \\
\text { Items }\end{array}$ & $\mathrm{N}$ of Items \\
\hline .766 & .825 & 18 \\
\hline
\end{tabular}

Item Statistics

\begin{tabular}{|l|r|r|r|}
\hline & \multicolumn{1}{|c|}{ Mean } & Std. Deviation & \multicolumn{1}{l|}{$\mathrm{N}$} \\
\hline QUAL & 11.348780 & .8767481 & 205 \\
SCHE & 10.734146 & 1.0330826 & 205 \\
VARI & 17.531654 & 11.7113817 & 205 \\
COMP & 2.974698 & 6.1689547 & 205 \\
ADAP & 26.193146 & 17.6826868 & 205 \\
WORK & 13.976400 & 12.1895969 & 205 \\
DECI & 2.419249 & 6.9091850 & 205 \\
ERRO & 2.635429 & 2.3535106 & 205 \\
GOAL & 13.190732 & 23.4608176 & 205 \\
TIME & 7.742093 & 11.7478877 & 205 \\
TEAM & 2.097561 & .5360018 & 205 \\
SUPE & 2.064460 & .5291155 & 205 \\
EMPO & 2.193496 & .5433531 & 205 \\
JOBS & 2.315474 & .6023200 & 205 \\
LEAR & 2.281301 & .5332133 & 205 \\
AUTO & 2.419698 & .4864685 & 205 \\
STAT & 2.296098 & .6016802 & 205 \\
EFFI & 2.384390 & .5464235 & 205 \\
\hline
\end{tabular}


Inter-Item Correlation Matrix

\begin{tabular}{|c|c|c|c|c|c|c|c|c|c|c|c|c|c|c|c|c|c|c|}
\hline & QUAL & SCHE & VARI & COMP & ADAP & WORK & $\mathrm{DECl}$ & ERRO & GOAL & TIME & TEAM & SUPE & EMPO & JOBS & LEAR & AUTO & STAT & EFFI \\
\hline$\overline{\text { QUAL }}$ & 1.000 & .470 & -.190 & -.130 & -.176 & -.190 & -.060 & -.132 & -.107 & -.120 & .113 & .134 & .126 & .116 & $\begin{array}{l}.022 \\
\end{array}$ & .175 & .074 & .045 \\
\hline SCHE & .470 & 1.000 & -.144 & -.240 & -.111 & -.179 & -.076 & .009 & -.118 & -.056 & .158 & .189 & .075 & .102 & -.007 & .124 & -.011 & .059 \\
\hline VARI & -190 & -.144 & 1.000 & .137 & .752 & .576 & .143 & .437 & .328 & .289 & .090 & .087 & .150 & .135 & .203 & .143 & .129 & .010 \\
\hline COMP & -.130 & -.240 & .137 & 1.000 & .433 & .586 & .699 & .130 & .646 & .394 & -.051 & -.171 & -.192 & -.131 & -.172 & -.217 & -.112 & -.095 \\
\hline ADAP & -.176 & -.111 & .752 & .433 & 1.000 & .668 & .445 & .452 & .649 & .455 & .169 & .129 & .086 & .125 & .104 & .156 & .124 & -.007 \\
\hline WORK & -190 & -179 & .576 & .586 & .668 & 1.000 & .436 & .444 & .606 & .593 & .083 & .034 & .028 & .031 & -.014 & .039 & .090 & -.050 \\
\hline DECI & -.060 & -.076 & .143 & .699 & .445 & .436 & 1.000 & .278 & .539 & .342 & .007 & -.071 & -.105 & -.023 & -.143 & -159 & -.074 & -.047 \\
\hline ERRO & -.132 & .009 & .437 & .130 & .452 & .444 & .278 & 1.000 & .275 & .206 & .090 & .098 & .130 & .121 & .107 & .112 & .136 & .091 \\
\hline GOAL & -.107 & -.118 & .328 & .646 & .649 & .606 & .539 & .275 & 1.000 & .460 & .081 & .024 & -.051 & .047 & -.049 & -.007 & .095 & .007 \\
\hline TIME & -.120 & -.056 & .289 & .394 & .455 & .593 & .342 & .206 & .460 & 1.000 & .200 & .221 & .098 & .122 & -.023 & .101 & .171 & .048 \\
\hline TEAM & .113 & .158 & .090 & -.051 & .169 & .083 & .007 & .090 & .081 & .200 & 1.000 & .666 & .594 & .687 & .496 & .561 & .621 & .468 \\
\hline SUPE & .134 & .189 & .087 & -.171 & .129 & .034 & -.071 & .098 & .024 & .221 & .666 & 1.000 & .646 & .677 & .568 & .596 & .714 & .553 \\
\hline EMPO & .126 & .075 & .150 & -.192 & .086 & .028 & -.105 & .130 & -.051 & .098 & .594 & .646 & 1.000 & .747 & .750 & .637 & .564 & .601 \\
\hline JOBS & .116 & .102 & .135 & -.131 & .125 & .031 & -.023 & .121 & .047 & .122 & .687 & .677 & .747 & 1.000 & .717 & .593 & .614 & .687 \\
\hline LEAR & .022 & -.007 & .203 & -.172 & .104 & -.014 & -.143 & .107 & -.049 & -.023 & .496 & .568 & .750 & .717 & 1.000 & .583 & .547 & .571 \\
\hline AUTO & .175 & .124 & .143 & -.217 & .156 & .039 & -.159 & .112 & -.007 & .101 & .561 & .596 & .637 & .593 & .583 & 1.000 & .609 & .487 \\
\hline STAT & .074 & -.011 & .129 & -.112 & .124 & .090 & -.074 & .136 & .095 & .171 & .621 & .714 & .564 & .614 & .547 & .609 & 1.000 & .520 \\
\hline EFFI & .045 & .059 & .010 & -.095 & -.007 & -.050 & -.047 & .091 & .007 & .048 & .468 & .553 & .601 & .687 & .571 & .487 & .520 & 1.000 \\
\hline
\end{tabular}

The covariance matrix is calculated and used in the analysis.

Inter-Item Covariance Matrix

\begin{tabular}{|c|c|c|c|c|c|c|c|c|c|c|c|c|c|c|c|c|c|c|}
\hline & QUAL & SCHE & VARI & COMP & ADAP & WORK & $\mathrm{DECl}$ & ERRO & GOAL & TIME & TEAM & SUPE & EMPO & JOBS & LEAR & AUTO & STAT & EFFI \\
\hline QUAL & .769 & .426 & -1.953 & -.704 & -2.729 & -2.029 & -.366 & -.273 & -2.192 & -1.233 & .053 & .062 & .060 & .061 & .010 & .075 & .039 & .022 \\
\hline $\mathrm{SCHE}$ & .426 & 1.067 & -1.738 & -1.531 & -2.027 & -2.259 & -.544 & .022 & -2.870 & -.676 & .087 & .104 & .042 & .063 & -.004 & .063 & -.007 & .033 \\
\hline VARI & -1.953 & -1.738 & 137.156 & 9.886 & 155.637 & 82.208 & 11.593 & 12.052 & 90.153 & 39.816 & .567 & .537 & .956 & .953 & 1.267 & .812 & .910 & .065 \\
\hline COMP & -.704 & -1.531 & 9.886 & 38.056 & 47.196 & 44.061 & 29.799 & 1.880 & 93.486 & 28.551 & -.170 & -.558 & -.644 & -.486 & -.566 & -.652 & -.417 & -.319 \\
\hline ADAP & -2.729 & -2.027 & 155.637 & 47.196 & 312.677 & 143.898 & 54.425 & 18.811 & 269.308 & 94.469 & 1.598 & 1.203 & .830 & 1.330 & .978 & 1.342 & 1.315 & -.068 \\
\hline WORK & -2.029 & -2.259 & 82.208 & 44.061 & 143.898 & 148.586 & 36.737 & 12.744 & 173.335 & 84.905 & .545 & .216 & .187 & .228 & -.090 & .233 & .660 & -.330 \\
\hline DECI & -.366 & -.544 & 11.593 & 29.799 & 54.425 & 36.737 & 47.737 & 4.516 & 87.411 & 27.789 & .025 & -260 & -396 & -.096 & -.528 & -.534 & -.308 & -.177 \\
\hline ERRO & -.273 & .022 & 12.052 & 1.880 & 18.811 & 12.744 & 4.516 & 5.539 & 15.201 & 5.689 & .114 & .122 & .166 & .171 & .135 & .128 & .193 & .117 \\
\hline GOAL & -2.192 & -2.870 & 90.153 & 93.486 & 269.308 & 173.335 & 87.411 & 15.201 & 550.410 & 126.871 & 1.014 & .302 & -.646 & .666 & -.607 & -.085 & 1.339 & .085 \\
\hline TIME & -1.233 & -.676 & 39.816 & 28.551 & 94.469 & 84.905 & 27.789 & 5.689 & 126.871 & 138.013 & 1.260 & 1.371 & .623 & .861 & -.145 & .580 & 1.209 & .306 \\
\hline TEAM & .053 & .087 & .567 & -.170 & 1.598 & .545 & .025 & .114 & 1.014 & 1.260 & .287 & .189 & .173 & .222 & .142 & . 146 & 200 & 137 \\
\hline SUPE & .062 & .104 & .537 & -.558 & 1.203 & .216 & -.260 & .122 & .302 & 1.371 & .189 & .280 & .186 & .216 & .160 & .153 & .227 & .160 \\
\hline EMPO & .060 & .042 & .956 & -.644 & .830 & .187 & -.396 & .166 & -.646 & .623 & .173 & .186 & .295 & .245 & .217 & .168 & .184 & .179 \\
\hline JOBS & .061 & .063 & .953 & -.486 & 1.330 & .228 & -.096 & .171 & .666 & .861 & .222 & .216 & .245 & .363 & .230 & .174 & .223 & .226 \\
\hline LEAR & .010 & -.004 & 1.267 & -.566 & .978 & -.090 & -.528 & .135 & -.607 & -.145 & .142 & .160 & .217 & .230 & .284 & .151 & .176 & .166 \\
\hline AUTO & .075 & .063 & .812 & -.652 & 1.342 & .233 & -.534 & .128 & -.085 & .580 & .146 & .153 & .168 & . 174 & .151 & .237 & 178 & .130 \\
\hline STAT & .039 & -.007 & .910 & -.417 & 1.315 & .660 & -.308 & .193 & 1.339 & 1.209 & .200 & .227 & .184 & .223 & .176 & .178 & .362 & .171 \\
\hline EFFI & .022 & .033 & .065 & -.319 & -.068 & -.330 & -.177 & .117 & .085 & .306 & .137 & .160 & 179 & 226 & .166 & . 130 & .171 & 299 \\
\hline
\end{tabular}

The covariance matrix is calculated and used in the analysis.

Summary Item Statistics

\begin{tabular}{|l|r|r|r|r|r|r|r|}
\hline & \multicolumn{1}{|c|}{ Mean } & Minimum & Maximum & \multicolumn{1}{c|}{ Range } & \multicolumn{1}{c|}{$\begin{array}{c}\text { Maximum / } \\
\text { Minimum }\end{array}$} & Variance & N of Items \\
\hline Item Means & 7.044 & 2.064 & 26.193 & 24.129 & 12.688 & 49.177 & 18 \\
Item Variances & 76.801 & .237 & 550.410 & 550.173 & 2325.824 & 21073.224 & 18 \\
Inter-Item Covariances & 11.798 & -2.870 & 269.308 & 272.178 & -93.846 & 1334.434 & 18 \\
Inter-Item Correlations & .207 & -.240 & .752 & .992 & -3.128 & .078 & 18 \\
\hline
\end{tabular}

The covariance matrix is calculated and used in the analysis. 
Item-Total Statistics

\begin{tabular}{|l|c|r|r|r|r|}
\hline & $\begin{array}{c}\text { Scale Mean if } \\
\text { Item Deleted }\end{array}$ & $\begin{array}{c}\text { Scale } \\
\text { Variance if } \\
\text { Item Deleted }\end{array}$ & $\begin{array}{c}\text { Corrected } \\
\text { Item-Total } \\
\text { Correlation }\end{array}$ & $\begin{array}{c}\text { Squared } \\
\text { Multiple } \\
\text { Correlation }\end{array}$ & $\begin{array}{c}\text { Cronbach's } \\
\text { Alpha if Item } \\
\text { Deleted }\end{array}$ \\
\hline QUAL & 115.450024 & 5013.163 & -.172 & .301 & .770 \\
SCHE & 116.064658 & 5013.155 & -.148 & .346 & .770 \\
VARI & 109.267151 & 4047.992 & .542 & .713 & .736 \\
COMP & 123.824107 & 4456.907 & .604 & .720 & .742 \\
ADAP & 100.605658 & 3104.880 & .799 & .796 & .696 \\
WORK & 112.822405 & 3693.500 & .777 & .711 & .708 \\
DECI & 124.379556 & 4446.677 & .541 & .578 & .744 \\
ERRO & 124.163375 & 4843.476 & .438 & .347 & .760 \\
GOAL & 113.608073 & 2736.633 & .695 & .632 & .739 \\
TIME & 119.056712 & 4030.083 & .553 & .451 & .734 \\
TEAM & 124.701244 & 4979.696 & .167 & .602 & .768 \\
SUPE & 124.734345 & 4983.529 & .118 & .684 & .768 \\
EMPO & 124.605309 & 4987.236 & .066 & .708 & .768 \\
JOBS & 124.483330 & 4981.654 & .124 & .749 & .768 \\
LEAR & 124.517504 & 4988.918 & .045 & .679 & .768 \\
AUTO & 124.379107 & 4986.227 & .089 & .570 & .768 \\
STAT & 124.502707 & 4979.641 & .148 & .634 & .768 \\
EFFI & 124.414414 & 4990.483 & .023 & .540 & .768 \\
\hline
\end{tabular}

Scale Statistics

\begin{tabular}{|c|l|r|r|}
\hline Mean & Variance & Std. Deviation & N of Items \\
\hline 126.7988 & 4992.589 & 70.6582583 & 18 \\
\hline
\end{tabular}

ANOVA with Friedman's Test

\begin{tabular}{|ll|c|r|r|r|r|}
\hline & & \multicolumn{1}{|c|}{$\begin{array}{c}\text { Sum of } \\
\text { Squares }\end{array}$} & \multicolumn{1}{c|}{$\mathrm{df}$} & Mean Square & \multicolumn{1}{c|}{$\begin{array}{c}\text { Friedman's } \\
\text { Chi-Square }\end{array}$} & Sig \\
\hline Between People & & 56582.681 & 204 & 277.366 & & \\
Within People & Between Items & $171382.3^{\mathrm{a}}$ & 17 & 10081.313 & 1505.161 & .000 \\
& Residual & 225430.5 & 3468 & 65.003 & & \\
Total & 396812.8 & 3485 & 113.863 & & \\
\hline
\end{tabular}

Grand Mean = 7.044378

a. Kendall's coefficient of concordance $\mathrm{W}=.378$.

b. The covariance matrix is calculated and used in the analysis. 
Appendix G. AMOS Structural Equation Modeling Output For Model C

(13 pages) 


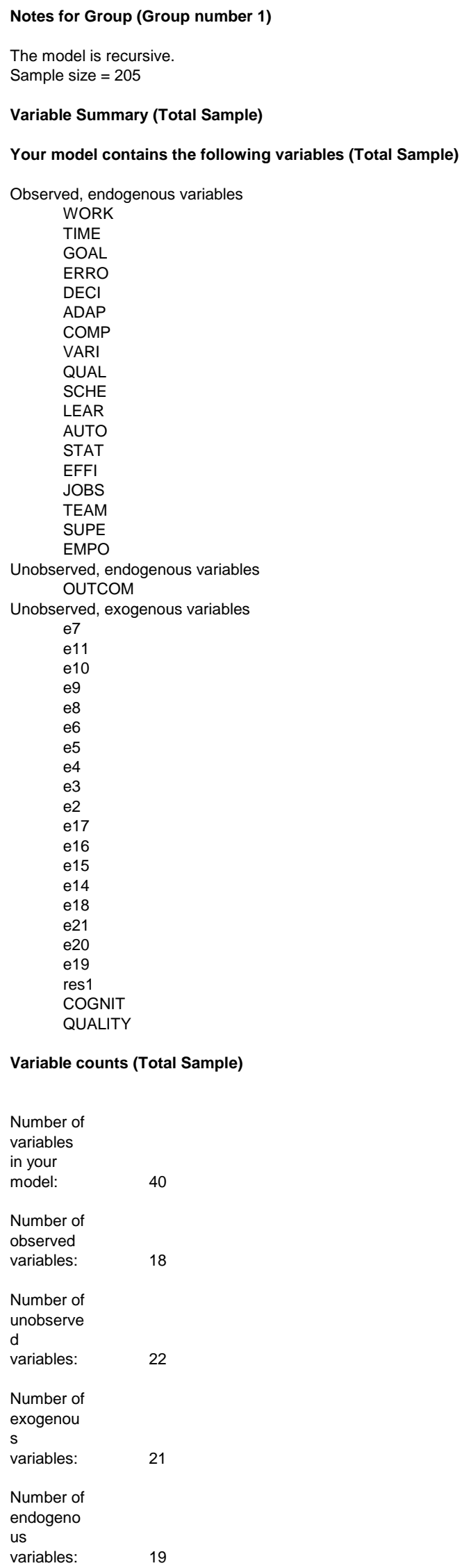


Parameter summary (Total Sample)

\begin{tabular}{|c|c|c|c|c|c|c|}
\hline & \multicolumn{3}{|c|}{ Covarianc } & \multirow[b]{2}{*}{ Means } & \multirow[b]{2}{*}{ Intercepts } & \multirow[b]{2}{*}{ Total } \\
\hline & Weights & es & Variances & & & \\
\hline Fixed & 22 & 0 & 1 & 0 & 0 & 23 \\
\hline Labeled & 0 & 0 & 0 & 0 & 0 & 0 \\
\hline Unlabeled & 17 & 3 & 20 & 0 & 0 & 40 \\
\hline Total & 39 & 3 & 21 & 0 & 0 & 63 \\
\hline
\end{tabular}

Assessment of normality (Total Sample)

\begin{tabular}{|l|rrrrrr|}
\hline Variable & min & max & skew & c.r. & kurtosis & c.r. \\
\hline EMPO & 1 & 4 & 0.372 & 2.173 & 0.266 & 0.776 \\
SUPE & 1 & 4 & 0.711 & 4.159 & 1.249 & 3.651 \\
TEAM & 1 & 4.6 & 1.514 & 8.849 & 4.791 & 14.003 \\
JOBS & 1.2 & 4.6 & 1.562 & 9.13 & 3.403 & 9.944 \\
EFFI & 1 & 4.2 & 0.574 & 3.355 & 0.736 & 2.151 \\
STAT & 1 & 5 & 0.929 & 5.428 & 2.224 & 6.5 \\
AUTO & 1.333 & 4.286 & 0.624 & 3.647 & 1.165 & 3.405 \\
LEAR & 1 & 3.667 & 0.242 & 1.417 & -0.009 & -0.026 \\
SCHE & 7 & 13 & -0.404 & -2.36 & 1.231 & 3.596 \\
QUAL & 10 & 14 & 0.199 & 1.166 & -0.474 & -1.384 \\
VARI & 0 & 66.7 & 1.3 & 7.596 & 2.241 & 6.548 \\
COMP & 0 & 33.3 & 3.17 & 18.527 & 11.201 & 32.735 \\
ADAP & 0 & 100 & 1.067 & 6.237 & 1.288 & 3.764 \\
DECI & 0 & 43.8 & 4.019 & 23.491 & 16.78 & 49.041 \\
ERRO & 0 & 11.5 & 0.954 & 5.575 & 0.774 & 2.262 \\
GOAL & 0 & 100 & 2.267 & 13.253 & 4.95 & 14.468 \\
TIME & 0 & 62.5 & 2.263 & 13.229 & 5.366 & 15.682 \\
WORK & 0 & 87.5 & 1.835 & 10.728 & 6.199 & 18.119 \\
Multivariat & & & & & & \\
e & & & & & 98.163 & 26.19 \\
\hline
\end{tabular}

Sample Covariances (Total Sample)

\begin{tabular}{|c|c|c|c|c|c|c|c|c|c|}
\hline & EMPO & SUPE & TEAM & JOBS & EFFI & STAT & AUTO & LEAR & $\mathrm{SCHE}$ \\
\hline EMPO & 0.295 & & & & & & & & \\
\hline SUPE & 0.186 & 0.28 & & & & & & & \\
\hline TEAM & 0.173 & 0.189 & 0.287 & & & & & & \\
\hline JOBS & 0.245 & 0.216 & 0.222 & 0.363 & & & & & \\
\hline EFFI & 0.179 & 0.16 & 0.137 & 0.226 & 0.299 & & & & \\
\hline STAT & 0.184 & 0.227 & 0.2 & 0.223 & 0.171 & 0.362 & & & \\
\hline AUTO & 0.168 & 0.153 & 0.146 & 0.174 & 0.13 & 0.178 & 0.237 & & \\
\hline LEAR & 0.217 & 0.16 & 0.142 & 0.23 & 0.166 & 0.176 & 0.151 & 0.284 & \\
\hline SCHE & 0.042 & 0.104 & 0.087 & 0.063 & 0.033 & -0.007 & 0.063 & -0.004 & 1.067 \\
\hline QUAL & 0.06 & 0.062 & 0.053 & 0.061 & 0.022 & 0.039 & 0.075 & 0.01 & 0.426 \\
\hline VARI & 0.956 & 0.537 & 0.567 & 0.953 & 0.065 & 0.91 & 0.812 & 1.267 & -1.738 \\
\hline COMP & -0.644 & -0.558 & -0.17 & -0.486 & -0.319 & -0.417 & -0.652 & -0.566 & -1.531 \\
\hline ADAP & 0.83 & 1.203 & 1.598 & 1.33 & -0.068 & 1.315 & 1.342 & 0.978 & -2.027 \\
\hline DECI & -0.396 & -0.26 & 0.025 & -0.096 & -0.177 & -0.308 & -0.534 & -0.528 & -0.544 \\
\hline ERRO & 0.166 & 0.122 & 0.114 & 0.171 & 0.117 & 0.193 & 0.128 & 0.135 & 0.022 \\
\hline GOAL & -0.646 & 0.302 & 1.014 & 0.666 & 0.085 & 1.339 & -0.085 & -0.607 & -2.87 \\
\hline TIME & 0.623 & 1.371 & 1.26 & 0.861 & 0.306 & 1.209 & 0.58 & -0.145 & -0.676 \\
\hline WORK & 0.187 & 0.216 & 0.545 & 0.228 & -0.33 & 0.66 & 0.233 & -0.09 & -2.259 \\
\hline
\end{tabular}

Condition number $=15965.157$

Determinant of sample covariance matrix $=2971385.180$ 
Sample Covariances (Total Sample)

\begin{tabular}{|l|rrrrrrrrr|}
\hline & QUAL & VARI & COMP & ADAP & DECI & ERRO & GOAL & TIME & WORK \\
\hline EMPO & & & & & & & & & \\
SUPE & & & & & & & & \\
TEAM & & & & & & & & \\
JOBS & & & & & & & & \\
EFFI & & & & & & & & \\
STAT & & & & & & & & \\
AUTO & & & & & & & & \\
LEAR & & & & & & & & \\
SCHE & & & & & & & & \\
QUAL & 0.769 & & & & & & & \\
VARI & -1.953 & 137.156 & & & & & & \\
COMP & -0.704 & 9.886 & 38.056 & & & & & \\
ADAP & -2.729 & 155.637 & 47.196 & 312.677 & & & & \\
DECI & -0.366 & 11.593 & 29.799 & 54.425 & 47.737 & & & \\
ERRO & -0.273 & 12.052 & 1.88 & 18.811 & 4.516 & 5.539 & & \\
GOAL & -2.192 & 90.153 & 93.486 & 269.308 & 87.411 & 15.201 & 550.41 & & \\
TIME & -1.233 & 39.816 & 28.551 & 94.469 & 27.789 & 5.689 & 126.871 & 138.013 & \\
WORK & -2.029 & 82.208 & 44.061 & 143.898 & 36.737 & 12.744 & 173.335 & 84.905 & 148.586 \\
\hline
\end{tabular}

Condition number $=15965.157$

Determinant of sample covariance matrix $=2971385.180$

Models

Default model (Default model)

Notes for Model (Default model)

Computation of degrees of freedom (Default model)

Number of

distinct

sample

moments:

171

Number of

distinct

parameter

$s$ to be

estimated:

40

Degrees

freedom

(171 - 40):

131

Result (Default model)

Minimum was achieved

Chi-square $=410.137$

Degrees of freedom $=131$

Probability level $=.000$ 
Maximum Likelihood Estimates

Regression Weights: (Total Sample - Default model)

\begin{tabular}{|c|c|c|c|c|c|c|}
\hline & & & Estimate & S.E. & C.R. & P Label \\
\hline OUTCOM & $<---$ & COGNIT & -0.029 & 0.01 & -2.826 & 0.005 par_8 \\
\hline OUTCOM & $<---$ & QUALITY & 0.321 & 0.151 & 2.132 & 0.033 par_16 \\
\hline VARI & $<---$ & COGNIT & 1 & & & \\
\hline COMP & $<---$ & COGNIT & 0.689 & 0.113 & 6.085 & *** par 1 \\
\hline ADAP & $<---$ & COGNIT & 2.292 & 0.238 & 9.613 & *** par_2 \\
\hline WORK & $<---$ & COGNIT & 1.647 & 0.223 & 7.402 & *** par_3 \\
\hline $\mathrm{DECl}$ & $<---$ & COGNIT & 0.671 & 0.118 & 5.668 & *** par_4 \\
\hline ERRO & $<---$ & COGNIT & 0.169 & 0.033 & 5.155 & *** par_5 \\
\hline GOAL & $<---$ & COGNIT & 3.076 & 0.468 & 6.573 & *** par_6 \\
\hline TIME & $<---$ & COGNIT & 1.192 & 0.192 & 6.195 & *** par_7 \\
\hline EFFI & $<---$ & QUALITY & 1 & & & \\
\hline STAT & $<---$ & QUALITY & 1.152 & 0.112 & 10.274 & *** par_9 \\
\hline AUTO & $<---$ & QUALITY & 0.911 & 0.091 & 10.057 & *** par_10 \\
\hline LEAR & $<---$ & QUALITY & 1.074 & 0.099 & 10.895 & *** par_11 \\
\hline JOBS & $<---$ & QUALITY & 1.357 & 0.11 & 12.298 & *** par_12 \\
\hline EMPO & $<---$ & QUALITY & 1.173 & 0.101 & 11.66 & *** par_13 \\
\hline SUPE & $<---$ & QUALITY & 1.085 & 0.099 & 11.012 & *** par_14 \\
\hline TEAM & $<---$ & QUALITY & 1.029 & 0.1 & 10.275 & *** par_15 \\
\hline QUAL & $<---$ & OUTCOM & 1 & & & \\
\hline SCHE & $<---$ & OUTCOM & 0.967 & 0.15 & 6.441 & *** par_18 \\
\hline
\end{tabular}

Standardized Regression Weights: (Total Sample - Default model)

\begin{tabular}{|lll|r|}
\hline & & & Estimate \\
\hline OUTCOM & $<---$ & COGNIT & -0.269 \\
OUTCOM & $<---$ & QUALITY & 0.188 \\
VARI & $<---$ & COGNIT & 0.52 \\
COMP & $<---$ & COGNIT & 0.681 \\
ADAP & $<---$ & COGNIT & 0.79 \\
WORK & $<---$ & COGNIT & 0.824 \\
DECI & $<---$ & COGNIT & 0.592 \\
ERRO & $<---$ & COGNIT & 0.438 \\
GOAL & $<---$ & COGNIT & 0.799 \\
TIME & $<---$ & COGNIT & 0.619 \\
EFFI & $<---$ & QUALITY & 0.714 \\
STAT & $<---$ & QUALITY & 0.747 \\
AUTO & $<---$ & QUALITY & 0.731 \\
LEAR & $<---$ & QUALITY & 0.786 \\
JOBS & $<---$ & QUALITY & 0.879 \\
EMPO & $<---$ & QUALITY & 0.842 \\
SUPE & $<---$ & QUALITY & 0.8 \\
TEAM & $<---$ & QUALITY & 0.749 \\
QUAL & $<---$ & OUTCOM & 0.759 \\
SCHE & $<---$ & OUTCOM & 0.624 \\
\hline
\end{tabular}

Covariances: (Total Sample - Default model)

\begin{tabular}{|lll|rrrr|}
\hline & & & Estimate & S.E. & C.R. & \multicolumn{1}{c|}{ P Label } \\
\hline COGNIT & $<-->$ & QUALITY & 0.135 & 0.187 & 0.718 & 0.472 par_17 \\
e6 & $<-->$ & e4 & 70.518 & 11.366 & 6.204 & ${ }^{* * *}$ par_19 \\
e8 & $<-->$ & e5 & 12.624 & 2.32 & 5.441 & *** par_20 \\
\hline
\end{tabular}

Correlations: (Total Sample - Default model)

\begin{tabular}{|lll|r|}
\hline & & & Estimate \\
\hline COGNIT & $<-->$ & QUALITY & 0.057 \\
e6 & $<-->$ & e4 & 0.65 \\
e8 & $<-->$ & e5 & 0.502 \\
\hline
\end{tabular}


Variances: (Total Sample - Default model)

\begin{tabular}{|c|c|c|c|c|}
\hline & Estimate & S.E. & C.R. & P Label \\
\hline COGNIT & 37.145 & 10.406 & 3.57 & ${ }^{* * *}$ par_21 \\
\hline QUALITY & 0.152 & 0.026 & 5.752 & *** par_22 \\
\hline res1 & 0.4 & & & \\
\hline e7 & 47.773 & 7.828 & 6.103 & *** par_23 \\
\hline e11 & 85.209 & 9.31 & 9.152 & ${ }^{* * *}$ par_24 \\
\hline e10 & 198.951 & 29.281 & 6.795 & *** par_25 \\
\hline e9 & 4.477 & 0.463 & 9.678 & ${ }^{* * *}$ par_26 \\
\hline e8 & 31.015 & 3.402 & 9.117 & ${ }^{* * *}$ par_27 \\
\hline e6 & 117.623 & 15.443 & 7.617 & ${ }^{* * *}$ par_28 \\
\hline e5 & 20.416 & 2.386 & 8.556 & ${ }^{* * *}$ par_29 \\
\hline e4 & 100.012 & 10.954 & 9.131 & ${ }^{* * *}$ par_30 \\
\hline e3 & 0.329 & 0.071 & 4.648 & *** par_31 \\
\hline e2 & 0.653 & 0.105 & 6.229 & *** par_32 \\
\hline e17 & 0.109 & 0.012 & 8.792 & *** par_33 \\
\hline e16 & 0.11 & 0.012 & 9.215 & *** par_34 \\
\hline e15 & 0.16 & 0.018 & 9.031 & ${ }^{* * *}$ par_35 \\
\hline e14 & 0.146 & 0.016 & 9.315 & *** par_36 \\
\hline e18 & 0.083 & 0.011 & 7.49 & *** par_37 \\
\hline e21 & 0.126 & 0.014 & 9.091 & ${ }^{* * *}$ par_38 \\
\hline e20 & 0.101 & 0.012 & 8.638 & ${ }^{\star * *}$ par_39 \\
\hline e19 & 0.086 & 0.01 & 8.186 & ${ }^{* * *}$ par_40 \\
\hline
\end{tabular}

Squared Multiple Correlations: (Total Sample - Default model)

\begin{tabular}{|l|r|}
\hline & Estimate \\
\hline OUTCOM & 0.102 \\
EMPO & 0.71 \\
SUPE & 0.641 \\
TEAM & 0.561 \\
JOBS & 0.773 \\
EFFI & 0.51 \\
STAT & 0.558 \\
AUTO & 0.534 \\
LEAR & 0.618 \\
SCHE & 0.389 \\
QUAL & 0.575 \\
VARI & 0.271 \\
COMP & 0.464 \\
ADAP & 0.624 \\
DECI & 0.35 \\
ERRO & 0.192 \\
GOAL & 0.639 \\
TIME & 0.383 \\
WORK & 0.678 \\
\hline
\end{tabular}


Implied (for all variables) Covariances (Total Sample - Default model)

\begin{tabular}{|c|c|c|c|c|c|c|c|c|c|c|c|}
\hline & QUALITY & COGNIT & OUTCOM & EMPO & SUPE & TEAM & JOBS & EFFI & STAT & AUTO & LEAR \\
\hline QUALITY & 0.152 & & & & & & & & & & \\
\hline COGNIT & 0.135 & 37.145 & & & & & & & & & \\
\hline OUTCOM & 0.045 & -1.051 & 0.445 & & & & & & & & \\
\hline EMPO & 0.179 & 0.158 & 0.053 & 0.295 & & & & & & & \\
\hline SUPE & 0.165 & 0.146 & 0.049 & 0.194 & 0.28 & & & & & & \\
\hline TEAM & 0.157 & 0.138 & 0.046 & 0.184 & 0.17 & 0.287 & & & & & \\
\hline JOBS & 0.207 & 0.182 & 0.061 & 0.242 & 0.224 & 0.212 & 0.363 & & & & \\
\hline EFFI & 0.152 & 0.135 & 0.045 & 0.179 & 0.165 & 0.157 & 0.207 & 0.299 & & & \\
\hline STAT & 0.175 & 0.155 & 0.052 & 0.206 & 0.19 & 0.18 & 0.238 & 0.175 & 0.362 & & \\
\hline AUTO & 0.139 & 0.123 & 0.041 & 0.163 & 0.151 & 0.143 & 0.188 & 0.139 & 0.16 & 0.237 & \\
\hline LEAR & 0.164 & 0.144 & 0.048 & 0.192 & 0.178 & 0.168 & 0.222 & 0.164 & 0.188 & 0.149 & 0.284 \\
\hline SCHE & 0.043 & -1.016 & 0.431 & 0.051 & 0.047 & 0.045 & 0.059 & 0.043 & 0.05 & 0.04 & 0.047 \\
\hline QUAL & 0.045 & -1.051 & 0.445 & 0.053 & 0.049 & 0.046 & 0.061 & 0.045 & 0.052 & 0.041 & 0.048 \\
\hline VARI & 0.135 & 37.145 & -1.051 & 0.158 & 0.146 & 0.138 & 0.182 & 0.135 & 0.155 & 0.123 & 0.144 \\
\hline COMP & 0.093 & 25.598 & -0.724 & 0.109 & 0.101 & 0.095 & 0.126 & 0.093 & 0.107 & 0.084 & 0.1 \\
\hline ADAP & 0.308 & 85.119 & -2.408 & 0.362 & 0.334 & 0.317 & 0.418 & 0.308 & 0.355 & 0.281 & 0.331 \\
\hline DECI & 0.09 & 24.922 & -0.705 & 0.106 & 0.098 & 0.093 & 0.122 & 0.09 & 0.104 & 0.082 & 0.097 \\
\hline ERRO & 0.023 & 6.281 & -0.178 & 0.027 & 0.025 & 0.023 & 0.031 & 0.023 & 0.026 & 0.021 & 0.024 \\
\hline GOAL & 0.414 & 114.258 & -3.232 & 0.485 & 0.449 & 0.426 & 0.561 & 0.414 & 0.477 & 0.377 & 0.444 \\
\hline TIME & 0.16 & 44.287 & -1.253 & 0.188 & 0.174 & 0.165 & 0.218 & 0.16 & 0.185 & 0.146 & 0.172 \\
\hline WORK & 0.222 & 61.194 & -1.731 & 0.26 & 0.24 & 0.228 & 0.301 & 0.222 & 0.255 & 0.202 & 0.238 \\
\hline
\end{tabular}

Implied (for all variables) Covariances (Total Sample - Default model)

\begin{tabular}{|c|c|c|c|c|c|c|c|c|c|c|}
\hline & $\mathrm{SCHE}$ & QUAL & VARI & COMP & ADAP & DECl & ERRO & GOAL & TIME & WORK \\
\hline \multicolumn{11}{|l|}{ QUALITY } \\
\hline COGNIT & & & & & & & & & & \\
\hline OUTCOM & & & & & & & & & & \\
\hline EMPO & & & & & & & & & & \\
\hline SUPE & & & & & & & & & & \\
\hline TEAM & & & & & & & & & & \\
\hline JOBS & & & & & & & & & & \\
\hline EFFI & & & & & & & & & & \\
\hline STAT & & & & & & & & & & \\
\hline AUTO & & & & & & & & & & \\
\hline LEAR & & & & & & & & & & \\
\hline SCHE & 1.069 & & & & & & & & & \\
\hline QUAL & 0.431 & 0.774 & & & & & & & & \\
\hline VARI & -1.016 & -1.051 & 137.156 & & & & & & & \\
\hline COMP & -0.7 & -0.724 & 25.598 & 38.056 & & & & & & \\
\hline ADAP & -2.328 & -2.408 & 155.637 & 58.659 & 312.677 & & & & & \\
\hline DECI & -0.682 & -0.705 & 24.922 & 29.799 & 57.11 & 47.737 & & & & \\
\hline ERRO & -0.172 & -0.178 & 6.281 & 4.329 & 14.394 & 4.214 & 5.539 & & & \\
\hline GOAL & -3.125 & -3.232 & 114.258 & 78.739 & 261.827 & 76.661 & 19.321 & 550.41 & & \\
\hline TIME & -1.211 & -1.253 & 44.287 & 30.52 & 101.487 & 29.715 & 7.489 & 136.229 & 138.013 & \\
\hline WORK & -1.674 & -1.731 & 61.194 & 42.171 & 140.229 & 41.058 & 10.348 & 188.234 & 72.961 & 148.586 \\
\hline
\end{tabular}

Implied Covariances (Total Sample - Default model)

\begin{tabular}{|c|c|c|c|c|c|c|c|c|c|c|c|}
\hline & EMPO & SUPE & TEAM & JOBS & EFFI & STAT & AUTO & LEAR & SCHE & QUAL & $\overline{\text { VARI }}$ \\
\hline EMPO & 0.295 & & & & & & & & & & \\
\hline SUPE & 0.194 & 0.28 & & & & & & & & & \\
\hline TEAM & 0.184 & 0.17 & 0.287 & & & & & & & & \\
\hline JOBS & 0.242 & 0.224 & 0.212 & 0.363 & & & & & & & \\
\hline EFFI & 0.179 & 0.165 & 0.157 & 0.207 & 0.299 & & & & & & \\
\hline STAT & 0.206 & 0.19 & 0.18 & 0.238 & 0.175 & 0.362 & & & & & \\
\hline AUTO & 0.163 & 0.151 & 0.143 & 0.188 & 0.139 & 0.16 & 0.237 & & & & \\
\hline LEAR & 0.192 & 0.178 & 0.168 & 0.222 & 0.164 & 0.188 & 0.149 & 0.284 & & & \\
\hline SCHE & 0.051 & 0.047 & 0.045 & 0.059 & 0.043 & 0.05 & 0.04 & 0.047 & 1.069 & & \\
\hline QUAL & 0.053 & 0.049 & 0.046 & 0.061 & 0.045 & 0.052 & 0.041 & 0.048 & 0.431 & 0.774 & \\
\hline VARI & 0.158 & 0.146 & 0.138 & 0.182 & 0.135 & 0.155 & 0.123 & 0.144 & -1.016 & -1.051 & 137.156 \\
\hline COMP & 0.109 & 0.101 & 0.095 & 0.126 & 0.093 & 0.107 & 0.084 & 0.1 & -0.7 & -0.724 & 25.598 \\
\hline ADAP & 0.362 & 0.334 & 0.317 & 0.418 & 0.308 & 0.355 & 0.281 & 0.331 & -2.328 & -2.408 & 155.637 \\
\hline DECI & 0.106 & 0.098 & 0.093 & 0.122 & 0.09 & 0.104 & 0.082 & 0.097 & -0.682 & -0.705 & 24.922 \\
\hline ERRO & 0.027 & 0.025 & 0.023 & 0.031 & 0.023 & 0.026 & 0.021 & 0.024 & -0.172 & -0.178 & 6.281 \\
\hline GOAL & 0.485 & 0.449 & 0.426 & 0.561 & 0.414 & 0.477 & 0.377 & 0.444 & -3.125 & -3.232 & 114.258 \\
\hline TIME & 0.188 & 0.174 & 0.165 & 0.218 & 0.16 & 0.185 & 0.146 & 0.172 & -1.211 & -1.253 & 44.287 \\
\hline WORK & 0.26 & 0.24 & 0.228 & 0.301 & 0.222 & 0.255 & 0.202 & 0.238 & -1.674 & -1.731 & 61.194 \\
\hline
\end{tabular}


Implied Covariances (Total Sample - Default model)

\begin{tabular}{|l|rrrrrrr|}
\hline & COMP & ADAP & DECI & ERRO & GOAL & TIME & WORK \\
\hline EMPO & & & & & & & \\
SUPE & & & & & & & \\
TEAM & & & & & & & \\
JOBS & & & & & & \\
EFFI & & & & & & \\
STAT & & & & & & \\
AUTO & & & & & & \\
LEAR & & & & & & \\
SCHE & & & & & & \\
QUAL & & & & & & \\
VARI & & & & & & \\
COMP & 38.056 & & & & & & \\
ADAP & 58.659 & 312.677 & & & & & \\
DECI & 29.799 & 57.11 & 47.737 & & & & \\
ERRO & 4.329 & 14.394 & 4.214 & 5.539 & & & \\
GOAL & 78.739 & 261.827 & 76.661 & 19.321 & 550.41 & & \\
TIME & 30.52 & 101.487 & 29.715 & 7.489 & 136.229 & 138.013 & \\
WORK & 42.171 & 140.229 & 41.058 & 10.348 & 188.234 & 72.961 & 148.586 \\
\hline
\end{tabular}

Residual Covariances (Total Sample - Default model)

\begin{tabular}{|c|c|c|c|c|c|c|c|c|c|c|c|}
\hline & EMPO & SUPE & TEAM & JOBS & EFFI & STAT & AUTO & LEAR & $\mathrm{SCHE}$ & QUAL & VAR \\
\hline EMPO & 0 & & & & & & & & & & \\
\hline SUPE & -0.008 & 0 & & & & & & & & & \\
\hline TEAM & -0.011 & 0.019 & 0 & & & & & & & & \\
\hline JOBS & 0.002 & -0.009 & 0.009 & 0 & & & & & & & \\
\hline EFFI & 0 & -0.005 & -0.02 & 0.019 & 0 & & & & & & \\
\hline STAT & -0.022 & 0.037 & 0.02 & -0.015 & -0.005 & 0 & & & & & \\
\hline AUTO & 0.006 & 0.003 & 0.004 & -0.015 & -0.009 & 0.018 & 0 & & & & \\
\hline LEAR & 0.026 & -0.017 & -0.027 & 0.008 & 0.003 & -0.013 & 0.002 & 0 & & & \\
\hline SCHE & -0.009 & 0.056 & 0.043 & 0.005 & -0.01 & -0.057 & 0.023 & -0.051 & -0.002 & & \\
\hline QUAL & 0.007 & 0.013 & 0.007 & 0 & -0.023 & -0.013 & 0.034 & -0.038 & -0.005 & -0.005 & \\
\hline VARI & 0.798 & 0.391 & 0.428 & 0.77 & -0.069 & 0.755 & 0.69 & 1.123 & -0.722 & -0.902 & 0 \\
\hline COMP & -0.752 & -0.658 & -0.265 & -0.612 & -0.411 & -0.524 & -0.736 & -0.666 & -0.831 & 0.02 & -15.712 \\
\hline ADAP & 0.468 & 0.868 & 1.281 & 0.912 & -0.376 & 0.96 & 1.061 & 0.647 & 0.3 & -0.321 & 0 \\
\hline DECI & -0.501 & -0.358 & -0.068 & -0.218 & -0.267 & -0.412 & -0.616 & -0.625 & 0.138 & 0.339 & -13.329 \\
\hline ERRO & 0.139 & 0.097 & 0.09 & 0.14 & 0.095 & 0.167 & 0.107 & 0.11 & 0.194 & -0.096 & 5.77 \\
\hline GOAL & -1.131 & -0.147 & 0.589 & 0.105 & -0.328 & 0.863 & -0.462 & -1.051 & 0.255 & 1.04 & -24.105 \\
\hline TIME & 0.435 & 1.197 & 1.096 & 0.644 & 0.146 & 1.024 & 0.434 & -0.318 & 0.535 & 0.02 & -4.472 \\
\hline WORK & -0.073 & -0.024 & 0.317 & -0.073 & -0.552 & 0.405 & 0.031 & -0.328 & -0.585 & -0.298 & 21.014 \\
\hline
\end{tabular}

Residual Covariances (Total Sample - Default model)

\begin{tabular}{|c|c|c|c|c|c|c|c|}
\hline & COMP & ADAP & $\mathrm{DECl}$ & ERRO & GOAL & TIME & WORK \\
\hline EMPO & & & & & & & \\
\hline SUPE & & & & & & & \\
\hline TEAM & & & & & & & \\
\hline JOBS & & & & & & & \\
\hline EFFI & & & & & & & \\
\hline STAT & & & & & & & \\
\hline AUTO & & & & & & & \\
\hline LEAR & & & & & & & \\
\hline $\mathrm{SCHE}$ & & & & & & & \\
\hline QUAL & & & & & & & \\
\hline VARI & & & & & & & \\
\hline COMP & 0 & & & & & & \\
\hline ADAP & -11.463 & 0 & & & & & \\
\hline DECI & 0 & -2.685 & 0 & & & & \\
\hline ERRO & -2.448 & 4.417 & 0.302 & 0 & & & \\
\hline GOAL & 14.747 & 7.481 & 10.75 & -4.121 & 0 & & \\
\hline TIME & -1.97 & -7.017 & -1.925 & -1.8 & -9.358 & 0 & \\
\hline WORK & 1.89 & 3.669 & -4.321 & 2.396 & -14.899 & 11.944 & 0 \\
\hline
\end{tabular}


Factor Score Weights (Total Sample - Default model)

\begin{tabular}{|l|rrrrrrrrrrr}
\hline & EMPO & SUPE & TEAM & JOBS & EFFI & STAT & AUTO & LEAR & SCHE & QUAL & VARI \\
\hline QUALITY & 0.139 & 0.11 & 0.083 & 0.167 & 0.069 & 0.073 & 0.084 & 0.1 & 0.002 & 0.003 & 0 \\
COGNIT & 0.024 & 0.019 & 0.014 & 0.028 & 0.012 & 0.012 & 0.014 & 0.017 & -0.068 & -0.14 & -0.028 \\
OUTCOM & 0.016 & 0.012 & 0.009 & 0.019 & 0.008 & 0.008 & 0.01 & 0.011 & 0.213 & 0.438 & 0 \\
\hline
\end{tabular}

Factor Score Weights (Total Sample - Default model)

\begin{tabular}{|l|rrrrrrr|}
\hline & COMP & ADAP & DECl & ERRO & GOAL & TIME & WORK \\
\hline QUALITY & 0 & 0 & 0 & 0 & 0 & 0 & 0 \\
COGNIT & 0.119 & 0.102 & 0.046 & 0.165 & 0.068 & 0.061 & 0.151 \\
OUTCOM & -0.001 & -0.001 & 0 & -0.002 & -0.001 & -0.001 & -0.002 \\
\hline
\end{tabular}

Standardized Total Effects (Total Sample - Default model)

\begin{tabular}{|l|rrr|}
\hline & QUALITY & COGNIT & OUTCOM \\
\hline OUTCOM & 0.188 & -0.269 & 0 \\
EMPO & 0.842 & 0 & 0 \\
SUPE & 0.8 & 0 & 0 \\
TEAM & 0.749 & 0 & 0 \\
JOBS & 0.879 & 0 & 0 \\
EFFI & 0.714 & 0 & 0 \\
STAT & 0.747 & 0 & 0 \\
AUTO & 0.731 & 0 & 0 \\
LEAR & 0.786 & 0 & 0 \\
SCHE & 0.117 & -0.168 & 0.624 \\
QUAL & 0.142 & -0.204 & 0.759 \\
VARI & 0 & 0.52 & 0 \\
COMP & 0 & 0.681 & 0 \\
ADAP & 0 & 0.79 & 0 \\
DECI & 0 & 0.592 & 0 \\
ERRO & 0 & 0.438 & 0 \\
GOAL & 0 & 0.799 & 0 \\
TIME & 0 & 0.619 & 0 \\
WORK & 0 & 0.824 & 0 \\
\hline
\end{tabular}

Direct Effects (Total Sample - Default model)

\begin{tabular}{|l|rrr|}
\hline & QUALITY & COGNIT & OUTCOM \\
\hline OUTCOM & 0.321 & -0.029 & 0 \\
EMPO & 1.173 & 0 & 0 \\
SUPE & 1.085 & 0 & 0 \\
TEAM & 1.029 & 0 & 0 \\
JOBS & 1.357 & 0 & 0 \\
EFFI & 1 & 0 & 0 \\
STAT & 1.152 & 0 & 0 \\
AUTO & 0.911 & 0 & 0 \\
LEAR & 1.074 & 0 & 0 \\
SCHE & 0 & 0 & 0.967 \\
QUAL & 0 & 0 & 1 \\
VARI & 0 & 1 & 0 \\
COMP & 0 & 0.689 & 0 \\
ADAP & 0 & 2.292 & 0 \\
DECI & 0 & 0.671 & 0 \\
ERRO & 0 & 0.169 & 0 \\
GOAL & 0 & 3.076 & 0 \\
TIME & 0 & 1.192 & 0 \\
WORK & 0 & 1.647 & 0 \\
\hline
\end{tabular}


Standardized Direct Effects (Total Sample - Default model)

\begin{tabular}{|l|rrr|}
\hline & QUALITY & COGNIT & OUTCOM \\
\hline OUTCOM & 0.188 & -0.269 & 0 \\
EMPO & 0.842 & 0 & 0 \\
SUPE & 0.8 & 0 & 0 \\
TEAM & 0.749 & 0 & 0 \\
JOBS & 0.879 & 0 & 0 \\
EFFI & 0.714 & 0 & 0 \\
STAT & 0.747 & 0 & 0 \\
AUTO & 0.731 & 0 & 0 \\
LEAR & 0.786 & 0 & 0 \\
SCHE & 0 & 0 & 0.624 \\
QUAL & 0 & 0 & 0.759 \\
VARI & 0 & 0.52 & 0 \\
COMP & 0 & 0.681 & 0 \\
ADAP & 0 & 0.79 & 0 \\
DECI & 0 & 0.592 & 0 \\
ERRO & 0 & 0.438 & 0 \\
GOAL & 0 & 0.799 & 0 \\
TIME & 0 & 0.619 & 0 \\
WORK & 0 & 0.824 & 0 \\
\hline
\end{tabular}

Indirect Effects (Total Sample - Default model)

\begin{tabular}{|l|rrr|}
\hline & QUALITY & COGNIT & OUTCOM \\
\hline OUTCOM & 0 & 0 & 0 \\
EMPO & 0 & 0 & 0 \\
SUPE & 0 & 0 & 0 \\
TEAM & 0 & 0 & 0 \\
JOBS & 0 & 0 & 0 \\
EFFI & 0 & 0 & 0 \\
STAT & 0 & 0 & 0 \\
AUTO & 0 & 0 & 0 \\
LEAR & 0 & 0 & 0 \\
SCHE & 0.31 & -0.028 & 0 \\
QUAL & 0.321 & -0.029 & 0 \\
VARI & 0 & 0 & 0 \\
COMP & 0 & 0 & 0 \\
ADAP & 0 & 0 & 0 \\
DECI & 0 & 0 & 0 \\
ERRO & 0 & 0 & 0 \\
GOAL & 0 & 0 & 0 \\
TIME & 0 & 0 & 0 \\
WORK & 0 & 0 & 0 \\
\hline
\end{tabular}

Standardized Indirect Effects (Total Sample - Default model)

\begin{tabular}{|l|rrr|}
\hline & QUALITY & COGNIT & OUTCOM \\
\hline OUTCOM & 0 & 0 & 0 \\
EMPO & 0 & 0 & 0 \\
SUPE & 0 & 0 & 0 \\
TEAM & 0 & 0 & 0 \\
JOBS & 0 & 0 & 0 \\
EFFI & 0 & 0 & 0 \\
STAT & 0 & 0 & 0 \\
AUTO & 0 & 0 & 0 \\
LEAR & 0 & 0 & 0 \\
SCHE & 0.117 & -0.168 & 0 \\
QUAL & 0.142 & -0.204 & 0 \\
VARI & 0 & 0 & 0 \\
COMP & 0 & 0 & 0 \\
ADAP & 0 & 0 & 0 \\
DECI & 0 & 0 & 0 \\
ERRO & 0 & 0 & 0 \\
GOAL & 0 & 0 & 0 \\
TIME & 0 & 0 & 0 \\
WORK & 0 & 0 & 0 \\
\hline
\end{tabular}


Modification Indices (Total Sample - Default model)

Covariances: (Total Sample - Default model)

\begin{tabular}{|c|c|c|c|c|}
\hline & & & M.I. & $\begin{array}{r}\text { Par } \\
\text { Change }\end{array}$ \\
\hline e21 & $<-->$ & e20 & 6.92 & 0.023 \\
\hline e14 & $<-->$ & e21 & 4.891 & -0.023 \\
\hline e14 & $<-->$ & e18 & 8.58 & 0.026 \\
\hline e15 & $<-->$ & e19 & 8.719 & -0.027 \\
\hline e15 & $<-->$ & e20 & 21.065 & 0.045 \\
\hline e15 & $<-->$ & $\mathrm{e} 21$ & 4.732 & 0.024 \\
\hline e15 & $<-->$ & e18 & 4.901 & -0.021 \\
\hline e16 & $<-->$ & e18 & 6.452 & -0.02 \\
\hline e16 & $<-->$ & e15 & 4.536 & 0.021 \\
\hline e17 & $<-->$ & res1 & 7.824 & -0.054 \\
\hline e17 & $<-->$ & e19 & 18.621 & 0.033 \\
\hline e17 & $<-->$ & e20 & 6.886 & -0.021 \\
\hline e17 & $<-->$ & e21 & 12.558 & -0.032 \\
\hline e2 & $<-->$ & e20 & 6.523 & 0.055 \\
\hline e2 & $<-->$ & e15 & 4.083 & -0.054 \\
\hline e4 & $<-->$ & e21 & 5.307 & -0.458 \\
\hline e4 & $<-->$ & e17 & 8.691 & 0.55 \\
\hline e5 & $<-->$ & QUALITY & 13.475 & -0.416 \\
\hline e5 & $<-->$ & $\mathrm{e} 2$ & 9.49 & -0.784 \\
\hline e5 & $<-->$ & e4 & 4.038 & -4.308 \\
\hline e6 & $<-->$ & e16 & 5.083 & 0.491 \\
\hline e8 & $<-->$ & e4 & 6.029 & -6.362 \\
\hline e8 & $<-->$ & e6 & 7.476 & 8.34 \\
\hline e9 & $<-->$ & e4 & 7.911 & 3.228 \\
\hline e9 & $<-->$ & e5 & 21.08 & -2.764 \\
\hline e9 & $<-->$ & e8 & 6.674 & 1.88 \\
\hline e10 & $<-->$ & e19 & 4.502 & -0.753 \\
\hline e10 & $<-->$ & e4 & 18.324 & -36.233 \\
\hline e10 & $<-->$ & e5 & 9.418 & 13.56 \\
\hline e10 & $<-->$ & e6 & 12.957 & 35.075 \\
\hline e10 & $<-->$ & e9 & 4.938 & -5.272 \\
\hline e11 & $<-->$ & QUALITY & 4.165 & 0.553 \\
\hline e11 & $<-->$ & $\mathrm{e} 20$ & 10.837 & 0.747 \\
\hline e11 & $<-->$ & e17 & 9.855 & -0.735 \\
\hline e7 & $<-->$ & e4 & 34.69 & 25.069 \\
\hline e7 & $<-->$ & e5 & 5.112 & 5.017 \\
\hline e7 & $<-->$ & e6 & 11.434 & -16.472 \\
\hline e7 & $<-->$ & e8 & 7.337 & -7.312 \\
\hline e7 & $<-->$ & e9 & 7.389 & 3.241 \\
\hline e7 & $<-->$ & e10 & 7.186 & -22.749 \\
\hline $\mathrm{e} 7$ & $<-->$ & e11 & 9.973 & 16.684 \\
\hline
\end{tabular}


Regression Weights: (Total Sample - Default model)

\begin{tabular}{|c|c|c|c|c|}
\hline & & & M.I. & $\begin{array}{r}\text { Par } \\
\text { Change }\end{array}$ \\
\hline EMPO & $<--$ & LEAR & 6.461 & 0.107 \\
\hline EMPO & $<--$ & GOAL & 4.04 & -0.002 \\
\hline SUPE & $<---$ & STAT & 8.597 & 0.115 \\
\hline SUPE & $<---$ & $\mathrm{SCHE}$ & 6.494 & 0.058 \\
\hline SUPE & $<---$ & TIME & 7.537 & 0.006 \\
\hline TEAM & $<--$ & LEAR & 4.344 & -0.102 \\
\hline TEAM & $<---$ & TIME & 4.59 & 0.005 \\
\hline EFFI & $<---$ & ADAP & 4.667 & -0.003 \\
\hline STAT & $<--$ & SUPE & 6.73 & 0.143 \\
\hline STAT & $<---$ & SCHE & 4.407 & -0.059 \\
\hline AUTO & $<---$ & COMP & 4.173 & -0.008 \\
\hline AUTO & $<--$ & $\mathrm{DECl}$ & 4.564 & -0.007 \\
\hline LEAR & $<--$ & OUTCOM & 4.475 & -0.094 \\
\hline LEAR & $<---$ & EMPO & 4.609 & 0.097 \\
\hline LEAR & $<---$ & TEAM & 5.124 & -0.103 \\
\hline LEAR & $<---$ & $\mathrm{SCHE}$ & 5.22 & -0.054 \\
\hline LEAR & $<---$ & VARI & 4.58 & 0.004 \\
\hline LEAR & $<---$ & TIME & 10.497 & -0.007 \\
\hline VARI & $<---$ & LEAR & 5.505 & 2.353 \\
\hline VARI & $<--$ & COMP & 7.261 & -0.234 \\
\hline VARI & $<---$ & DECl & 10.174 & -0.247 \\
\hline VARI & $<---$ & ERRO & 6.223 & 0.567 \\
\hline VARI & $<---$ & GOAL & 5.252 & -0.052 \\
\hline VARI & $<---$ & WORK & 8.425 & 0.127 \\
\hline COMP & $<---$ & QUALITY & 13.428 & -2.728 \\
\hline COMP & $<---$ & EMPO & 11.593 & -1.759 \\
\hline COMP & $<---$ & SUPE & 14.201 & -1.999 \\
\hline COMP & $<---$ & TEAM & 5.631 & -1.243 \\
\hline COMP & $<---$ & JOBS & 11.298 & -1.566 \\
\hline COMP & $<---$ & STAT & 7.561 & -1.283 \\
\hline COMP & $<--$ & AUTO & 13.485 & -2.119 \\
\hline COMP & $<---$ & LEAR & 5.45 & -1.229 \\
\hline COMP & $<---$ & SCHE & 9.795 & -0.85 \\
\hline COMP & $<---$ & VARI & 10.733 & -0.079 \\
\hline COMP & $<---$ & ADAP & 4.784 & -0.035 \\
\hline COMP & $<---$ & ERRO & 16.606 & -0.486 \\
\hline ADAP & $<---$ & TEAM & 4.2 & 2.41 \\
\hline ADAP & $<---$ & AUTO & 5.394 & 3.009 \\
\hline DECI & $<---$ & ERRO & 5.24 & 0.33 \\
\hline ERRO & $<---$ & EMPO & 4.039 & 0.556 \\
\hline ERRO & $<---$ & VARI & 11.269 & 0.043 \\
\hline ERRO & $<---$ & COMP & 7.313 & -0.066 \\
\hline GOAL & $<---$ & VARI & 5.431 & -0.221 \\
\hline GOAL & $<---$ & COMP & 7.326 & 0.487 \\
\hline TIME & $<---$ & QUALITY & 4.148 & 3.626 \\
\hline TIME & $<---$ & SUPE & 11.746 & 4.348 \\
\hline TIME & $<--$ & TEAM & 5.665 & 2.981 \\
\hline TIME & $<---$ & STAT & 4.224 & 2.293 \\
\hline WORK & $<---$ & VARI & 18.113 & 0.203 \\
\hline WORK & $<---$ & ERRO & 5.831 & 0.573 \\
\hline WORK & $<---$ & TIME & 5.816 & 0.115 \\
\hline
\end{tabular}

Minimization History (Default model)

\begin{tabular}{|c|c|c|c|c|c|c|c|c|}
\hline Iteration & & $\begin{array}{r}\text { Negative } \\
\text { eigenvalu } \\
\text { es }\end{array}$ & $\begin{array}{r}\text { Condition } \\
\#\end{array}$ & $\begin{array}{r}\text { Smallest } \\
\text { eigenvalu } \\
\mathrm{e}\end{array}$ & Diameter & $\mathrm{F}$ & NTries & Ratio \\
\hline 0 & e & 6 & & -1.159 & 9999 & 2238.583 & 0 & 9999 \\
\hline 1 & e & 6 & & -0.322 & 3.822 & 1118.519 & 20 & 0.213 \\
\hline 2 & e & 3 & & -0.464 & 0.748 & 836.466 & 5 & 0.807 \\
\hline 3 & $e^{*}$ & 1 & & -0.091 & 0.587 & 714.179 & 5 & 0.537 \\
\hline 4 & & 0 & 1156.041 & & 1.283 & 491.218 & 7 & 0.845 \\
\hline 5 & e & 0 & 535.968 & & 0.484 & 458.083 & 3 & 0 \\
\hline 6 & e & 0 & 331.567 & & 0.577 & 422.67 & 1 & 1.186 \\
\hline 7 & & 0 & 363.825 & & 0.375 & 412.626 & 1 & 1.196 \\
\hline 8 & e & 0 & 513.111 & & 0.347 & 410.53 & 1 & 1.155 \\
\hline 9 & & 0 & 757.644 & & 0.17 & 410.16 & 1 & 1.13 \\
\hline 10 & e & 0 & 865.656 & & 0.062 & 410.137 & 1 & 1.048 \\
\hline 11 & & 0 & 883.835 & & 0.005 & 410.137 & 1 & 1.005 \\
\hline 12 & & 0 & 882.959 & & 0 & 410.137 & 1 & 1 \\
\hline
\end{tabular}


Model Fit Summary

CMIN

\begin{tabular}{|l|rrrrr|}
\hline Model & NPAR & CMIN & DF & P & CMIN/DF \\
\hline $\begin{array}{l}\text { Default } \\
\text { model }\end{array}$ & 40 & 410.137 & 131 & 0 & 3.131 \\
$\begin{array}{l}\text { Saturated } \\
\text { model }\end{array}$ & 171 & 0 & 0 & & \\
Independe & & & & & \\
nce model & 18 & 2313.699 & 153 & 0 & 15.122 \\
\hline
\end{tabular}

RMR, GFI

\begin{tabular}{|l|rrrr|}
\hline Model & RMR & GFI & AGFI & PGFI \\
\hline $\begin{array}{l}\text { Default } \\
\text { model } \\
\begin{array}{l}\text { Saturated } \\
\text { model }\end{array}\end{array}$ & 3.938 & 0.811 & 0.753 & 0.621 \\
Independe & 0 & 1 & & \\
nce model & 36.257 & 0.328 & 0.249 & 0.294 \\
\hline
\end{tabular}

Baseline Comparisons

\begin{tabular}{|l|rrrrr|}
\hline Model & $\begin{array}{r}\text { NFI } \\
\text { Delta1 }\end{array}$ & $\begin{array}{r}\text { RFI } \\
\text { rho1 }\end{array}$ & $\begin{array}{r}\text { IFI } \\
\text { Delta2 }\end{array}$ & $\begin{array}{r}\text { TLI } \\
\text { rho2 }\end{array}$ & CFI \\
\hline $\begin{array}{l}\text { Default } \\
\text { model } \\
\begin{array}{l}\text { Saturated } \\
\text { model }\end{array}\end{array}$ & 0.823 & 0.793 & 0.872 & 0.849 & 0.871 \\
$\begin{array}{l}\text { Independe } \\
\text { nce model }\end{array}$ & 1 & & 1 & & 1 \\
\hline
\end{tabular}

Parsimony-Adjusted Measures

\begin{tabular}{|l|rrr|}
\hline Model & PRATIO & PNFI & PCFI \\
\hline $\begin{array}{l}\text { Default } \\
\text { model } \\
\text { Saturated } \\
\text { model }\end{array}$ & 0.856 & 0.704 & 0.746 \\
Independe & 0 & 0 & 0 \\
nce model & 1 & 0 & 0 \\
\hline
\end{tabular}

NCP

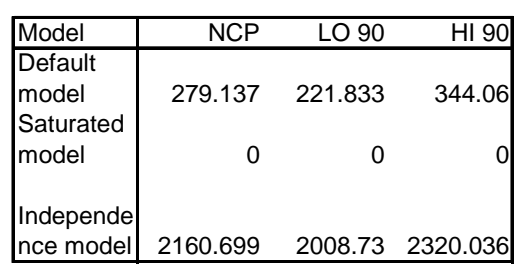

FMIN

\begin{tabular}{|l|rrrr|}
\hline Model & FMIN & F0 & LO 90 & HI 90 \\
\hline $\begin{array}{l}\text { Default } \\
\text { model } \\
\begin{array}{l}\text { Saturated } \\
\text { model }\end{array}\end{array}$ & 2.01 & 1.368 & 1.087 & 1.687 \\
Independe & 0 & 0 & 0 & 0 \\
nce model & 11.342 & 10.592 & 9.847 & 11.373 \\
\hline
\end{tabular}


RMSEA

\begin{tabular}{|l|rrrr|}
\hline Model & RMSEA & LO 90 & HI 90 & PCLOSE \\
\hline $\begin{array}{l}\text { Default } \\
\text { model }\end{array}$ & 0.102 & 0.091 & 0.113 & 0 \\
$\begin{array}{l}\text { Independe } \\
\text { nce model }\end{array}$ & 0.263 & 0.254 & 0.273 & 0 \\
\hline
\end{tabular}

AIC

\begin{tabular}{|l|rrrr|}
\hline Model & AIC & BCC & BIC & CAIC \\
$\begin{array}{l}\text { Default } \\
\text { model } \\
\text { Saturated } \\
\text { model }\end{array}$ & 490.137 & 498.353 & 623.058 & 663.058 \\
$\begin{array}{l}\text { Independe } \\
\text { nce model }\end{array}$ & 342 & 377.124 & 910.235 & 1081.235 \\
\hline
\end{tabular}

\section{ECVI}

\begin{tabular}{|l|rrrr|}
\hline Model & ECVI & LO 90 & HI 90 & MECVI \\
\hline $\begin{array}{l}\text { Default } \\
\text { model }\end{array}$ & 2.403 & 2.122 & 2.721 & 2.443 \\
$\begin{array}{l}\text { Saturated } \\
\text { model }\end{array}$ & 1.676 & 1.676 & 1.676 & 1.849 \\
$\begin{array}{l}\text { Independe } \\
\text { nce model }\end{array}$ & 11.518 & 10.773 & 12.299 & 11.536 \\
\hline
\end{tabular}

HOELTER

\begin{tabular}{|l|cr|}
\hline & \multicolumn{2}{|c|}{ HOELTER HOELTER } \\
Model & 0.05 & 0.01 \\
\hline $\begin{array}{l}\text { Default } \\
\text { model }\end{array}$ & 79 & 86 \\
Independe & & \\
nce model & 17 & 18 \\
\hline
\end{tabular}

Execution time summary

$\begin{array}{lr}\begin{array}{lr}\text { Minimizati } \\ \text { on: }\end{array} & 0.06 \\ \text { Miscellane } & \\ \text { ous: } & 0.751 \\ & \\ \text { Bootstrap: } & 0 \\ \text { Total: } & 0.811\end{array}$




\section{CURRICULUM VITAE}

NAME:

ADDRESS:

DOB:

EDUCATION \& TRAINING:
John Kenneth Layer

1870 Fairview Church Road

Corydon, Indiana 47112

December 21, 1963

B.S. Mechanical Engineering, Magna Cum Laude, (including international study at Harlaxton College, England) University of Evansville, Evansville, Indiana 1987

M.B.A., Arizona State University, Tempe, Arizona 1991

Ph.D., Industrial Engineering, University of Louisville, Louisville, Kentucky Expected 2005

AWARDS: $\quad$ Sigma Iota Epsilon Honorary Management Fraternity Pi Tau Sigma National Mechanical Engineering Honorary Kappa Mu Epsilon National Mathematics Honor Society Phi Kappa Phi National Honorary

Phi Beta Chi Science Honorary

Mortar Board Honorary

Blue Key National Honor Fraternity

The Royal Aeronautical Society Honorary Member, England

PROFESSIONAL Professional Engineer, Mechanical Engineering, LICENSE: $\quad$ Arizona License No. 25358

PATENTS: $\quad$ Rotary Conveyor Singulation System, US Patent No. 5,372,236 
RESEARCH: $\quad$ Risø National Laboratory, Roskilde, Denmark: The HumanDigital Library Interface Review in support of the European DELOS Network of Excellence in digital library technologies. 